\title{
Regenerating the Urban Landscape An Architectural Journey through Fallow Time
}

\author{
by \\ Heather Gayle McArthur, B.A.Hons.
}

\author{
A thesis submitted to the \\ Faculty of Graduate and Postdoctoral Affairs \\ in partial fulfillment of the requirements \\ for the degree of
}

Master of Architecture
M.Arch. (Professional)

Carleton University

Ottawa, Ontario, Canada

April 2012

(C) 2012, Heather Gayle McArthur 
Library and Archives

Canada

Published Heritage

Branch

395 Wellington Street

Ottawa ON K1A ON4

Canada
Bibliothèque et

Archives Canada

Direction du

Patrimoine de l'édition

395 , rue Wellington

Ottawa ON K1A ON4

Canada
Your file Votre référence

ISBN: 978-0-494-91523-3

Our file Notre référence

ISBN: $978-0-494-91523-3$
NOTICE:

The author has granted a nonexclusive license allowing Library and Archives Canada to reproduce, publish, archive, preserve, conserve, communicate to the public by telecommunication or on the Internet, loan, distrbute and sell theses worldwide, for commercial or noncommercial purposes, in microform, paper, electronic and/or any other formats.

The author retains copyright ownership and moral rights in this thesis. Neither the thesis nor substantial extracts from it may be printed or otherwise reproduced without the author's permission.
AVIS:

L'auteur a accordé une licence non exclusive permettant à la Bibliothèque et Archives Canada de reproduire, publier, archiver, sauvegarder, conserver, transmettre au public par télécommunication ou par l'Internet, prêter, distribuer et vendre des thèses partout dans le monde, à des fins commerciales ou autres, sur support microforme, papier, électronique et/ou autres formats.

L'auteur conserve la propriété du droit d'auteur et des droits moraux qui protege cette thèse. $\mathrm{Ni}$ la thèse ni des extraits substantiels de celle-ci ne doivent être imprimés ou autrement reproduits sans son autorisation.
In compliance with the Canadian Privacy Act some supporting forms may have been removed from this thesis.

While these forms may be included in the document page count, their removal does not represent any loss of content from the thesis.
Conformément à la loi canadienne sur la protection de la vie privée, quelques formulaires secondaires ont été enlevés de cette thèse.

Bien que ces formulaires aient inclus dans la pagination, il n'y aura aucun contenu manquant. 


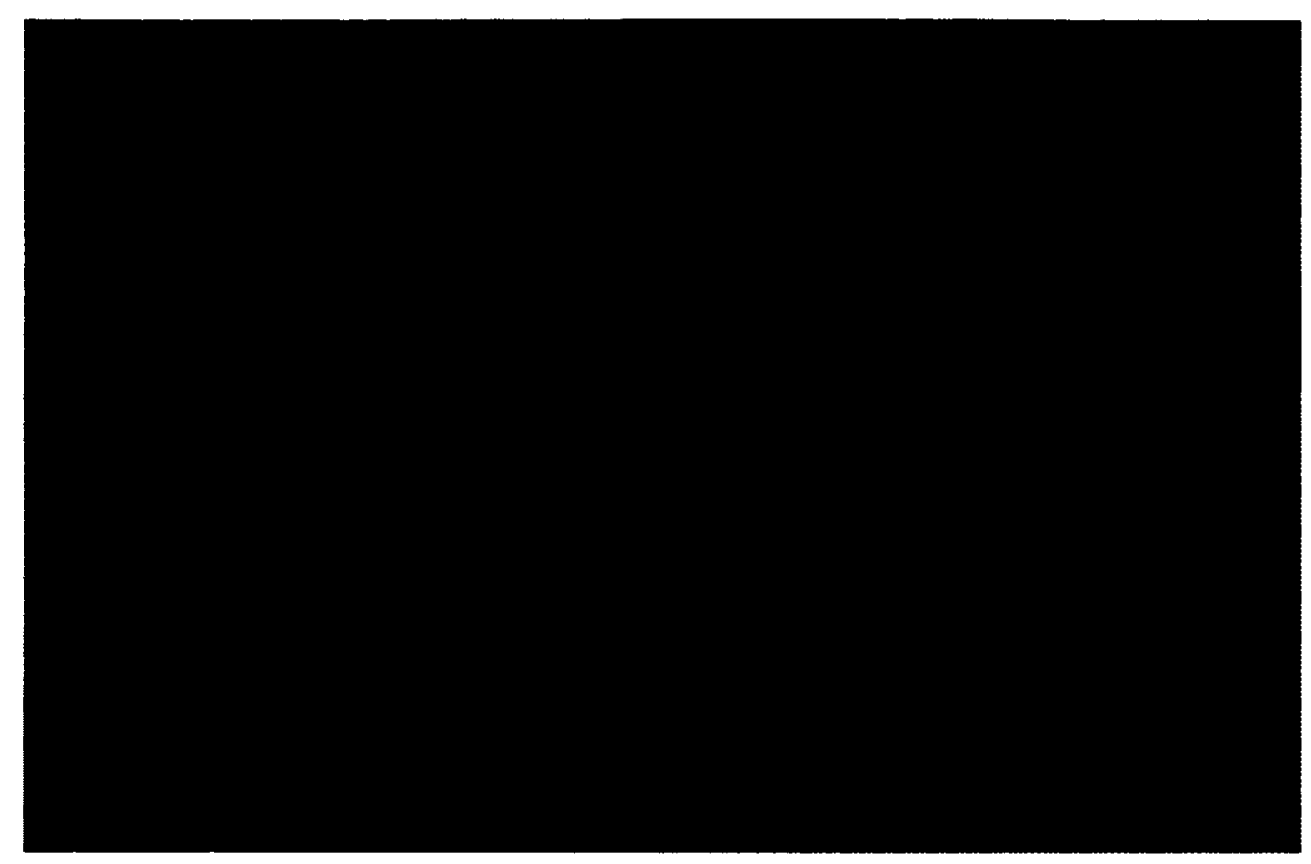


To Alex, for seeing me through with patience and endurance. 


\section{Abstract}

This thesis investigates the redevelopment of an abandoned military site, located at the edge of the historic urban centre of Bologna, Italy. The redevelopment process is considered in metaphorical terms, employing the notion of agricultural fallowing as a strategy of urban regeneration. This notion requires thinking of the site as having entered into a fallow time - that is, a deliberate pause during which time the imperatives of economic development are suspended.

Taking from cultural landscape theory the idea of the gradual accumulation of rituals and artefacts that achieve equilibrium over time, incorporating the notion of catalysts in urban eco-systems, and concluding with the concept of 'the unfinished,' the thesis proposes a framework for incremental change and gradual occupation of the post-military site through time. It concludes with a project proposal that aims at re-developing the site in its own rite by offering a flexible stage for sustained urban development. 
I am dealing in stereotypes, I know, but it is thanks to them that I have been getting by.

From The Mysterious Flame of Queen Loana, a novel by Umberto Eco (2005)

I would like to thank my thesis co-advisors, Dr. Stephen Fai and Dr. Claudio Sgarbi, for skillfully guiding me through this journey, for seeing what I couldn't see, and for showing me how to make it my own.

I also wish to thank Professors Luisa Bravo and Luigi Bartolomei of the University of Bologna for introducing me to Bologna's other histories, and Professor Lucie Fontein for helping me to understand the fullness of fallow time.

Finally, I wish to extend my deepest thanks to my family for their support - my partner Alex for everything, my dad Archie for dotting i's and crossing t's, my mom Catherine for tending to the small things while I focussed on this big one, and my sister Erin for many stimulating conversations, her probing questions and especially her enthusiasm. 


\title{
Contents
}

\author{
Title Page i \\ Frontispiece ii \\ Dedication iii \\ Abstract iv \\ Acknowledgements $\quad \mathrm{v}$ \\ Table of Contents vi \\ List of Illustrations vii \\ List of Appendices $\quad \mathrm{X}$ \\ 00_Preparing the Ground 1 \\ 01_Letting Fields Lie Fallow 10 \\ 02_Tilling Soil 21 \\ 03_Sowing Seeds 42 \\ 04_Harvest 74 \\ 05_Yield 100 \\ Postscript 103 \\ Bibliography $\quad 105$ \\ Appendices $\quad 109$
}




\section{List of Illustrations}

Figure 1: Aerial images of Bologna, Italy. Images from Google Earth. 2

Figure 2: Conservation and reuse plan, 2007. Source: City of Bologna. 7

Figure 3: Piazza Maggiore, looking east from the City Hall. Source: City of Bologna. 23

Figure 4: eBO Exhibition Pavilions, Piazza Re Enzo, Bologna. Source:

www.mcarchitects.it. 26

Figure 5: Map of Bologna, 1640, by Blaeu. North is down. Source:

www.florenceprints.com/USAcitta_italia.htm. 44

Figure 6: Left: Padiglione dell'Archittetura. Source: Chiesa e Quartiere (book), $p$ 44. Right: Map of Bologna's parishes. Source: Chiesa e Quartiere (book), p 18. 49

Figure 7: Cardinal Lercaro consecrating ground at the site of a future church. Source: Chiesa e Quartiere (book), p 16.51

Figure 8: Urban Conservation Plan, 1969, showing buildings to be preserved. Source: City of Bologna. 53

Figure 9: Images from photographic census by Paolo Monti. Source: Bologna Centro Storico, Catalog of the exhibition at Palazzo d'Accursio, Alfa, Bologna 1970. 54

Figure 10: Early-1800's watercolour showing orchards in foreground, and the Carabinieri buildings (at left). View from south, with historic centre in the background. Source: City of Bologna. 57

Figure 11: Detail of 1888 Plan of Bologna showing major monuments. Source: City of Bologna. 58

Figure 12: Aerial view of the Staveco site, looking south. Source: Bing Maps. 59 
Figure 13: Photographic survey of the Staveco site and buildings. Source: Photos by author. 62

Figure 14: Left: "Key to the hills" concept by Fernandez and Calvet Arquitectes. Right: Vignali concept for consolidating the university campus at the Staveco site. Source: City of Bologna. 63

Figure 15: City of the Hills framework. Source: City of Bologna 64

Figure 16: Annas Kollectiv performance, entitled Patina, in vacant Staveco building, 2007. Source: http://www.annaskollektiv.ch/. 65

Figure 17: Top: Illustrations of ephemeral events that might occur in the lower piazza, including installation art (left) and performances (right). Bottom: Allowing vegetation to take over buildings. Source: by the author. 73

Figure 18: Anticipatory study of site evolution over a period of four decades. Drawings by the author. 76

Figure 19: Study showing axes and selection of catalyst site. (North down) Drawing by the author. 77

Figure 20: Site plan (north down). Drawing by the author. 78

Figure 21: Catalyst site (north down) features two piazzas framed by a diversity of functions. Drawing by the author. 79

Figure 22: Proposed alterations and addition to Caffè / Coop Building. Drawing by the author. 80

Figure 23: Shift from military road to orchard path. Montages by the author. 81

Figure 24: View looking south along Via Principale, with Archive Building on axis. Montage by the author. 83

Figure 25: Site investigation: View of future Caffè / Co-op building from second storey of Common House. Photos courtesy of Benoît Lagacé. 84

Figure 26: Montage of Lower Piazza, with Common House at right, Site Office at left, Co-op in background. Montage by the author. 85

Figure 27: View towards Upper Piazza, with Archive and Documentation Centre on axis. Montages by the author. 87

Figure 28: Left: Site model, oriented south. Right: detail of site model. Model and images by the author. 89 
Figure 29: Catalyst site model. Various views and details. Model and images by the author. 90

Figure 30: Catalyst site model. Model and image by the author. 93

Figure 31: North-south section (looking east). Drawing by the author. 94

Figure 32: East-west section across Lower Piazza (looking south). Drawing by the author. 95

Figure 33: North-south section through the Via Principale (looking west).

Drawing by the author. 96

Figure 34: Orchard occupying a collapsing building. Montage by the author. 97

Figure 35: Fallow time lain across the Staveco site. Montage by the author. 102 


\section{List of Appendices}

Appendix_01:

Essay: Occupying the Gap; an Architectural Journey through Fallow Time

Appendix_02:

Operational Guidelines for the Implementation of the World Heritage Convention, UNESCO [Excerpt, Definition and Categories of Cultural Landscapes]

Appendix_03:

Piano Strutturale Comunale, 2007 Commune di Bologna; City of the hills - A new statute [Excerpt]

114 
One can follow many parallel lives, an episode at a time, year after year, with no effort, by merely sitting at a cafe table, as one does in the main street or in a piazza everywhere in Italy.

From The Italians, a book by Luigi Barzini (1964)

\section{0_Preparing the Ground}

This thesis investigates the redevelopment of an abandoned military base, which is located at the edge of the historic urban centre of Bologna, Italy. I had the great fortune of spending the winter of 2011 in this northern Italian city, where I was able to investigate the site, and become acquainted with the growing city.

The military base, known as STA.VE.CO ${ }^{1}$ (or referred to here as, Staveco), features military buildings of considerable historical and architectural interest. These are set within a typically rational landscape of parades, roads and paths. Since being decommissioned in

\footnotetext{
${ }^{1}$ The facility, originally named the Officina Riparazione Mezzi Corazzati (ORMeC), a workshop for the repair of armoured vehicles later became the Stabilimento dei Veicoli da Combattimento (Combat Vehicle Establishment) which abbreviated to STA.VE.CO.
} 
2003 , and the city's subsequent acquisition of the property in 2007 , the site has remained inaccessible with little or no stabilization having been undertaken on the building stock and landscape features.

Several roofs have collapsed or are beginning to collapse, causing significant deterioration of walls and interiors. Vegetation has also been allowed to overgrow, and this is particularly problematic where vines are beginning to infiltrate window and door openings leading to further deterioration. The site has entered into a type of fallow timethat is, a deliberate pause in its economic development.

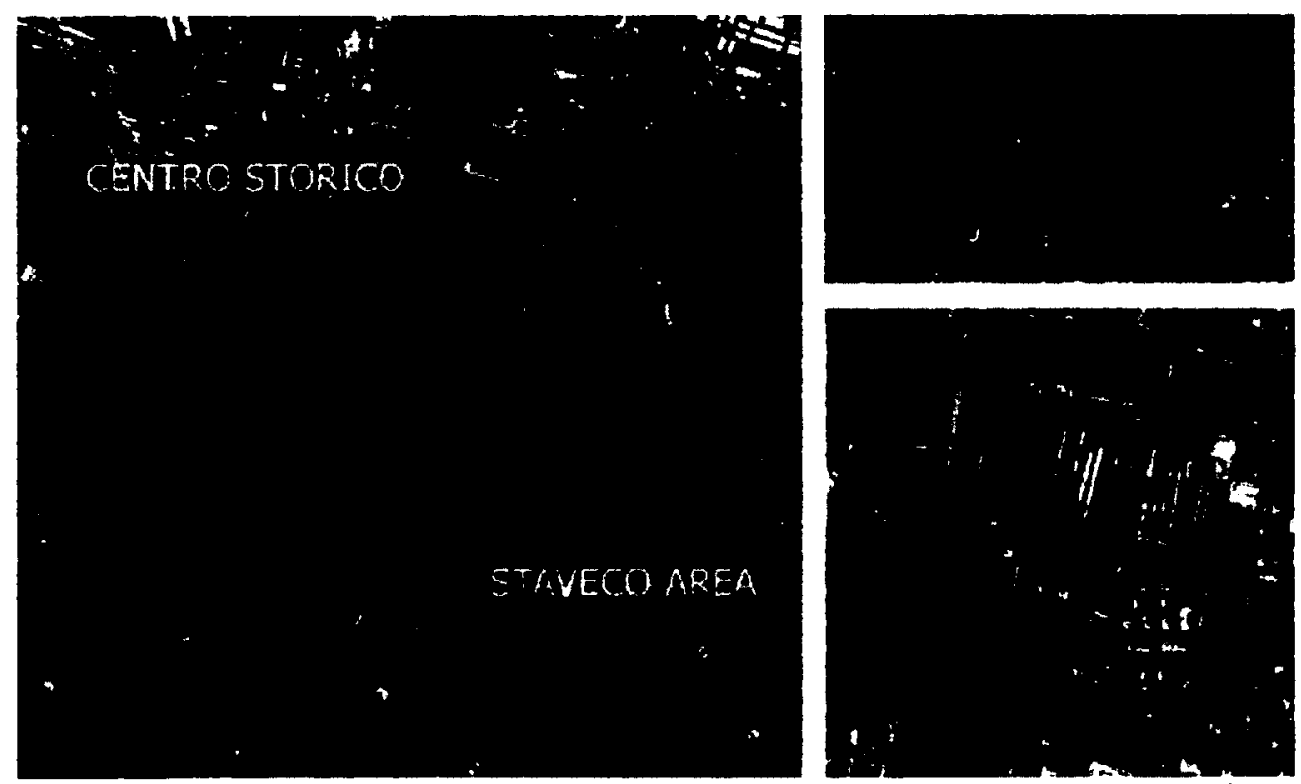

Figure 1: Aerial images of Bologna, Italy, showing location of the Staveco relative to the historic centre, and its ring-road. Images from Google Earth.

In its 2011 Recommendation on the Historic Urban Landscape, the United Nations Education, Scientific and Cultural Organization 
(UNESCO) noted that rapid and uncontrolled urban development is transforming urban areas and their settings. Such haste causes fragmentation and deterioration in the quality of the urban environment and in particular its urban heritage. To mitigate these threats, UNESCO calls for the adoption of the larger goals of sustainable development by integrating a cultural landscape approach into local urban development processes.

This thesis presumes that the Staveco site is a historic urban landscape; which is a type of cultural landscape. A cultural landscape is an "idea embedded in a place;" 2 that is to say, it is a representation of a community's relationship to a specific place. Urban landscapes, and historic urban landscapes in particular, are the cultural landscapes of urban dwellers, ${ }^{3}$ the type of enriched urban environments that only come about through the slow accumulation and layering of cultural and natural values. ${ }^{4}$

A cultural landscape of value is one that achieves equilibrium between the rituals of inhabitation (the intangible experiences of a place) and the artefacts of inhabitation (the tangible infrastructure and objects that sustain the rituals). This equilibrium requires careful

\footnotetext{
${ }^{2}$ Smith (2010), 46.

${ }^{3}$ Smith (2010), 47.

${ }^{4}$ UNESCO (2011), 3.
} 
management, because it is usually achieved over a long period of time, and as such is difficult to sustain. It follows that, if "every community has its own cultural landscapes," 5 then an abandoned historic urban landscape might simply be considered a cultural landscape out of equilibrium.

If an abandoned landscape lacks the necessary activity of dwelling, then this thesis asks if and how the equilibrium of that abandoned landscape can be re-established; in other words, how do you approach the re-occupation of an abandoned historic urban landscape?

It is my contention that such a site may be gradually re-developed and reintegrated to its broader productive eco-system by employing a metaphorical notion of agricultural fallowing as a strategy of regeneration. This notion requires thinking of these urban landscapes as being in a moment of pause, or in fallow time, rather than in abandon.

Why a metaphor? If metaphor is to apply the characteristics of one kind of object or concept to the understanding and experience of another object, ${ }^{6}$ then it might be considered a process that "yield[s]

\footnotetext{
${ }^{5}$ Smith (2010), 50.

${ }^{6}$ Canadian Oxford Dictionary.
} 
some insight about reality."7 By turning concepts or experiences into artefact (that is, text), metaphor uncovers levels of meaning that were previously unknown about our relationship to things. In the context of this thesis, it may help us arrive at a new understanding of the architectural experience. ${ }^{8}$ In this way, the use of metaphor aims to contribute an understanding of the experiences of a particular place.

But metaphor does more than this. It includes a cognitive moment, in which imagination is aroused by the metaphorical concept, but is also controlled by it. Metaphor simultaneously "abolishes and preserves literal meaning" by "maintain[ing] ordinary vision in tension with the new one it suggests." 9

In this way, metaphor renders "imagination as fiction" by allowing us to suspend our direct references to ordinary objects while reading reality in a new way. ${ }^{10}$

It is in this context that the metaphor of fallow time is employed to create a critical frame around the question of the gradual transformation of an historic urban landscape. The term fallow time is

\footnotetext{
${ }^{7}$ Ricoeur, 143.

${ }^{8}$ Frascari, 16-7.

${ }^{9}$ Ricoeur, 154.

${ }^{10}$ Ricoeur, 157.
} 
understood as both ritual and artefact; an idea and as physical process / product.

One might ask why traditional heritage conservation practice would not suffice for exploring the re-development of a historically significant (but abandoned) site. While heritage conservation practice is careful to prescribe guidelines for contemporary insertions that protect and enhance the historic setting in which they are proposed, it tends to rely on an aesthetic appreciation of buildings-as-artefacts. This approach can be cavalier in its disregard for associated processes of use and occupation -both past and future -- and also neglects the more holistic notion of sustainable development in the urban landscape. While this thesis may seek to be somewhat provocative, it does not aim to be impertinent by ignoring cultural processes.

This thesis also deliberately bypasses the notion of elaborating on a master plan that was previously developed for the Staveco site (2008). That plan reflects its modernist origins in that it proposes a hierarchical organizing and zoning of the site into pre-defined functions and uses. It assumes a linear trajectory towards an ideal (utopian) future condition, and therefore becomes a rational and rigid tool for prescribing, rather than managing, growth. 


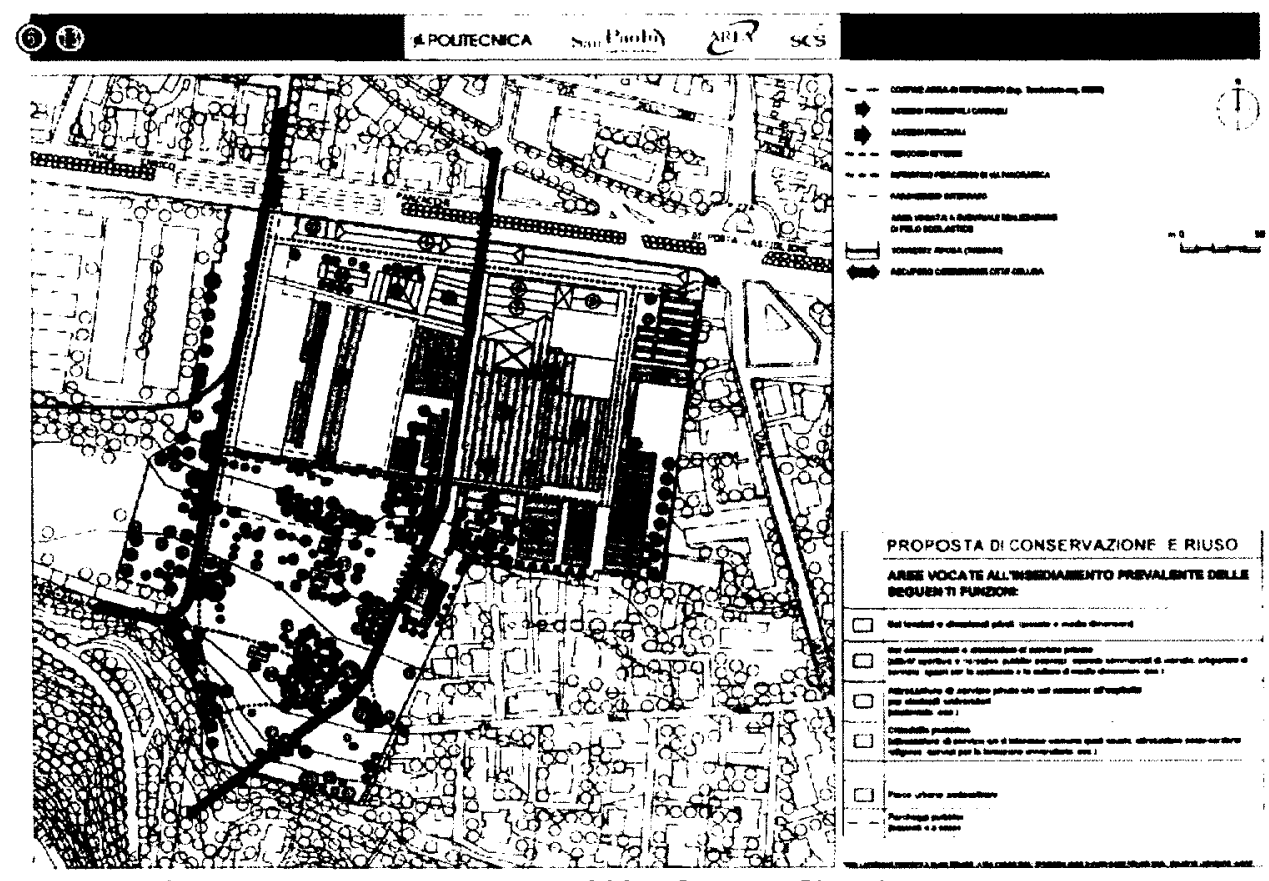

Figure 2: Conservation and reuse plan, 2007. Source: City of Bologna.

As in a traditional conservation approach, a conventional master plan takes a typological inventory of the building stock, and quickly assigns functional value to these containers. This in turn drives the zoning of the site. In the race to leave history behind, so too are left behind the historically and locally-derived knowledge of the place, the social values at play, and the multiplicity of identities.

By neglecting historical processes, the master plan becomes an expert-driven (that is to say, top-down) proposal that often results in blandness, a loss of individual expression within a community, a disregard for multiple perspectives, and few opportunities for 
chance. ${ }^{11}$ This situation is exacerbated by the impulse of developerdriven urban planning, which demands rapid development in order to maximize financial returns. This is not to say that a master plan could not offer flexibility, but I prefer to think of the site as needing managers, rather than a master.

Instead, taking from cultural landscape theory the idea of the gradual accumulation of rituals and artefacts that achieve equilibrium over time, incorporating with it notions of shifts and catalysts in urban eco-systems, and further combining the idea of 'the unfinished,' I propose a framework of incremental change through time.

In addition to synthesizing these concepts, it may prove helpful to think of the urban re-development process in metaphorical terms. This thesis considers a metaphorical comparison between agricultural fallowing and urban pause, and uses this metaphor as a guide in the gradual transformation / incremental change of the abandoned historic urban landscape. The thesis thereby explores the architectural implications of design conceived in fallow time.

${ }^{11}$ Till. 
The ideas explored in this thesis come from an earlier investigation of an abandoned industrial landscape, where a strategy of layering and peeling was employed as a means of uncovering / revealing multiple understandings of the site. Many questions were raised during that investigation, which led to an exploratory essay on fallow time. That essay is included here in Appendix_01. This thesis picks up from the lingering question of contemporary insertions in the historic environment and their potential to catalyze positive change, while avoiding destabilizing an already fragile place.

If an architectural strategy is to incorporate the notion of fallow time, then we need to know what is implied by the use of the term. The following chapter (01) moves away from architecture, in order to define the conditions of fallow time, and extract some principles that may guide a strategy for intervention. Chapter 02 develops an approach to fallowing an urban landscape, while Chapter 03 proposes a framework for the gradual redevelopment of the Staveco site. Chapter 04 tests the idea in a proposal that introduces new artefacts of inhabitation, which might in turn create the conditions for new rituals of inhabitation to evolve. Chapter 05 provides an opportunity for reflection and conclusion. 
Life, hopes, and human things seem wrapped away, With shrouds and spectres, in one long decay.

From The Autumn Waste, a poem by Archibald Lampman (c.1900)

\section{1_Letting Fields Lie Fallow}

While the notion of an architectural strategy of fallowing might be a new one, the practice of fallowing an agricultural landscape is not new. By understanding agricultural processes, we might be able to incorporate notions about fallow time more effectively into an architectural strategy of urban regeneration.

Fallow The term fallow comes from the Old English verb fealgian which meant to harrow, turn or break up ground. ${ }^{12}$ In present-day English, the term still denotes land that has been ploughed and harrowed, but is qualified as left unsown for a specific

\footnotetext{
${ }^{12}$ Online Etymology Dictionary. http://www.etymonline.com/.
} 
period of time. ${ }^{13}$ Accordingly, a fallow period is associated with a condition, a state or an idea, such that to lie fallow is not only to be left unsown, but to be uncultivated, inactive, potentially useful, but not yet in use. ${ }^{14}$ In this sense, then, to fallow the land may be understood as a pause or hiatus between cropping cycles. Further, it might also be understood as both ritual and artefact - that is an experience or practice, and a tangible object that sustains rituals.

Synonyms of fallowinclude unused, undeveloped, inactive, dormant, idle, resting, or inert. Is fallow time truly idle time? We can get a better sense of the nature of fallow time by having a closer look at the practice of laying a field fallow.

\section{Fallow practice This practice serves many purposes.}

Primarily, the objective is to regain soil fertility. Fallow periods may also be employed to ensure weed control and pest management, or to conserve moisture as in the summer fallow technique used in dryland farming. ${ }^{15}$

Fallowing can also be a matter of religious faith and ritual. Judaism, for example, requires that Jewish-owned farms lie fallow in the seventh year of the seven-year agricultural cycle. During the Shmita

\footnotetext{
${ }^{13}$ Canadian Oxford Dictionary.

${ }^{14}$ Canadian Oxford Dictionary.

${ }^{15} \mathrm{http}: / /$ en.wikipedia.org/wiki/Fallow_(disambiguation), 2011.09.15
} 
year all agricultural activity is forbidden. The reward for letting the land lie fallow is a Biblical promise of bounty in subsequent years. ${ }^{16}$

Likewise in secular farming, fallow time is characterized by a parallel practice of land optimization, which brings its own unique set of rituals and practices, of which there are generally three types: to allow natural vegetation to cover the ground; to deliberately introduce alternative plantings, for example non-crop products such as fast growing woods, fibres and medicinal plants; or to allow pasture for livestock. ${ }^{17}$

Increasingly, however, as in the urban environment, fallow times are being reduced to respond to land pressures. The result is soil and vegetation degradation and declining crop yields. This propensity towards shorter fallow periods, or even none at all may have short term economic advantages, but it is proving less advantageous in overexploited systems where soil capacity is declining and farms are being wholly abandoned. ${ }^{18} \mathrm{~A}$ strategy of sustainable intensification would help mitigate these consequences.

In sum, while fallow time may be understood as a pause or hiatus between cropping cycles, the aim is to regenerate the soil and thereby

\footnotetext{
${ }^{16}$ www.answers.com/topic/shmita.

${ }^{17}$ Styger and Fernandes, 426.

${ }^{18}$ Styger and Fernandes, 433.
} 
contribute to the resiliency of the land and the community that it supports. ${ }^{19}$ To that end, we may extract the following notions about the rituals and artefacts of fallowing.

Fallow time is intentional To fallowimplies intent. This notion is particularly useful, as one does not arbitrarily leave fallow a plot of arable land. One makes a conscious decision to till the land, and then leave it un-cropped for a period of time.

Fallow time is a form of dwelling To lie fallow may also be considered an active component of dwelling, where to dwell is to "cherish and protect, to preserve and care for." 20 As Heidegger explains, preserving and nurturing do not "make anything;" 21 they do not necessarily produce a tangible artefact. Fallowing as a form of dwelling is not aimed at exploiting or wearing out or mastering the earth, but rather at being steward of the earth by letting be what it wants to be. In this way, fallow time is characterized by a type of activity that differs from the rituals and practices of the crop years, but still constitutes dwelling.

Fallow time is productive time, whose duration varies While the land is uncultivated, at least as far as cropping is concerned, it is not

\footnotetext{
${ }^{19}$ De Landa, 165.

${ }^{20}$ Heidegger, 161.

${ }^{21}$ Heidegger, 161.
} 
necessarily inactive or unproductive. On the contrary, there are processes of regeneration that are encouraged by fallowing practices. These processes can be characterized as productive, albeit in a different form from that of cropping years. Improvement in soil fertility is not only a function of non-cropping, but also depends on external factors and conditions that need to be managed and anticipated, but whose interactions and outcomes are not wellknown.22

Additionally, fallow periods may be as short as one cropping season, or as long as 20 years. This length of time may be defined by the needs of the soil, the availability of means, the maturity rate of non-crop vegetation (for example perennial plantings versus ground cover), or by religious observance. Regardless, fallow time comes to an end when the field and the farmer are prepared for it. While it is intentional and planned, the outcome and duration of fallow time are contingent on and can be shifted by outside forces (example, climatic forces). By the same token, fallow time can also affect those outside forces. In other words, change is reciprocal.

Fallow time is a component of landscape management Even fallow lands require to be managed. To lay a field fallow for a year, or two, or

${ }^{22}$ Styger and Fernandes, 426, 433. 
five, can have dramatic impact on adjacent fields, the economic viability of the farmstead, and thereby the ecology of the broader agricultural landscape. A wealth of indigenous knowledge, that is to say knowledge that is acquired locally -- in a specific place and through experience of that place -- develops around the diversity and richness of the fallow time, and thereby guides sustainable change owing to awareness of and direct experience with the land.

Fallow time is cyclical In addition to managing the cycles of fallowing and cropping, the fallow time itself also seeks to manage the cycles of other species: for example weed growth, pest and disease cycles. Fields may need to be lain fallow on a regular basis in order to enhance production and soil fertility. Inherent in this is the need to lay other processes fallow, and thereby manage biological cycles and their interactions, so that the whole system can regain diversity and equilibrium..$^{23}$

\section{Fallow time in the Urban Landscape}

One might then ask to what extent the conditions of fallow time are immediately relevant to architecture and the urban realm. I offer the

\footnotetext{
${ }^{23}$ Styger and Fernandes, 427.
} 
notion of fallow time as an artefact - or as Manuel De Landa might suggest, a structure that is "the product of specific historical processes." 24 All cities undergo cycles of building up, filling in, demolition, reconfiguration and redevelopment of urban plot patterns. By and large, cities manage these fluctuations, and continue to develop, produce and innovate over time, with only relatively small periods of decline and transition. ${ }^{25}$ In this way, fallow time might begin to describe the common ebb and flow of urban development.

However, there are specific circumstances when urban landscapes might more aptly be considered fallowed, specifically instances of neglect, accident, economic failure, decommissioning, divestment, speculation, and urban renewal. In these situations, fallow time is arrived at through complex historical processes: in most circumstances the fallow time is intentionally entered into, even if the outcome is not anticipated; the duration depends on internal and external forces; it plays a part in overall urban development.

Conversely, fallow time may not prove directly helpful in responding to the tragic instances of natural disaster or war. These situations would surely require a more specialized consideration of cultural

\footnotetext{
${ }^{24}$ De Landa, 11.

${ }^{25}$ For an historical account of urban development processes, see Spiro Kostof's two volume exploration -- The City Shaped and The City Assembled.
} 
recovery and healing, which fallow time may not immediately address.

As in the agricultural realm, I propose that, rather than thinking of these unoccupied urban sites as being abandoned, they be considered in a moment of pause, or hiatus. This pause - fallow time - then describes that moment in the process of urban development when the equilibrium between the rituals and the artefacts of inhabitation have shifted from one state to another. As in agriculture, fallow time should not be considered a threat. Rather, as Jeremy Till suggests, these moments of seeming uncertainty might instead be considered a "profound chance and opportunity" 26 for change.

Thus, fallow time, in the context of the urban landscape, may be understood as the result of a deliberate choice to transition an urban place into a period of pause or hiatus. This hiatus may cause disequilibrium, where the previous rituals and artefacts of inhabitation - that is the form of dwelling that once defined a place - cannot be, or are no longer, sustained. However, fallow time retains the potential to be useful and to be productive. While the outcome of

${ }^{26}$ Till, 55. 
fallow time may be contingent on outside forces; it also affects the environment of which it is a part.

Consequent to the onset of fallow time is the process of putting a site back into production, which might be considered a process of regeneration unique to itself and to a specific locale. This notion carries with it the intent to mitigate ecological-environmental conditions. When extended in the urban realm, this process might also incorporate the intent to sustain and enhance cultural conditions.

Rather than putting a field to rest, we may begin to understand fallowing as a period of time during which a different type of activity occurs - which is a type of dwelling - that aims at regeneration and future stability.

In brief, I offer the following provisional definition of fallowing in the urban landscape as a time during which an active contribution is made towards (re)establishing the equilibrium of inhabitation of the fallow site and the broader community, of which it is a part.

In sum, we can take from this examination that fallow time is both ritual and artefact, or an idea embedded in a place. As an artefact, 
fallow time is the result of specific historic processes, which are expressed in a tangible way in the urban/agricultural landscape. It is a tangible expression of the idea of cultural/sustainable landscape management, which carries with it a wealth of indigenous knowledge, accumulated locally and over time. The accumulation of ritualized practices and experiences begin to shape the land(scape), as some systems take precedence and others recede.

As a ritual - which I would argue is its primary identity - the practice of fallowing is widespread, but has variants that are adapted to each and every region in which they are practiced. As such, inherent in fallowing is the notion of adapting and modifying a ritualized practice to suit a specific place, making it unique to that place.

As an intentional practice, fallowing carries with it the expectation of an anticipated outcome - a return on investment, as it were. In order to yield returns, fallowing manages the overall health of an urban/agricultural landscape by putting some 'fields' into full production and others into hiatus on a cyclical basis. Fallowing then suggests that some histories have to wait for reactivation. By fallowing we arrive at choices for interventions, but also the opportunity to postpone those interventions until the time is ripe. 
The result of this decision-making process is an accumulated knowledge and an expectation that the hiatus will bring future productivity and contribute to a long-term equilibrium of the landscape-at-large.

The remainder of this thesis explores fallow time as an active and positive component of urban development, and thereby seeks to discover a vision of the unoccupied Staveco site that would facilitate a gradual and flexible redevelopment over time; that is, through a strategy of fallowing.

The following chapter develops an approach to fallowing the urban landscape. 
The lives of individuals of the human race form a constant plot,

in which every attempt to isolate one piece of living that has a meaning separate from the rest-for example, the meeting of two people, which will become decisive for both-must bear in mind that each of these two brings with himself a texture of events, environments, other people, and that from the meeting, in turn, other stories will be derived which will break off from their common story.

From If on a winter's night a traveller, a book by Italo Calvino (1979)

\section{2_Tilling Soil}

This chapter explores and describes an approach to regenerating an historic urban landscape that finds itself in a moment of pause - in fallow time. The approach - which I refer to as fallowing an urban landscape - is informed by a cultural landscape understanding of place, by a philosophy of urban development as urban ecosystem, and the notion of the unfinished. These combine to suggest that architectural development of a fallow site involves bringing the site to a level of density (whether artefact or ritual) that allows it to selfgenerate and thereby thrive and evolve alongside its established neighbours. 


\section{Urban (Re)generation}

As noted earlier, UNESCO proposes that a cultural landscape approach be integrated with urban planning processes as a means of mitigating fragmentation and deterioration in historic urban environments. The suggestion is that a cultural landscape approach brings notions of sustainable development and deceleration in the rate of urban change by providing pause and time for reflection. Reading and managing an urban landscape as a cultural landscape requires taking the time to account for, assess, and protect the values of a particular place.

In his UNESCO submission on the historic urban landscape, architect and conservationist Julian Smith offered the definition of a cultural landscape as "an idea embedded in a place;" 27 which is to say that a place is defined by patterns of use (rituals) and occupation (of artefacts). Further, Smith asserts that a cultural landscape is defined and evolves from within, and therefore can only be understood through direct experience. Accordingly, it cannot be defined nor developed from above or from without (i.e. by experts). ${ }^{28}$

\footnotetext{
${ }^{27}$ Smith, 46.

${ }^{28}$ Smith, 47.
} 


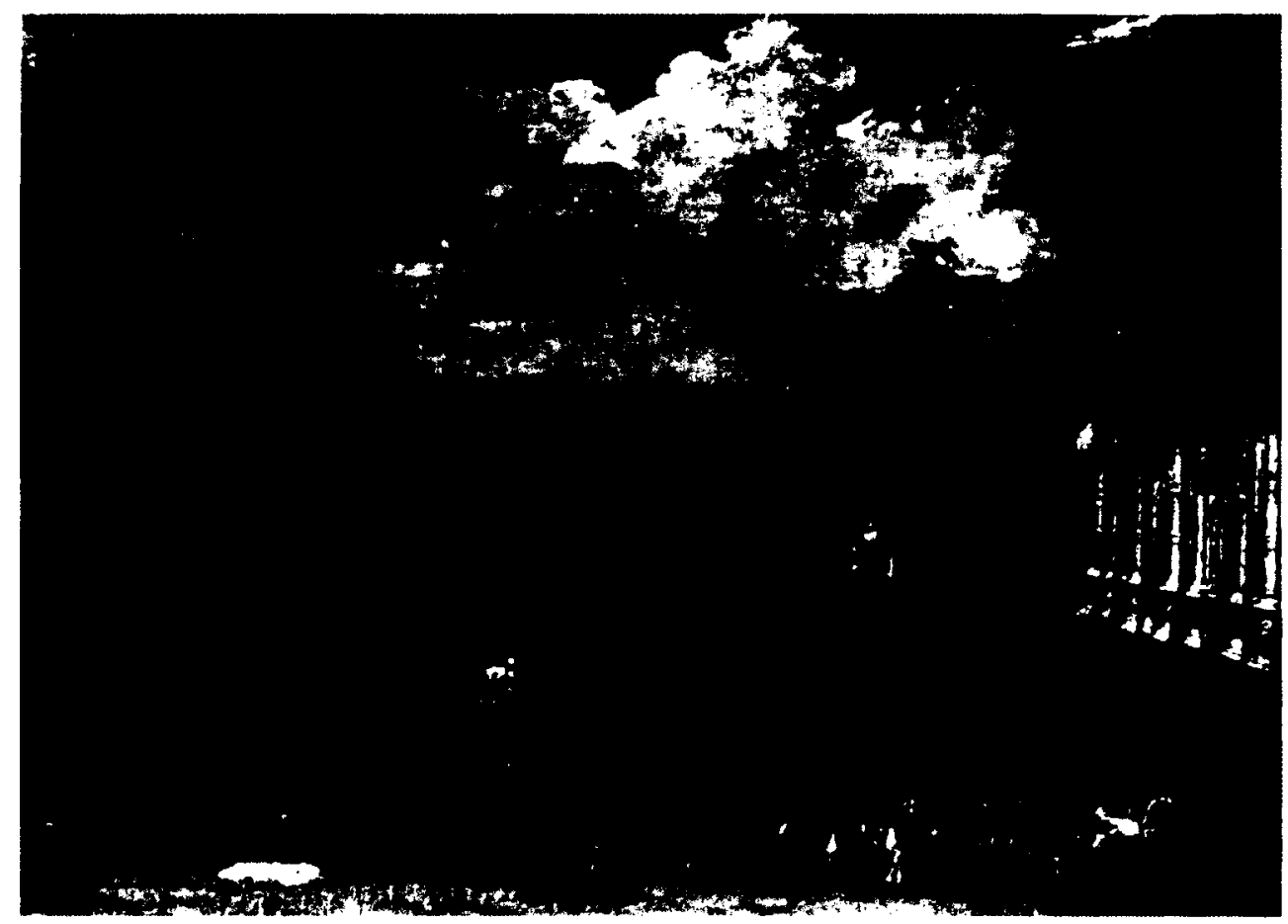

Figure 3: Piazza Maggiore. Looking east from the City Hall, the San Petronio Church is at right, Notaries Palace beyond, Palazzo Re Enzo at left. Source: City of Bologna.

If, as Smith suggests, urban landscapes are the cultural landscapes of urban dwellers, then cultural landscapes can exist simultaneously, layered in a single place, with overlapping boundaries, patterns of use and occupation, and identities. ${ }^{29}$ In this way, a cultural landscape is not necessarily the environment of a singular community. It can be heterogeneous.

${ }^{29}$ Smith, 47. 
For example, Bologna's Piazza Maggiore is the main square in the heart of the city. It is simultaneously a crossroads and meeting spot -a place to meet, to see and be seen; a centre of demonstration, rally and protest; an historical intersection of power where the former City Hall, the Notaries Palace, the former Stock Exchange (peripherally), and the Basilica of San Petronio all meet and overlook the Piazza; it is also a place of entertainment, exhibition and performance, and it is a tourist destination. Each community that uses and traverses this piazza has its own rituals, meanings and values ascribed to this physical place.

To make changes in the interest of one community could compromise the ability of another community to continue its enjoyment of the same place. For example, to allow a Sunday thrift market to occupy the square would very likely jeopardize the ability of churchgoers to gather in the square before and after liturgical services; or to regularly and loudly broadcast music from an adjacent caffè would inhibit the ability of political orators to stand on their proverbial soapbox to profess and debate politics with whomever will engage, which is a daily occurrence on the piazza. 
Suffice it to say that some cultural landscapes may take precedence over others ${ }^{30}$ by virtue of their significance. This is a choice we make in managing a place as a cultural landscape, meaning that some cultural landscapes, for example an indigenous landscape (whether aboriginal or, as per the above example, the local political orator) must take precedence over another cultural landscape (for example the tourist landscape). The latter could overwhelm the former, and for this reason its development may be intentionally constrained. Some histories have to wait.

A heterogeneous cultural landscape gains resilience over time, as Smith suggests, when the rituals and artefacts of inhabitation are in equilibrium, and thereby provide "a sense of identity and a sense of place."31 Following the example above, when churchgoers are able to congregate in the Piazza on Sunday mornings; and the orator can be heard when professing his political convictions. Moreover, Smith points out that this equilibrium is somewhat fragile because it is both difficult to attain and to sustain. ${ }^{32}$ When overlapping patterns of use and occupation begin to compete, and if left unchecked (that is, unmanaged) some uses will begin to fade while others predominate. When a community decides that a certain cultural landscape must be

\footnotetext{
${ }^{30}$ Smith, 50.

${ }^{31}$ Smith, 47.

${ }^{32}$ Smith, 47.
} 
protected, preserved and enhanced, then the whole of the cultural landscape must be managed to ensure a balance is achieved.

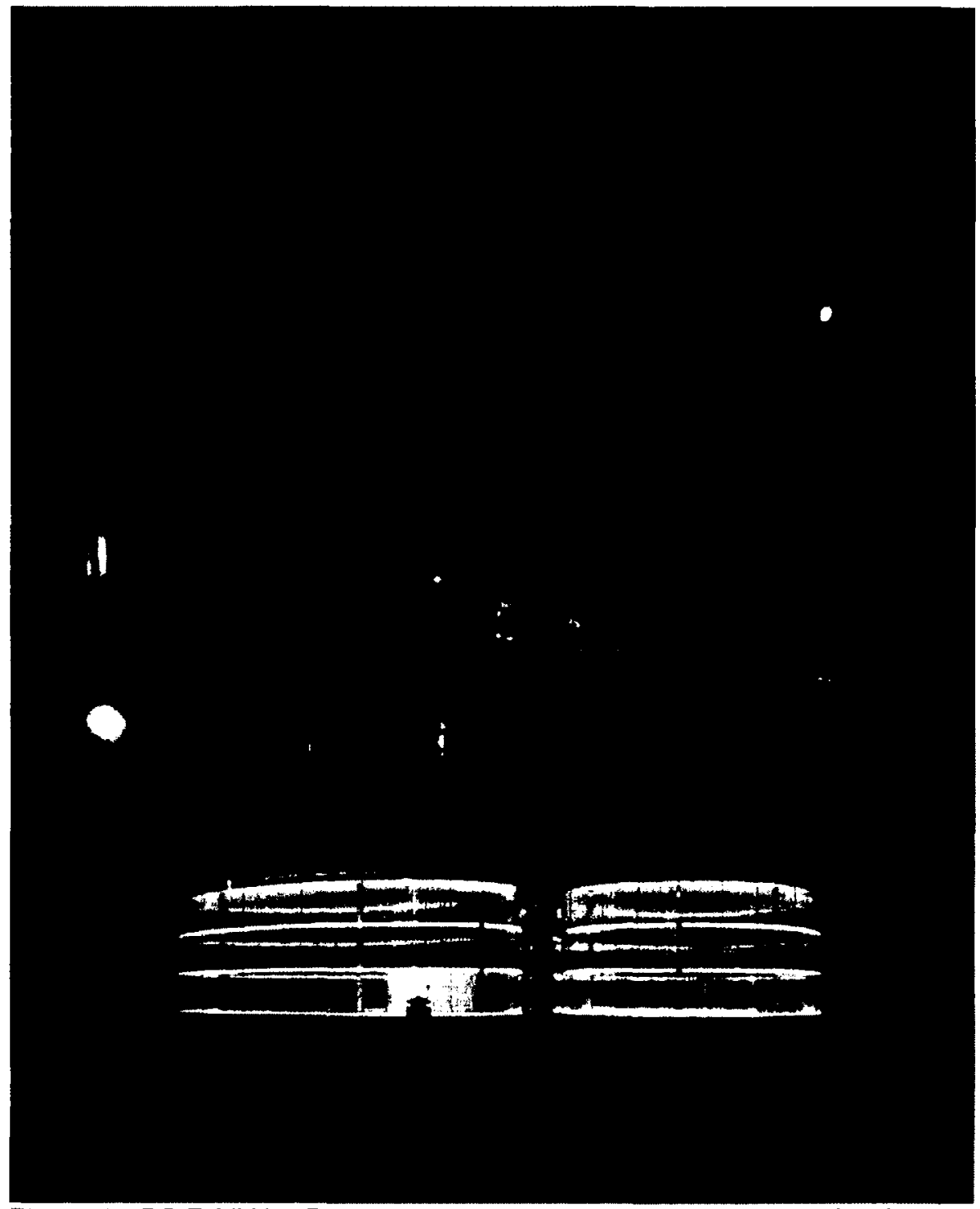

Figure 4: eBO Exhibition Pavilions, Piazza Re Enzo, Bologna. Piazza Maggiore is on the opposite side of these buildings. Mario Cucinella Architect, 2003. Source: www.mcarchitects.it. 
According to Smith, the test of resilience is whether a cultural landscape can tolerate new insertions - be they rituals or artefacts. Coming back to Bologna, by way of example, the City built a new entrance to an underground gallery located at the Palazzo Re Enzo, which is adjacent to the Piazza Maggiore. Immediately, the insertion was met with strong resistance. The contemporary design was perceived as an affront to its historic setting. The entrance was dismantled less than one year after being built.

Smith advises that contemporary interventions of this nature can only be made when the values of the community involved have been identified and determined to be resilient enough to accept change. The provocation of a new intervention or stimulus - whether ritual or artefact, or both - might challenge the old, but it should still encompass it and not destabilize it. ${ }^{33}$ In this way, a provocation without destabilization can be effective in building resilience.

In his book, A Thousand Years of Nonlinear History, philosopher Manuel De Landa also addresses the question of resilience. Referring to urban ecosystems, he finds a close relationship between stability and the degree of heterogeneity, whereby the latter

\footnotetext{
${ }^{33}$ Smith, 51.
} 
endows a system not only with said stability, but perhaps more importantly with resilience. ${ }^{34}$ According to De Landa, a system is resilient when it has "the capacity to absorb major external and internal fluctuations by switching between several alternative stable states;" 35 that is, by maintaining equilibrium among a complexity of coexistences and interactions occurring within the system.

While urban ecosystems emerge through drift - by being "propelled along a multitude of different currents" which will carry a meshwork forward and spill it into areas beyond itself, ${ }^{36}$ they tend ultimately towards hierarchy, organization and efficiency. Even though city development arises from the coexistence of what De Landa calls hierarchies and meshworks, ultimately, they tend towards homogenization and routinization, led by a wide variety of institutions, which has resulted in "the homogenized world [that] we inhabit today." 37

More specifically, De Landa reveals that urban biological ecosystems tend to be homogeneous, forming a hierarchy of synonymous parts that are susceptible to fluctuations in the food chain and in the spread of contagious diseases and parasites. On the other hand, urban

\footnotetext{
${ }^{34}$ De Landa, 97.

${ }^{35}$ De Landa, 107.

${ }^{36}$ De Landa, 174.

${ }^{37}$ De Landa, 179.
} 
cultural ecosystems have the potential towards heterogeneity - that is, to be self-organized meshworks of 'species' interconnected by their functional synergies.

If heterogeneity endows a system with resilience and equilibrium, then De Landa suggests that to attain this self-organizing condition, a system must first achieve a "threshold of complexity." ${ }^{38}$ This consists of coexisting forms of varying complexity (i.e. attractors) interacting and causing fluctuations that attract more energy flows into the system, and thereby further increase interaction between the components.

As an intense flow of energy moves through an ecosystem, it can push it far from equilibrium. While generating a seeming crisis, even minor fluctuations can play a crucial role in deciding the number and type of possible outcomes for that system..$^{39}$ Thus, a crisis (such as a drought, the plague - which is De Landa's example, disaster, or perhaps more simply a fallow time) can catalyse into existence a number of forces (institutions, reactions, revolutions) that will gain complexity over time by their interactions with other forces. This "meeting of two

\footnotetext{
${ }^{38}$ De Landa, 78.

${ }^{39}$ De Landa, 14.
} 
substances" combines to redistribute energy flows, so as to render a system self-organizing. ${ }^{40}$

De Landa is careful to point out that this process is nonlinear. That is, equilibrium (self-organization) is cyclical, whereby cities gain and lose vitality through time. Where a city faces "internal limits to growth," it can circumvent these by attracting external energy flows into the catalytic loop, and replicating these internally. ${ }^{41}$ These replicators, or catalysts, will either facilitate or inhibit the selforganizing process, ${ }^{42}$ and as such can be said to determine the nature of the stable states that are available to the system - for example, an internally derived state, or an externally imposed one.

De Landa suggests that stability and resilience therefore arise from a system being able to shift from one stable state to another (at a critical moment called bifurcation), all the while accumulating the coexistence and interaction of different stable states, in increasing complexity - that is, by accumulating heterogeneity.

The notion of accumulation is significant, as it implies a layering of histories, rather than a linear evolution. De Landa rejoins Smith with the notion of layering, whereby each layer of history, culture,

\footnotetext{
${ }^{40}$ De Landa, 62.

${ }^{41}$ De Landa, 80-1.

${ }^{42}$ De Landa, 147.
} 
attachment and idea of a place is recognized as an accumulation that coexists and interacts with all the others. None are left "in the past," as it were, nor advance in stages of increased perfection. Rather, human history gathers a slow accumulation of different types of 'materials,' that gradually build complexity by coexisting and interacting to arrive at their own equilibrium.

If the potential exists for a system to evolve in any number of directions, De Landa shows that the most resilient and adaptable urban ecosystems are the ones characterized by heterogeneity and synergies among its components. ${ }^{44}$ These systems are not only capable of withstanding fluctuations, including pressures from other systems, but more importantly are able to balance multiple flows of energy into and through the system, each one moving at a different speed, and bringing about different rates of change. When the system attains a level of density that allows it to dominate adjacent ecosystems, it could be said it has reached a level of self-organization, and thereby resilience. ${ }^{45}$

De Landa's notion of urban equilibrium lends to fallow time the understanding that stability comes in waves between crises, and that

\footnotetext{
${ }^{43}$ De Landa, 16.

${ }^{44}$ De Landa, 97.

${ }^{45}$ De Landa, 128-30.
} 
as a crisis passes, a diversity of flows may enter or return to the fallow landscape, and bring with it a shift in the relationship between ecosystems. In return, fallow time might offer the necessary pause to reflect on this process, and how the next catalyst might lead away from homogenization in order to recover heterogeneity. Afterall, as De Landa recognizes, fallowing contributes to resiliency by interrupting the natural cycle of weeds. ${ }^{46}$ Perhaps in the urban landscape, it might it also interrupt the cycle of homogenization.

In his book Architecture Depends, architect Jeremy Till proposes that buildings be situated "in and through time," suggesting that the construction of architecture (cultural, social and environmental) continues after the building process. ${ }^{47}$ Like De Landa, Till argues that the results of occupation (which are like flows of matter-energy) are unpredictable owing to the countless and "unknown combinations" that might result from their interaction and layering over time. ${ }^{48}$

Temporality thus becomes a continuous influence on the life of buildings, in particular the forces of what Till might call "positive

\footnotetext{
${ }^{46}$ De Landa, 165.

${ }^{47}$ Till points to Mostafavi and Leatherbarrow's notion of physical completion, which occurs through processes of weathering; however his interest lies primarily in the inhabitation of buildings, and less on the surface changes to buildings.

48 Till, 107.
} 
entropy" - the continuous remaking of a place over time. In this way, a building is never finished because it is being constantly remade by its interaction with the elements (weather, decay), and more importantly with social forces (changing uses, occupants, economic circumstance, cultural preference). ${ }^{49}$

Observing Lars Lerup's call to "build the unfinished," Till encourages the architect to leave a building conceptually unfinished, so as to allow occupants to appropriate the building and "claim the architecture" 50 over time. In listening to the voice of occupants during the architectural process, the architect may only "start what time and others continue."51

Till cautions that, while an architectural approach might be shaped by other events and ideas, it must also be purposeful enough on its own not to be overwhelmed by those other forces. There must be a vision, but the architect should be modest and light-footed enough to allow that vision to be adjusted to circumstance. While we bring a concrete background to our choices, this background must only be used to inform, not determine, the way we deal with choices. Our knowledge is partial, and so is the knowledge of others, which means none of us

\footnotetext{
${ }^{49}$ Till, 104-6.

50 Till, 42.

51 Till, 106.
} 
can claim "universal relevance or authority;" rather we are best to work humbly, "gathering the past in order to shape better futures."52

To use De Landa's term, the architect's proposal catalyzes, but does not control the sequence of events to follow, since each catalyst takes on a life and duration of its own. By providing a "provisional framework" that anticipates being taken over by occupants, the architect neither prescribes nor predicts the life course of buildings or interventions. Rather, s/he leaves space for interpretation, "openness to appropriation"53 and the freedom for occupants to define and evolve their own rituals within the artefacts of inhabitation.

These accounts of urban processes acknowledge multiple realities and a multiplicity of attachment and understanding of place. While incremental change occurs at somewhat unpredictable rates, small gestures can have significant (positive) outcomes, as long as there is resilience. Urban landscapes go through a sequence of events; with pressures coming to bear (that are both internal and external); but whose outcome we cannot predict, but can certainly facilitate.

Three principles might be extracted from this, namely:

\footnotetext{
52 Till, 59-61.

${ }^{53}$ Till, 107-8.
} 
Architecture as catalyst Architectural intervention may act as a catalyst by instigating and provoking catalytic reaction in a fallow urban landscape. That is, architecture brings with it rituals, practices and patterns of use that interact and combine to animate a place such that it may become self-sustaining. The insertion of new artefacts / rituals facilitates the self-organizing process and, moreover, sets the tone for further catalysis (that is, development). In this way, even seemingly small gestures can have big impacts -- both positive and negative -- whereby they can either stimulate or destabilize. Gradual change may be instigated by a layering of catalysts, each one animated from within, but also interacting with its environment.

Sustainable change Urban landscapes are in process, where patterns of dwelling evolve and change over time. These changes come both from within and from outside forces. Some histories naturally lie in wait, while others progress at different rates and intensities. A sustainable path acknowledges this nonlinear layering of attachment and identity, and allows these to evolve at their own rate by admitting time and the opportunity for inhabitation to finish what the catalyst starts.

Buildings, like their urban landscapes, become sustainable by never being complete, that is by accepting the bifurcations brought by time and continually adapting to these changing and evolving rituals. 
Resilience in heterogeneity Resilience is achieved by introducing a balance of rituals and artefacts to a landscape in a way that does not destabilize, but allows for future change. Resilience comes from being able to shift from one state to another (from fallow to regenerative, for example) while maintaining a sense of identity and place; that is, continuity with history and historical processes.

Shifts (or bifurcations) include the insertion of new architectural interventions, or new practices, which can accumulate in increasing complexity (i.e. heterogeneity), and thereby contribute to a growing resilience.

\section{An approach to fallowing an urban landscape}

In the same way that there is no generic formula for managing an agricultural landscape, any approach to fallowing an urban landscape would also need to be adapted to its specific location and conditions. Some general principles are therefore offered towards an approach to fallowing an urban landscape.

\section{Develop a management plan The fallowing process needs to be} managed. The management structure should reflect the values and inheritance of the fallow landscape, and should be conceived locally - 
by citizens and the community(ies) directly involved. The architect's role is best conceived as an interpreter-instigator-facilitator (not creator-rebel-dictator).

Move towards stability Development of the fallow landscape should be allowed to proceed at its own (unpredictable) rate, suggesting that some histories will have to wait for reactivation, while others evolve more quickly. The overall ecology of the landscape may develop its own equilibrium, and be sustained over time.

Attaining equilibrium will depend on effective management as well as investment. Types and intensity of investment will be determined by the nature and duration of the preceding fallow time - are existing buildings usable? If not, can they be recovered? Are infrastructure upgrades required? Investment should seek to build stability within the landscape, and may be required for a long time before equilibrium is reached.

If equilibrium occurs in cycles and is founded in history, then what happened previously, and today, affects what may happen in the future. A process of trial and error builds in and contributes to stability and resilience. 


\section{Allow for diversity As the regeneration process}

unfolds, a strong identity, or identities, may come to dominate the landscape. However, at the outset, all overlapping identities, claims to the fallow landscape (if these exist), and competing understandings of place should be acknowledged and explored, without prescribing or pre-determining which one will emerge over time. Multiple, overlapping identities may ultimately co-exist and thrive.

By opening up to multiplicity, the regeneration process might also reveal synergies among seemingly different communities / uses. These synergies might then be seized to form what De Landa refers to as "economies of agglomeration" 54 - as opposed to economies of scale, which tend towards homogenization. Diversity thus contributes to creating a sustainable process, which is important for ecological balance, diversification and ultimately resilience.

Gently catalyze Each catalytic gesture is an opportunity to change course - to bifurcate. The consequences are numerous, and possible outcomes unpredictable. For this reason, catalysts should be conceived as a process of trial and error. This reflects the reality of historic urban landscapes where balance and stability are achieved over a long period of time.

${ }^{54}$ De Landa, 97. 
Catalysts should also seek to preserve energy within the fallow landscape, that is to avoid losing the embodied energy found in existing buildings, landscape features and other resources. This energy should be recycled, not exported - this includes, where possible, reusing buildings and materials present in the landscape, whether in situ or in other innovative and adaptive ways.

Allow for flexibility and adaptability If a sustainable path allows for a diversity of rituals, it must also provide a diversity of artefacts. Architectural catalysts should acknowledge their own inherent unpredictability by leaving space for interpretation, simultaneity and appropriation by future dwellers. Interventions should be lasting, flexible, and adaptive to change; able to absorb all instances of cultural flows (which change with time). Interventions should be immediately useful, engaging the community, while leaving opportunity for a layering of patterns of use to emerge.

Flexibility among artefacts facilitates the adaptation of rituals to the fallow landscape, and therefore contributes to building resilience. Further adaptations will need to be made with the introduction of new identities and the invention of traditions over time. Flexibility allows for bifurcation, which, while not predictable, can be anticipated with built-in flexibility. In this way, there may be elements of both 
hierarchy and structure associated with elements of meshwork and chance. Combined, they provide flexibility within stability.

\section{Care for the specificity of place A fallow place risks}

being made an instrument of the larger community to which it belongs; that is, it risks being homogenized into a dominant landscape, and thereby losing its unique identity. A fallow urban landscape is in a fragile moment, since its resources are underused and an indigenous community is absent - the landscape may not have any defenders.

As the regeneration process begins to build complexity, care should be taken to avoid a situation in which an adjacent stable ecosystem (for example, an adjacent neighbourhood) extends its 'energy loop' into the fallow urban landscape as a means of circumventing its own limits to growth. Instead, the regenerating landscape should be protected so that it can reach its own internal equilibrium.

We may imagine that an architectural approach to fallowing an urban landscape means to take possession of the phase between a previous occupation and future development. It assumes incompleteness and is focussed on process, rather than product. This approach seeks to manage change, rather than define the changes itself, and therefore 
offers opportunities to arrive at decisions or choices for interventions, but also the opportunity to postpone.

Fallowing an urban landscape also accounts for cities in process that contain multiple identities, and recognizes that small gestures can have a big impact (both positive and negative).

Fallow time thus becomes a component of a broader approach to fallowing an urban landscape. By establishing a relationship between the old and the new - between the histories that brought the past forward, and contemporary experience - fallowing an urban landscape might then be understood as phase transition - the process of an urban landscape shifting from a (stable) state of fallowness to a (stable) state of regeneration.

The following chapter explores how this broad approach of fallowing an urban landscape might become a framework for regenerating the Staveco site. 
Not everything will necessarily happen tomorrow, some things will happen only the day after tomorrow.

From The Cave, a novel by José Saramago (2008)

\section{3_Sowing Seeds}

This chapter draws from a selective history of Bologna and the Staveco site to propose a framework for regenerating the latter. This historical account extracts elements and experiences that might provide clues towards regenerating the Staveco site in a way that is meaningful and lasting to the people of Bologna. The account draws on primary materials, including planning documents - both current and past; presentations delivered by historians, planners, architects, artists and others practicing and living in Bologna; and of course my own physical reading of the Staveco site. While this reading may be imperfect, and most certainly tinged by the bias of the source materials, I offer the following account of Bologna's urban landscape. 


\section{Bologna's urban landscape}

Geographically, Bologna is located on the north face of the Tuscan-Emilian Apennine Mountains. This is an unusual, perhaps even an anomalous urban history, since cities have tended to situate in either a valley or the hilltop, ${ }^{55}$ neither of which is the case with Bologna. Indeed, the city must have recognized its own peculiarity early on, since early mappings tend to orient north at the bottom of the page.

Several waterways skirt the city, with some being diverted into the town by way of canals, which is what secured Bologna's seat as a centre of commerce and trade. In addition to a commercial sector, a fertile countryside also fostered a strong agricultural sector. This contributed to Bologna becoming the heart of the strong northern Italian agricultural region, offering a centralized wholesale and distribution network and other supporting services.

In the post-unification era (1860s) many church properties (outside of the city centre) were divested for use in the expanding agricultural sector. Concurrent with this move, Bologna also proved an important military location, with

${ }^{55}$ Kostof, 73. 
camps and barracks being installed within and around the city centre.

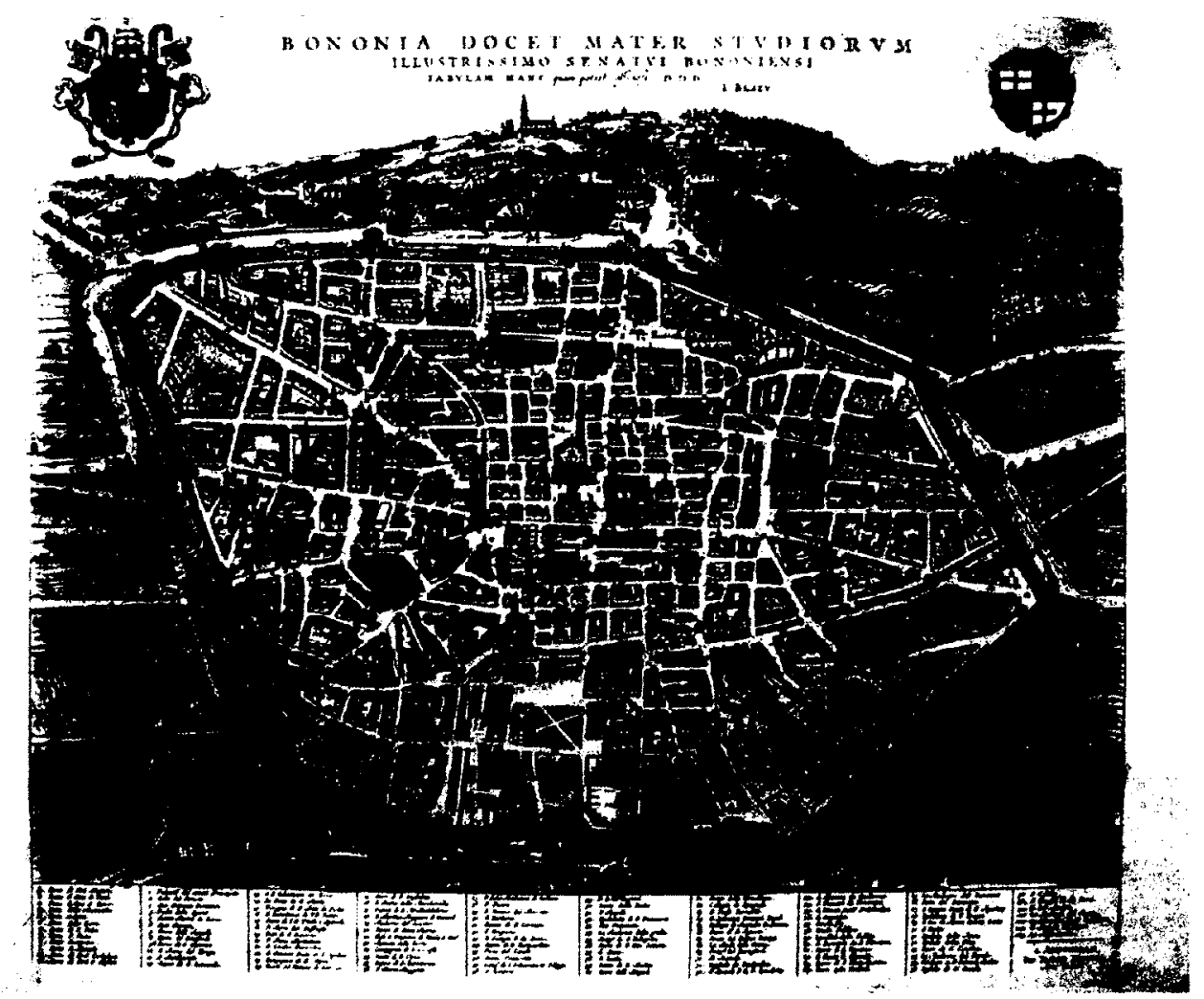

Figure 5: Map of Bologna, 1640, by Blaeu. North is down. Source: wuw. florenceprints.com/USAcitta_italia.htm.

Also in the late 1800 s, a new political structure was developing in Bologna, whose power resided in the strength of the growing middle-class. This had the effect of reviving the university sector, ${ }^{56}$ in particular the scientific disciplines. On

\footnotetext{
${ }^{56}$ Bologna hosts Europe's oldest university, having been established in about 1,055 . Its presence plays an important role in both the physical and cultural makeup of the city.
} 
the other hand, an industrial sector was slow to develop, frustrating the working-class, who were migrating from the countryside to the city.

The period between the First and Second World Wars marked a significant stagnation for Bologna, as elsewhere in Italy, with far-reaching effects on the fabric of the city. This will be discussed in further detail in the following section.

In the post-WWII era, the nation's economy, industry, and living standards were on the rise. The Italian 'Economic Miracle'57 brought an influx of workers to Bologna, who settled into the rapidly growing suburbs. Rising social demands would play a role transforming the image of the city into a centre of small and medium-size companies specializing in the service industries and the retail sector. The city's economic development was further aided by the creation of a regional highway and the construction of an international airport, which made of Bologna a new transportation hub.

\section{Fallow Time in Bologna's urban landscape}

Bologna's post-war evolution cannot be fully understood without considering the effects of the governing political party.

\footnotetext{
${ }^{57}$ Economic boom from 1947 to 1973.
} 
One need only consider the following examples to see how political ideology reinvented the image of the historic city centre. ${ }^{58}$ Among many important events in Bologna's history, three stand as being particularly pertinent to defining a way forward for the Staveco site: (a) the city's long flirtation with communism; (b) Cardinal Lercaro's 1950's church-building campaign; and (c) the 1969 Conservation Plan for the historic centre. In each of these can be found a tangible trace of fallow time.

Bologna's Communism Bologna has long been a centre of socialist politics, the roots of which can be found in the era of the Papal downfall, when Bologna would launch several class-conscious conflicts against the contractortenants in support of labourers. ${ }^{59}$ Since 1914 , the municipal council has been firmly in the hands of the "reds", with the exception of the inter-war period during which Mussolini's fascists made Bologna a stronghold and a showcase for overcoming socialism. In effect, normal political life disappeared from Bologna in the interwar period, when

\footnotetext{
${ }^{58}$ One could attempt to demonstrate the effect of the Communist Party values on all aspects of Bologna's culture and society, but that exercise is beyond the scope of this proposal.

${ }^{59}$ Evans, 6.
} 
political and democratic freedom (or equilibrium), along with socialism, went into exile. 60

Only the Communists remained somewhat active and vocal in their opposition to Mussolini's fascists. Indeed, by the end of the war, they were successful in appealing for unity among all anti-fascists, including the Christian Democrats and the bourgeoisie. By 1945, the Communist Party of Italy was the only properly organized party in Bologna. It swept to power in the municipal elections that same year, in effect, occupying the gap left by the political fallow time. Bologna and neighbouring regions (so called "red regions") would lend their support to the Italian Communist Party for decades to come. ${ }^{61}$

The communist strategy for resolving the political fallow time was to invent a sense of unity. While a truly united Bologna was a myth, it was a necessary fabrication that would allow the growing anti-fascist movement and the Resistance to gather the strength needed to counter the fascist oppression. ${ }^{62}$ However, in its drive to fill the void of political and cultural leadership in the post-war period, the city administration left another void in its midst.

\footnotetext{
${ }^{60}$ Evans, 6.

${ }^{61}$ Indeed, while the Communist Party of Italy is now defunct, its successor -- the Democratic Party - continues to hold the Mayorship in Bologna.

${ }^{62}$ See Lowenthal for an exploration of 'fabricating heritage,' and Barzini (chapter 5) for an explanation of the Italian reliance on symbols and spectacles.
} 
The post-war shift from agricultural hub to services hub brought a massive influx of people to Bologna's suburbs. This rapid urban development was neither planned for, nor managed. In fact, it was not until 1955 that the City Administration developed a new Urban Plan for the entirety of Bologna's territory. Until that time, it relied on the 1889

Regulatory Plan - a 66-year-old document.

Not surprisingly, this void resulted in a number of unanticipated fallow times, in particular in the socio-religious sector and the very urban fabric of the city. Social and religious infrastructure could not keep up with the expanding suburbs. At the same time, the working class population was fleeing a declining and derelict city centre, which was also failing to meet social and cultural needs.

\section{Lercaro's campaign In 1953, Archbishop Giacomo}

Lercaro was elevated to Cardinal of Bologna, and quickly became known for his "energetic action against the Communist Party" and "for his ideas of renewing the Catholic liturgy."63 64

\footnotetext{
${ }^{63}$ Evans, 66.

${ }^{64}$ Of course, in Bologna as elsewhere, there is a complex relationship between politics and religion, a discussion of which is beyond the scope of the present research. For a full discussion, see Evans. Suffice it to say, the Cardinal launched several initiatives aimed at influencing the electorate away from the Communist Party, including creating the frati volanti - a squad of "flying monks" who, during elections, would drive from one electoral meeting to another to instruct people how to vote - for the Christian Democrats, of course.
} 
While the social doctrine of Cardinal Lercaro was generally clear, none of his initiatives were as effective as the churchbuilding campaign that he launched in 1955 , which aimed at developing Bologna's exploding suburbs around new religious centres.
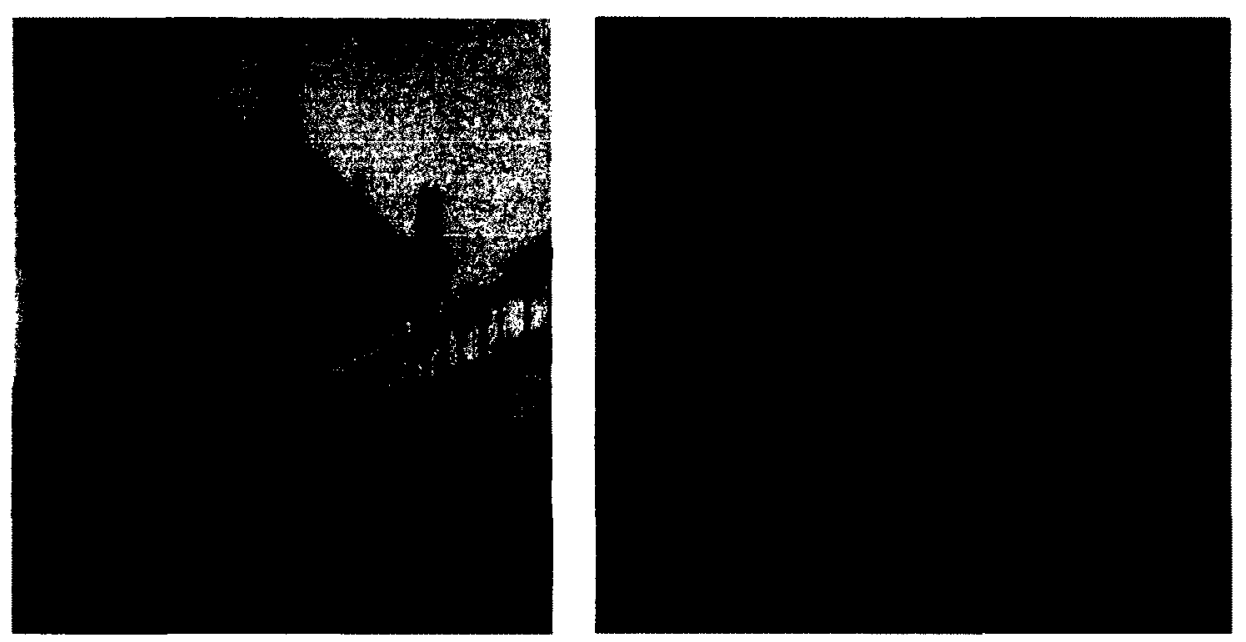

Figure 6: Left: Padiglione dell'Archittetura, temporary pavilion built to host the National Congress on Sacred Architecture (1955) installed at the Piazza Rossini, centro storico. Source: Chiesa e Quartiere (book), p 44. Right: Map of Bologna's parishes. The centro storico is in white (bottom-centre). Black dots represent future church-building sites. Source: Chiesa e Quartiere (book), p 18.

In 1955, the Cardinal hosted the first National Congress on Sacred Architecture, which placed Bologna at the centre of a deep reflection on sacred space and the role of modern architecture in both renewing the Catholic liturgy and in creating new urban centres around which a collective modern identity could be built. The Congress and the Cardinal's 
campaign became a locus for discussion among architects, liturgists and artists on the future of cities and the role that the Church might play in the organization of social life. ${ }^{65}$

The Cardinal used the opportunity of his opening remarks to the Congress to point out that of 79 churches in Bologna, 58 were located in the historic centre, where less than one third of the population lived. ${ }^{66}$ In calling for the construction of new churches, the Cardinal appealed for action "on the city, in the city, for the city"67 and in a single day he blessed the grounds for 23 new churches. ${ }^{68}$ These buildings were among the first to depart from traditional sacred architectural forms, and gave to Bologna's bland suburbs both a contemporary architectural language and centres for religious and social gathering. ${ }^{69}$

The religious fallow time that stimulated the Cardinal's action was characterized by a breakdown in both Church and municipal planning, which had failed to anticipate the rapid growth of the suburbs and the means by which people's social

\footnotetext{
${ }^{65}$ Accompanying the campaign was a publication entitled Chiesa e Quartiere (Church and Neighbourhood), in which the debate was furthered and international modern religious projects were highlighted.

${ }^{66}$ Indeed, at its height in the early $18^{\text {th }}$ century, there were some 96 convents located in and around the historic centre. Bologna could aptly be described as one of the most heavily Christianized landscapes in Italy; and perhaps this is no coincidence, given the political propensity of the population.

${ }^{67}$ Chiesa e Quartiere, 17.

68 Evans, 68.

${ }^{69}$ Fondazione Lercaro, http://www. fondazionelercaro.it/.
} 
and spiritual needs would be met. The disequilibrium in the rituals of worship and the broader rituals of inhabitation was resolved not only by the introduction of a physical space in which to worship, but more specifically in the attempt to foster the broader rituals of inhabitation by offering religious, as well as broader social gathering spaces to communities in need.

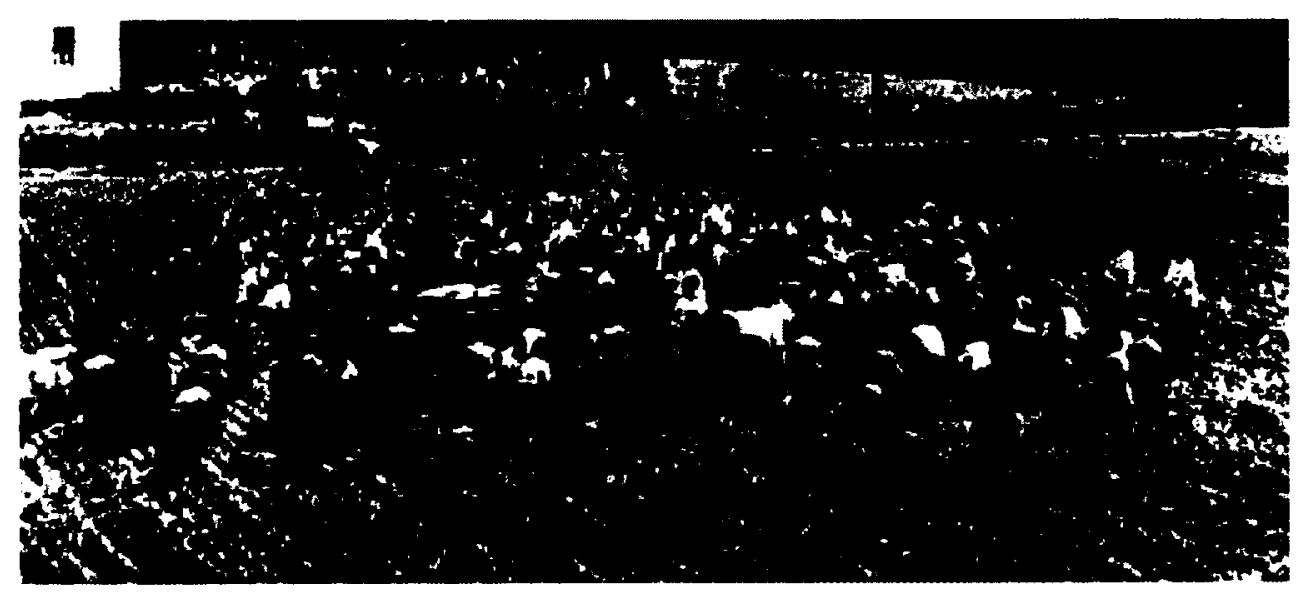

Figure 7: Cardinal Lercaro consecrating ground at the site of a future church. Source: Chiesa e Quartiere (book), p 16.

The Conservation Plan for the Historic Centre What

Lercaro's churches did for the suburbs, the 1969 Conservation Plan attempted to do for the centro storico. Indeed, if Bologna's urban centre had always stressed continuity with history and adaptation to cultural conditions, the planning void of the post-war period marked an abrupt disruption in this pattern. 
By the 1960s, the population of the core had dwindled to a mere 80,000 inhabitants. The middle-class escaped declining infrastructure, while the working and lower class remained with few resources and little social support.

In response, the Communist government launched an initiative to rescue the centro storico from further deterioration, and thereby redefined not only the historic centre but the urban identity of Bologna. The 1969 Conservation Plan advocated more than preservation of the historic built environment, it also gave a central position to social considerations. The plan avoided the pitfalls of gentrification by preserving the built form in a way that would also preserve the economic stability of the centre.

The Conservation Plan designated the entire historic core as a single 'organism' in which building types and urban patterns had undergone a continual process of change in order to accommodate functional, social and economic changes. The administration set out to renovate and upgrade the housing stock; and to convert large institutional "containers" 70 into community and social use. The Plan achieved its intended effect. Very quickly, the quality of life improved in the centro

\footnotetext{
${ }^{70}$ This is the term employed in the Conservation Plan to refer to large-scale facilities such as convents.
} 
storico, as the equilibrium between rituals and artefacts was re-established.

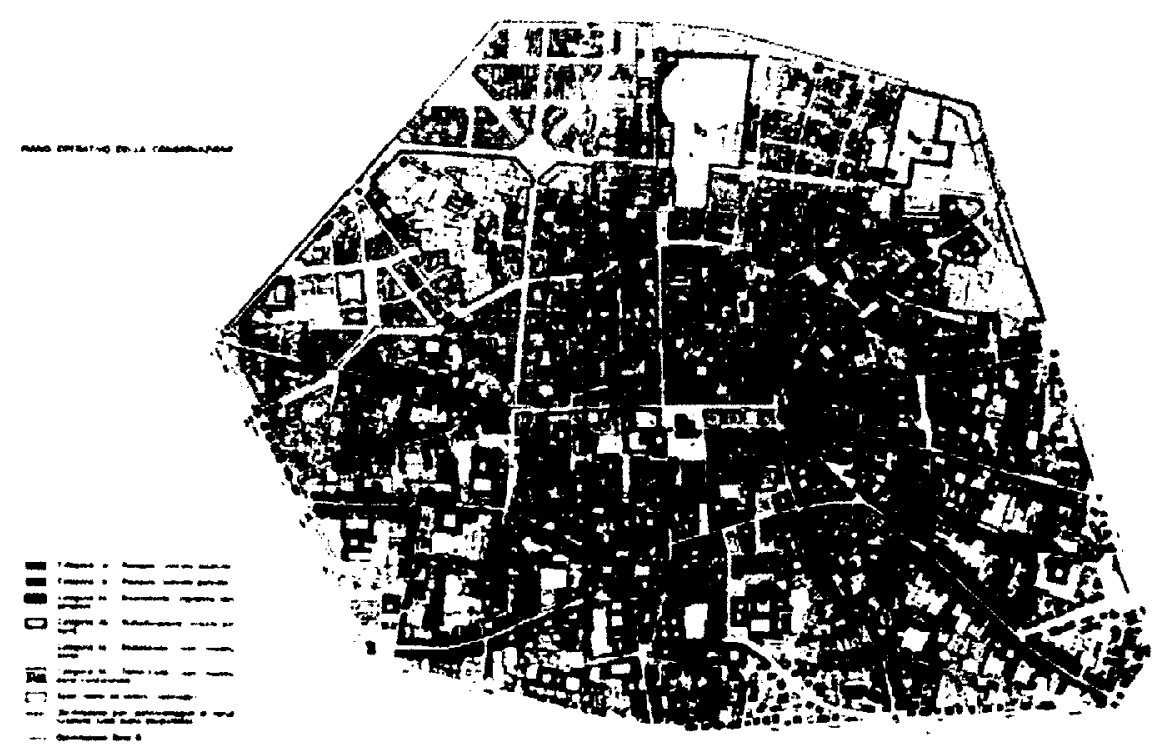

Figure 8: Urban Conservation Plan, 1969, showing buildings to be preserved. Source: City of Bologna.

While groundbreaking in terms of its social agenda and its consideration of the historic centre as an 'organism' (or, ecological system), the resulting development guidelines have had the effect of freezing the fabric of the historic centre in time, rather than allowing it to freely evolve. ${ }^{71}$ The image of the centre was based on an understanding of a city that no longer existed - an idealized image, taken from a previous

${ }^{71}$ In effect, I would argue that the centre was not treated like an organism at all, but rather as a museum - a collection of specimen-artefacts, restored to some ideal historic image, protected from further change, to be preserved in perpetuity. 
time in history, generated from above (by 'experts'), ${ }^{72}$ rather than defined from within. While the fabric was conserved and even restored, it would not evolve.

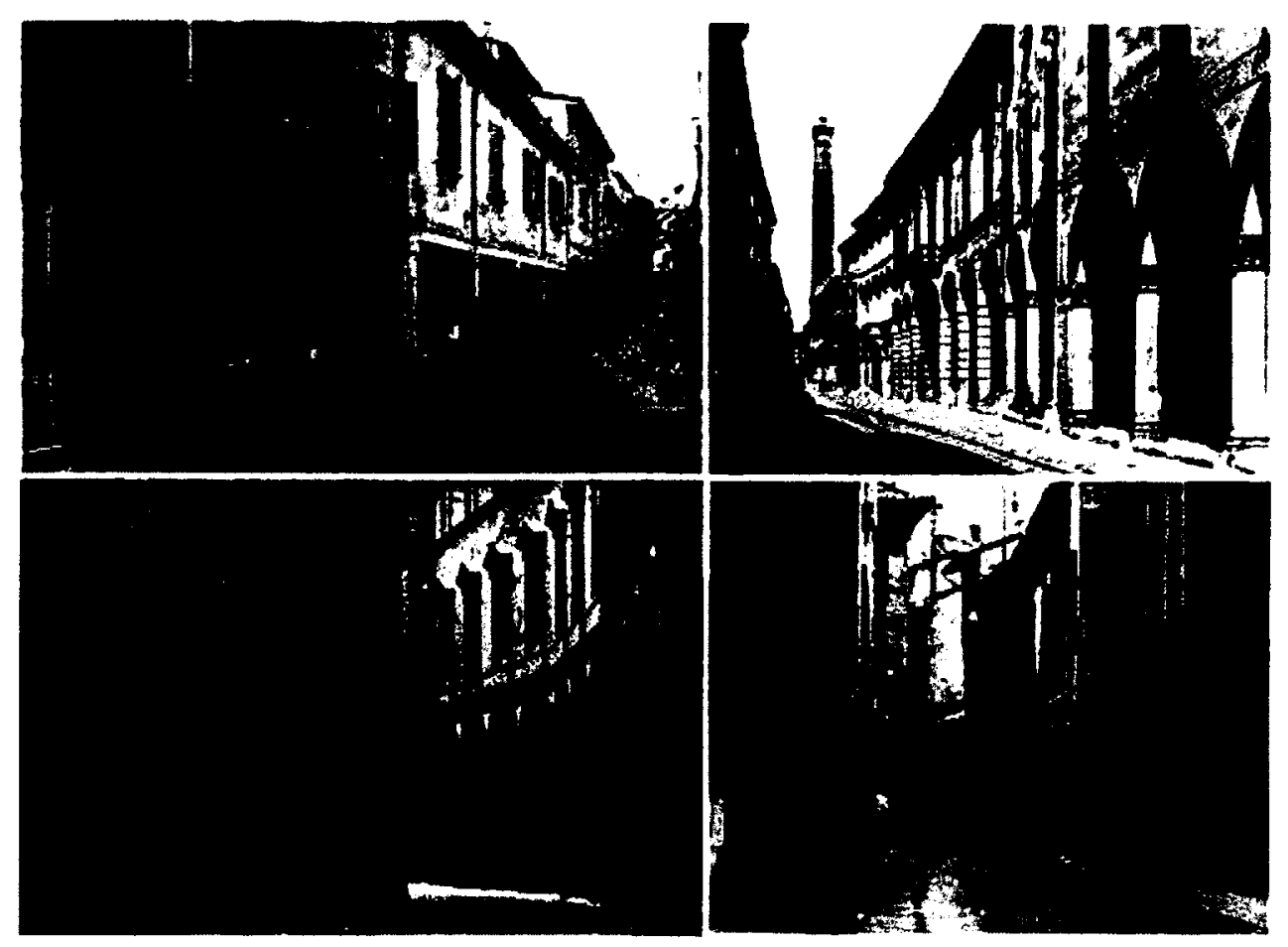

Figure 9: Images from photographic census by Paolo Monti. Source: Bologna Centro Storico, Catalog of the exhibition at Palazzo d'Accursio, Alfa, Bologna 1970.

Despite living conditions being brought to contemporary standards - the centre continues to be a desirable place to live - the city has been prevented from evolving. So, while it cannot be said that the rituals and artefacts are once again in

\footnotetext{
${ }^{72}$ De Pieri and Scrivano, 39.
} 
disequilibrium, what can be noted is what appears to be a pause in the bifurcation of the built environment. New built insertions in the city centre tend towards imitation of the historical, rather than the contemporary. Indeed, contemporary provocations elicit resistance - as was revealed at Palazzo Re Enzo where the pavilions were removed less than a year after construction.

Even if there is delight and pleasure derived from the many ephemeral events that take place against the backdrop of Bologna's historic centre, the lack of physical expressions of our time will surely be seen as a pause or hiatus from contemporary expression that the future will look back on with curiosity and perhaps sadness.

\section{Bologna today}

Beyond politics Bologna is also heavily indebted to its location amidst a beautiful and fertile agricultural landscape. Perhaps because of this, it has developed a reputation for being environmentally conscious. The city hosts many new and innovative enterprises, specifically in the sustainability and slow food movements. Added to these are a number of other tertiary industries, which have begun to supplant the city's traditional agricultural role. Many former agricultural plants 
have been vacated, with some being redeveloped as mixed-use, commercial or residential centres.

With a population of approximately 375,000 , Bologna remains the hub of the Emilia Romagna region, and provides commercial and community access for a regional population of over 1 million people. Despite this, the city retains a desirable small town feel with its abundance of independent shops and restaurants, vital markets, and intimate cultural gathering spaces.

In recent decades, Bologna's population has remained generally steady, and is now on the rise as it attracts young families, immigrants, and the creative class, thus allowing Bologna to be accurately described as a progressive community with an informed, active citizenry. It is perhaps owing to the legacy of Communism that Bologna has become a convivial city, that is warm and generous, and where public infrastructure and cultural development are strongly emphasized.

\section{The Story of Staveco}

Prior to 1880 , the Staveco site was part of a monastery property and was used for orchards and kitchen gardens. 
Beginning in 1880, a major arsenal was established at this southern edge of the city centre. For nearly 125 years, this site was destined for use as a munitions factory, armoured vehicle maintenance depot and barracks. The area now known as Staveco became one of the largest establishments of Bologna, reaching a peak of 12,000 workers in 1918. In the interwar period, the site was significantly underused, regaining activity only during the Second World War, and then resuming a gradual but definitive decline in the post-war era.

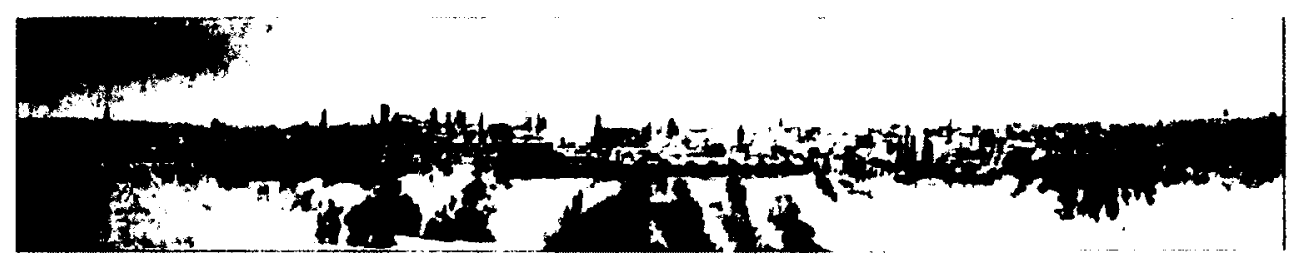

Figure 10: Early-1800's watercolour showing orchards in foreground, and the Carabinieri buildings (at left). View from south, with historic centre in the background. Source: City of Bologna.

Simultaneous with a shifting agricultural sector was a decline in the military sector. Starting in 2007, the Italian government began a process to release some 803 surplus Ministry of Defence properties, of which 19 were located in and around the city of Bologna. This included the Staveco site. For Bologna, this site represents one of the most significant and strategic opportunities for the re-development of the city; its major potential owing to its sheltered location between the 
city's historic urban core to the north, and the lush foothills of the Apennine Mountain range to the south.

The property was decommissioned in 2003 , and the City of Bologna acquired it in 2007, designating it for public and community use, as well as for sport facilities and parking. Throughout its entire vocation as a military area - both occupied and decommissioned, the Staveco site has remained generally inaccessible to the people of Bologna.

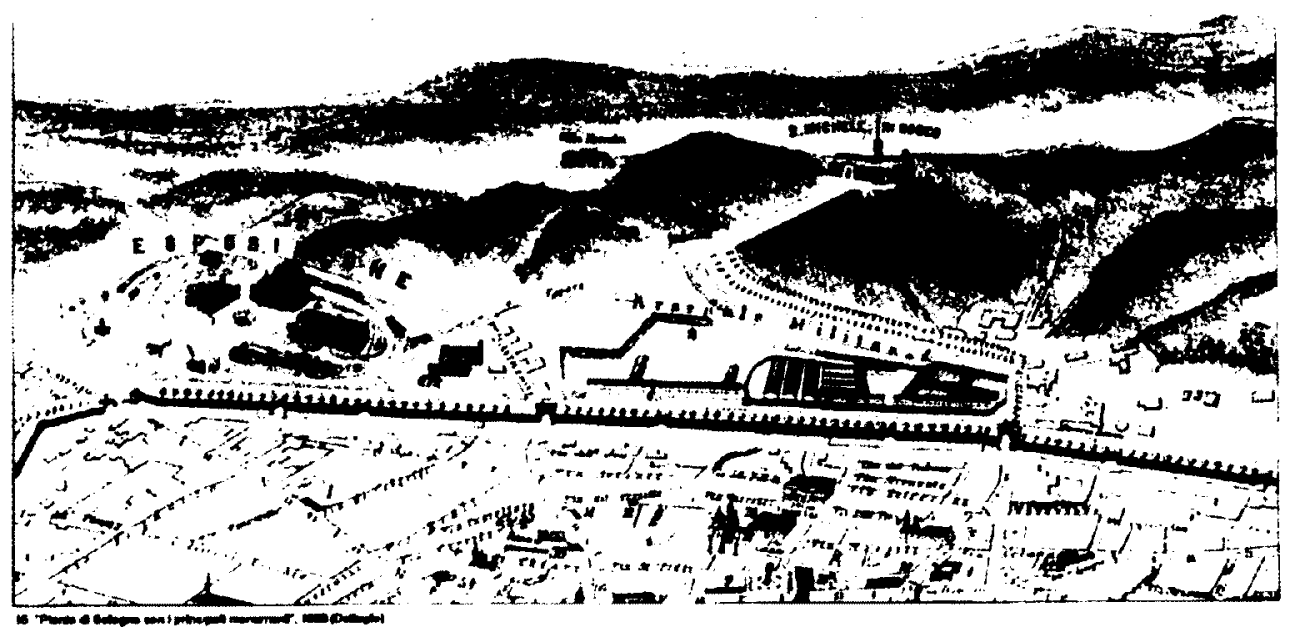

Figure 11: Detail of 1888 Plan of Bologna showing major monuments. Staveco is seen in the centre, with the well-developed Carabinieri site to the right, and the Giardini Margherita (with caption Esposizione) at left. Source: City of Bologna.

The Staveco site Located within the neighbourhood of Santo Stefano, the Staveco sits immediately south of the city's historic centre, and extends over an expansive 9.12 hectares 
(22.8 acres). To the east is the well-used Giardini Margherita, the city's largest, and formally designed, public park. To the immediate west is the compound of the Carabinieri - the Italian state police. Most of the buildings on this site are vacant and derelict. ${ }^{73}$ An exclusive residential enclave adjoins the site to the south, whereas a middle and working-class neighbourhood (contained within the centro storico) adjoins the site to the north.

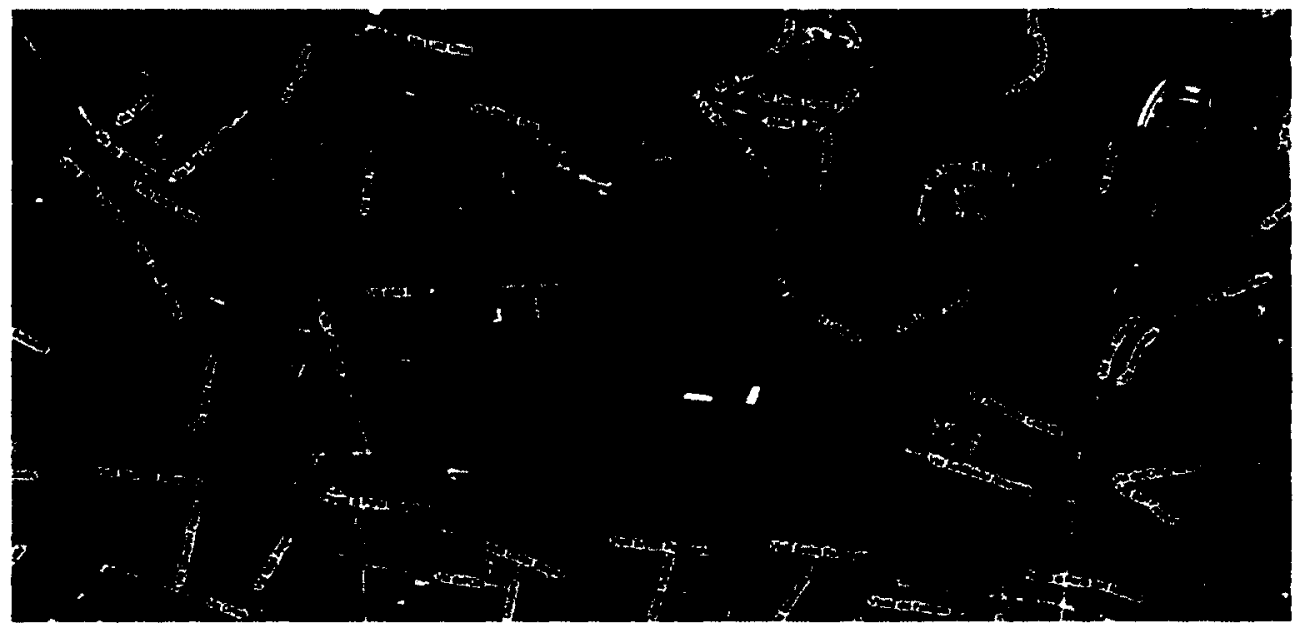

Figure 12: Aerial view of the Staveco site, looking south. Source: Bing Maps.

Skirting the western border of the Staveco is the Torrente d'Aposa - the subterranean Aposa Stream. This natural water course was rerouted into and through the city in about the $2^{\text {nd }}$

${ }^{73}$ It is anticipated that the Carabinieri site will also revert to the City of Bologna, but that transfer is a ways off. For this reason, the site is not considered part of the regeneration strategy for the Staveco area. 
century BC, when it served both defensive and civilian purposes - acting as a moat, a supply channel, and a municipal 'drain.' While urban development resulted in the stream being built over, water continues to course through the channel to this day.

Topographically, the Staveco site marks the point where Bologna begins its climb into the foothills. The site rises $18 \mathrm{~m}$ in elevation from the Viale Panzacchi at its northern edge, to the Via Codivilla on its southern edge.

Overlooking the site (from the south), is the impressive San Michele in Bosco Church and Benedictine Abbey, which sits a tall $43 \mathrm{~m}$ above the Staveco. Adjacent to this church is the Istituto Ortopedico Rizzoli, a specialized orthopedic care facility. Two other churches also border the area: the SS. Annunziata Church and Convent to the west (just beyond the Carabinieri), and the Misericordia Church to the east (sandwiched between the Staveco and the Giardini Margherita). These important resources are well known, and serve as strong signifiers - both historic and contemporary of the city.

The site's historic boundaries are clearly defined by building edges and strong fencing, particularly along its northern edge. Currently, part of the site is used for municipal parking and 
private tennis courts for military veterans. The remainder of the site is inaccessible and unused.

\section{The Buildings of Staveco Approximately 52 buildings}

remain standing on-site, some of which are amalgamated into a single monolithic unit. There are 5 administrative buildings; 16 residential, barracks and supporting buildings; 27 industrial buildings, including manufactures, shops and sheds; and 4 service buildings (including two electrical plants). The barracks buildings are in fair shape. Most of the sheds are at or near collapse.

The administrative and service buildings are constructed of brick masonry walls, with wood frame and tile roofs. These are in fair shape; however some roofs are beginning to collapse. The manufacturing buildings are largely in good repair. Some are brick masonry construction, some are steel / iron frame, and some are reinforced concrete.

The latter three groups comprise an important building stock that is flexible for reuse, and exemplifies the history and function of the site. 
Chapter 03_Sowing Seeds
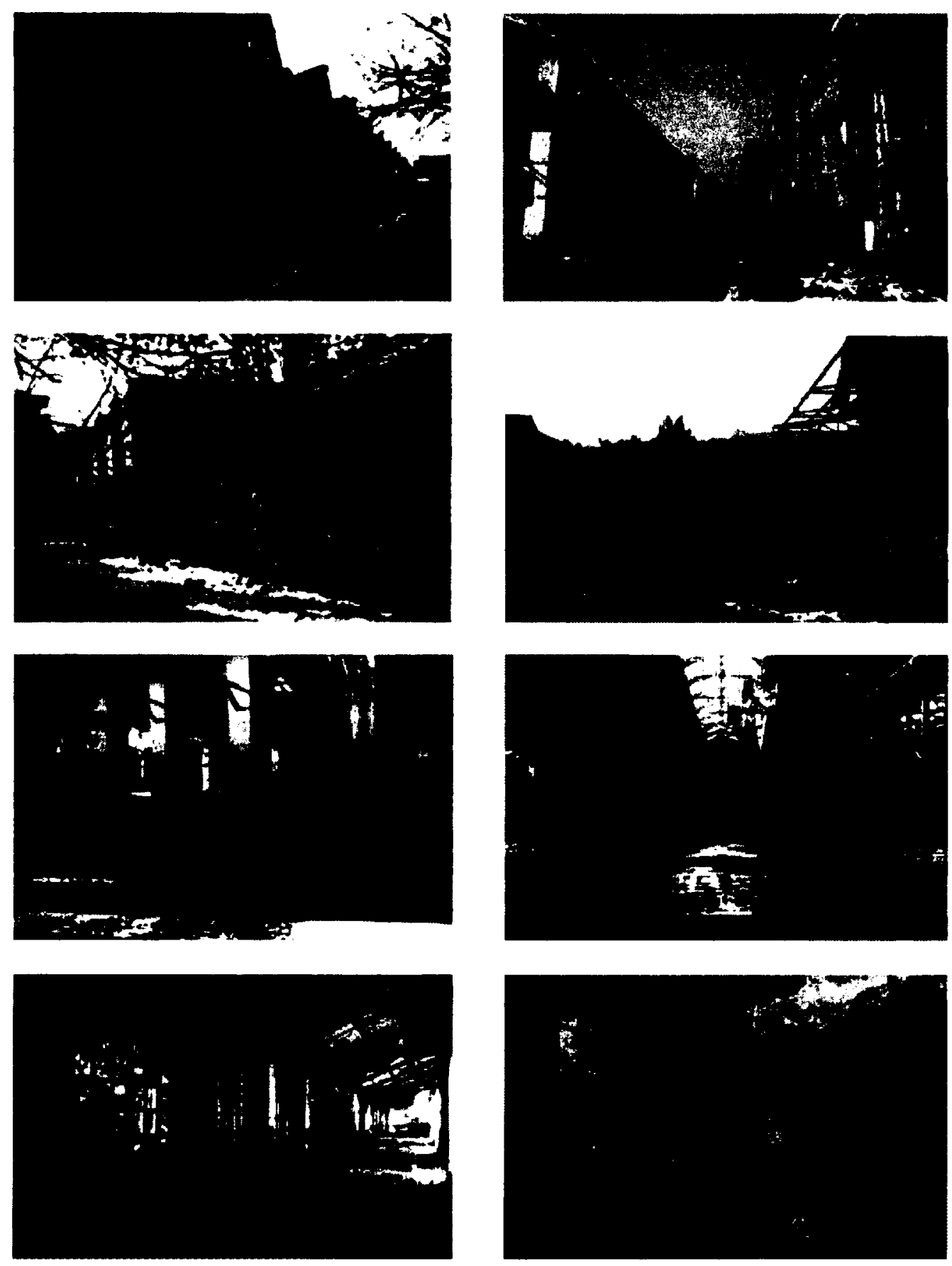

Figure 13: Photographic survey of the Staveco site and buildings. Source: Photos by author. 


\section{Redevelopment Pressure for redevelopment has}

been mounting for over 30 years. Previous studies have suggested various uses, including consolidation of the University of Bologna onto a new campus. ${ }^{74}$
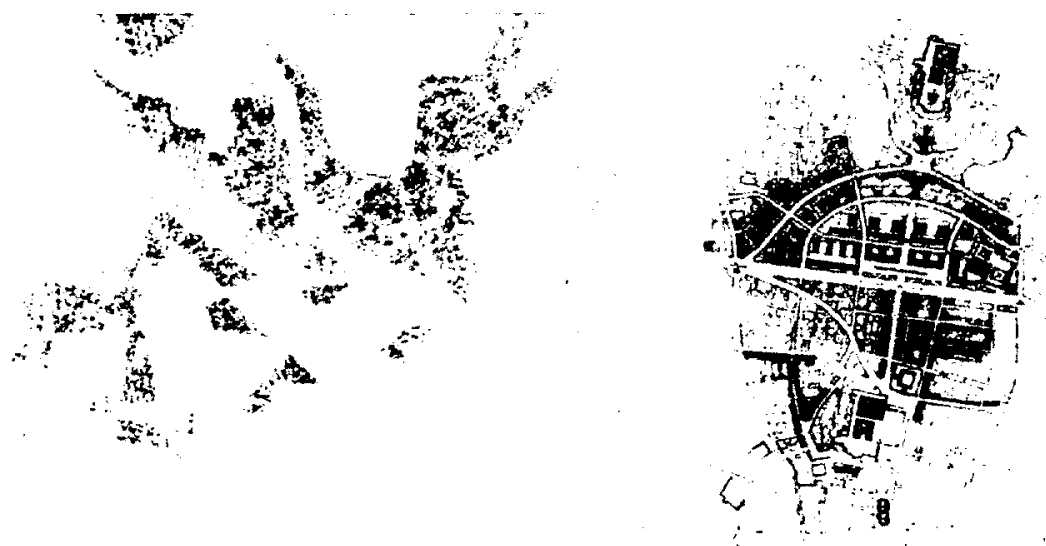

Figure 14: Left: "Key to the hills" concept by Fernandez and Calvet Arquitectes. Right: Vignali concept for consolidating the university campus at the Staveco site. Source: City of Bologna.

More recently, Bologna developed a Strategic Urban Plan entitled a City of Cities - seven cities, to be precise. The Staveco site is a key component of the City of the Hills framework, which calls for the site to provide an opening between the historic city centre and the verdant hills to the south. The key objectives are to "break taboos" by (re)constructing a "system of connections" between the historic city centre and the hills, while creating "a mosaic of 
ecological, agricultural and semi-urban environments" that are available for various uses by a diversity of inhabitants. ${ }^{75}$

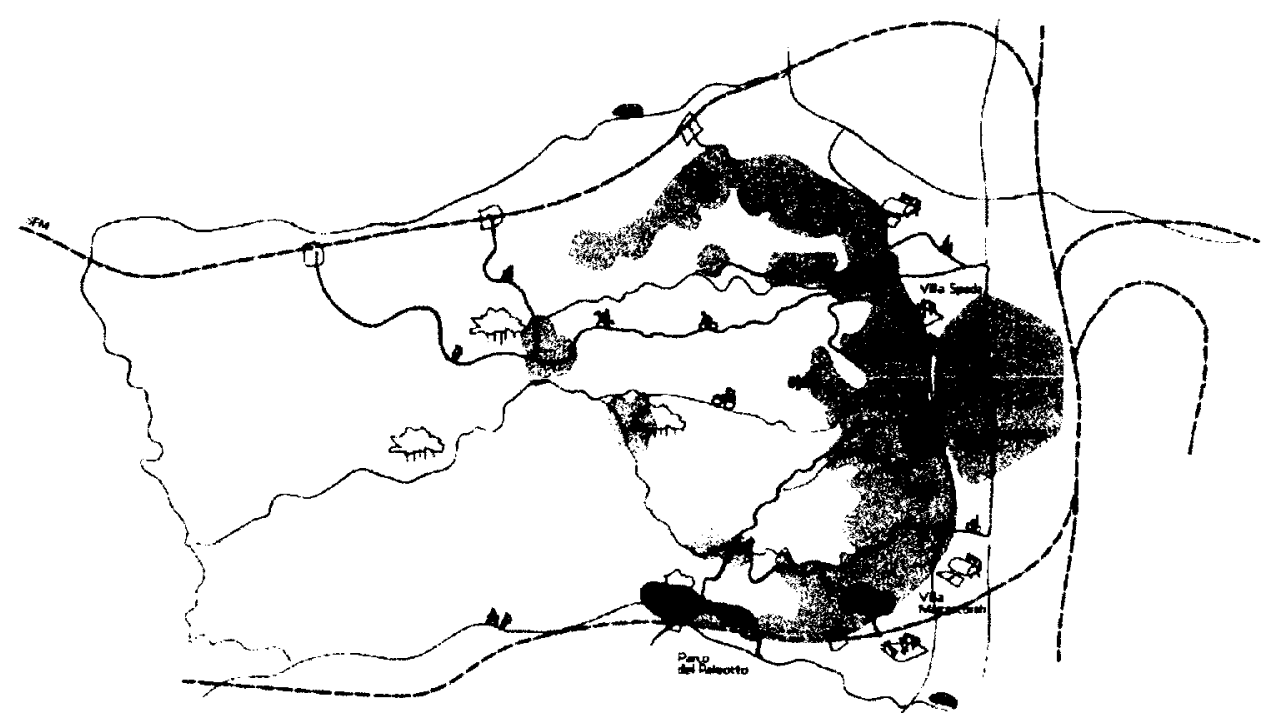

Figure 15: City of the Hills framework. North is oriented right. The centro storico is the shaded area at right. Staveco is the dark shaded area at bottom-centre of the centro storico, with three pathways traversing it. Source: City of Bologna

In addition to efforts by the City administration to build awareness about the site, ${ }^{76}$ there are two notable events that have contributed to developing an imagination around the potential of the site. In 2007, as part of Bologna's annual Danza Urbana festival, Swiss dance troupe Annas Kollectivperformed a contemporary routine, entitled 'Patina', in one of the

\footnotetext{
${ }^{75}$ Bologna (2007). See full text excerpt in Appendix_02.

${ }^{76}$ For example, the City has hosted several guided tours of the site in the context of developing the City of Cities plan.
} 
abandoned buildings on the Staveco site. Among the attendees were former military members who had been stationed at the Staveco complex. It was reported that they were delighted and invigorated by the dance troupe's alternative 'reading' of the building, which allowed them to imagine this place in a new way ${ }^{77}$.

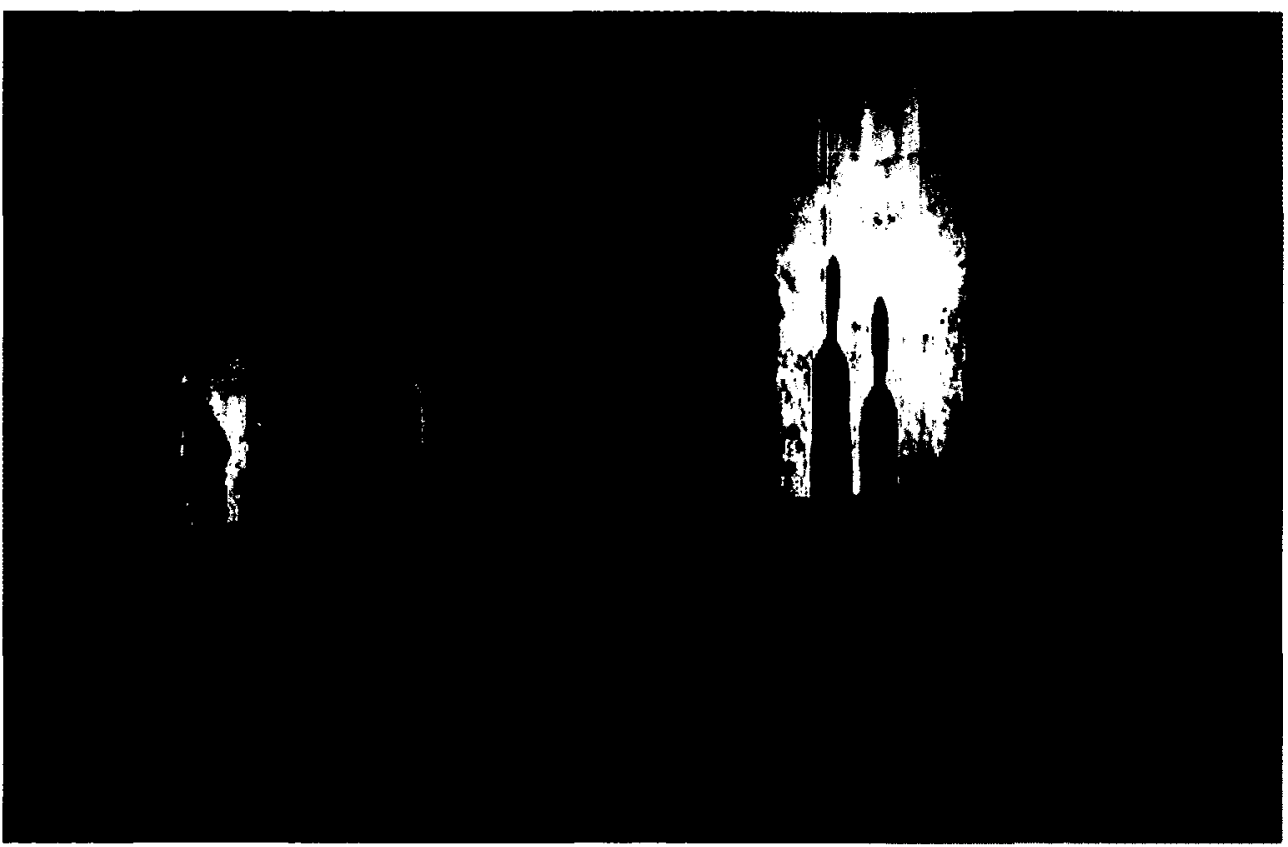

Figure 16: Annas Kollectiv performance, entitled Patina, in vacant Staveco building, 2007. Source: http://www.annaskollektiv.ch/.

${ }^{77}$ Annas Kollectiv describes their work as site specific events and installations. They typically work on the facade of buildings. Through choreography, light and music, they seek to challenge how space (or our perception of it) can change through the everyday movements of the body: walk, run, sit, stand, jump. 
In 2008 , a photographic exhibit of the Staveco area was mounted by the Santo Stefano Community Association. A public meeting and a community survey accompanied the exhibit. Respondents to the survey called for Staveco to be developed in a way that would alleviate two major issues: a lack of cultural and communal gathering spaces, and traffic congestion.

Currently, economic circumstance presents a significant challenge to development. Estimates to recover the buildings on the Staveco site come in at about $\mathbf{4 0}$ million euros. The current State budget places very low priority on cultural and heritage projects. ${ }^{78}$ State funding to develop the Staveco site seems unlikely or limited at this time.

Further, a legacy of the Conservation Plan is a resistance to the "new", unless it is ephemeral. Because a deep attachment to the Staveco buildings has not developed, this may be an opportunity to showcase how a (permanent) contemporary insertion can be provocative, yet acceptable. Perhaps reversible interventions and gradual transformation would

\footnotetext{
${ }^{78}$ Rohter, in NY Times online.
} 
provide the assurance the Bolognese seek, in order to accept the "new".

Finally, the site has, for a long time, marked the separation of proletariat and bourgeois landscapes. Add to these a multiplicity of other cultural landscape attachments (veterans, hospital families, students, and commuters in need of parking) which claim the site and the potential that these might begin to overlap at Staveco provide the beginning of an exciting and challenging opportunity!

So, is Bologna ready?

\section{Framework for regeneration}

Fallow time comes to a close when new rituals and artefacts of inhabitation begin to bridge the gap between the fallow time and regeneration. One could argue that the Staveco's fallow time was initiated as early as 1880 , or as recently as 2003 . In either case, the site was intentionally removed from the larger sphere of urban development. While there was a time when it was internally active and productive, that moment has come to pass.

Bologna has proven itself resilient in accepting difficult moments of pause and stagnation. Its most recent 
ensure their individual viability, as well as generating a stable framework in which to add future gestures.

Maintain stability

The absence of dwelling requires careful consideration when introducing new artefacts and rituals of inhabitation to the site. New catalysts must not destabilize the legibility of the military landscape. As much fabric as possible should be preserved for future use. The reason is twofold: the loss of fabric could lead to loss of memory; the loss of embodied energy (in the form of demolition) would be counter to the inclination of this proposal towards sustainability and conservation. To counter Till's contention, architecture does nothave to be "waste in transit."80

To that end, in addition to preserving the built fabric, the memory of past traditions and practices that once animated this place - and are evident in the configuration of axes, vistas, and openings - should also be preserved and protected from significant alteration.

Build in flexibility and adaptability Change should be flexible, lasting and adaptive. Even though we want to preserve the fabric and memory of Staveco's past; we don't want to

${ }^{80}$ Till, 67. 
freeze it in that past. I revert here to the language of traditional heritage conservation planning, which asserts that new work should 'be of its own time.' Avoid letting the resistance of the centro storico prevent contemporary interventions from expressing our time. The regeneration process should be open to all possibilities for change and expression. The management committee will decide which ones are appropriate and which are not.

Protect the specificity of place In extending the city into the site, it is important to resist making Staveco an instrument of the city. The Staveco is not the release valve for the pressures plaguing the centro storico. As such, it must be addressed as its own ecosystem, and be allowed to evolve in its own way. This is not to suggest that there should not be integration, only that Staveco retain an identity.

Testing the framework Initial explorations aimed at testing ephemeral events, in which temporary interventions would be staged and then allowed to dissipate with time. However, these strategies engaged only a limited audience, and lacked a lasting effect that could be built upon.

I also explored the possibility of allowing for a significant process of decay to overtake some of the buildings, before 
engaging a process of inhabitation. However, this lacked the desired aim of sustainability.
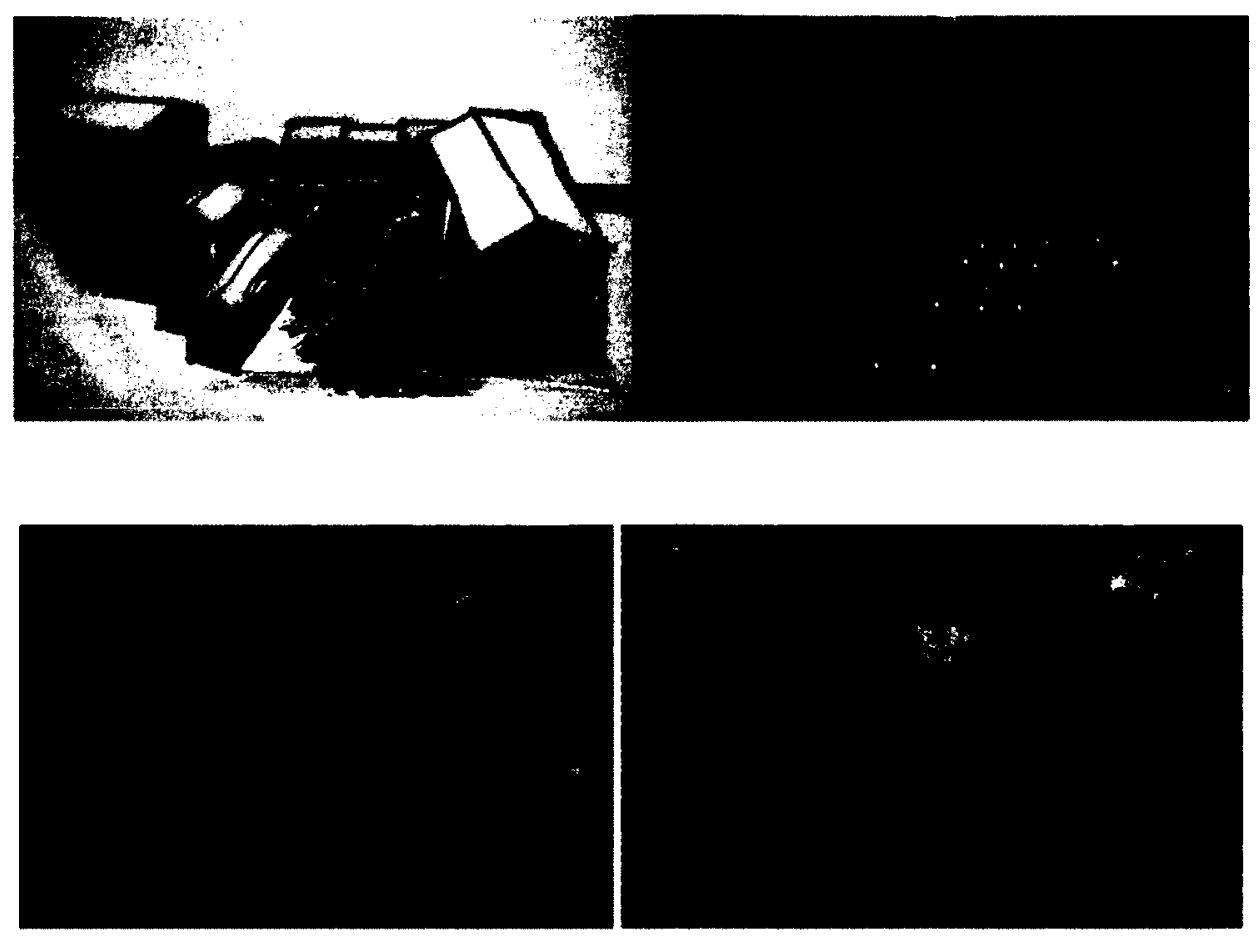

Figure 17: Top: Illustrations of ephemeral events that might occur in the lower piazza, including installation art (left) and performances (right). Bottom: Allowing vegetation to take over buildings. Source: by the author.

Accounting for this framework, the following chapter proposes an initial set of interventions for the Staveco site. 
But now that I wanted to build, here I was ... prepared to make a permanent mark on the land.

From A Place of My Own, a novel by Michael Pollan (1997)

\section{4_Harvest}

This thesis proposes a project of gradual re-inhabitation of the Staveco site. The initial set of changes is structural. That is, physical modifications are brought to the site, its landscape and to a select number of buildings. The remaining buildings are to be stabilized, without being modified. Generally, the changes are gentle and reversible, and do not require a major shift in values. The history of the Staveco site remains evident, even while a new layer is being grafted onto the existing. This allows for the population of Bologna to be introduced to the site, to familiarize them with its history, without forcing an uncomfortable or radical shift in their perceptions of how to adapt an historic environment to new uses. 
Regenerating the Urban Landscape An Architectural Joumey through Fallow Time

A layering of interventions seeks to introduce a diversity of uses, and therefore a heterogeneous population to the site. Through the introduction of these specific but significant insertions, the anticipation is that new rituals of inhabitation will begin to evolve, such that desire and value will gradually be ascribed to the site and in the imagination of the dweller; and thereby create a shift whose direction we cannot yet predict.

Each intervention has a natural life span - some more knowable than others; none are parallel. In this way, a transition of functions is anticipated over time. The proposed functions / programmes are each distinct, and yet have synergetic potential, whereby the activities of one may be shared by, benefitted, or used by others. This will be determined by time and use. Future transitions may be influenced by these initial programmes, or may bifurcate in a new direction. This cannot be determined, and for this reason, these architectural proposals seek to build flexibility in anticipation of unknown futures.

In a first instance, the site is imagined as a pedestrian zone, whose quiet character allows the fallow time to linger a little bit longer, while also mediating between the bustle of the city centre and the stillness of the hills. Farm equipment may be heard in the distance, and might, on occasion, traverse the pedestrian paths and piazzas. Public vehicle access may be admitted later on, when density requires it. 


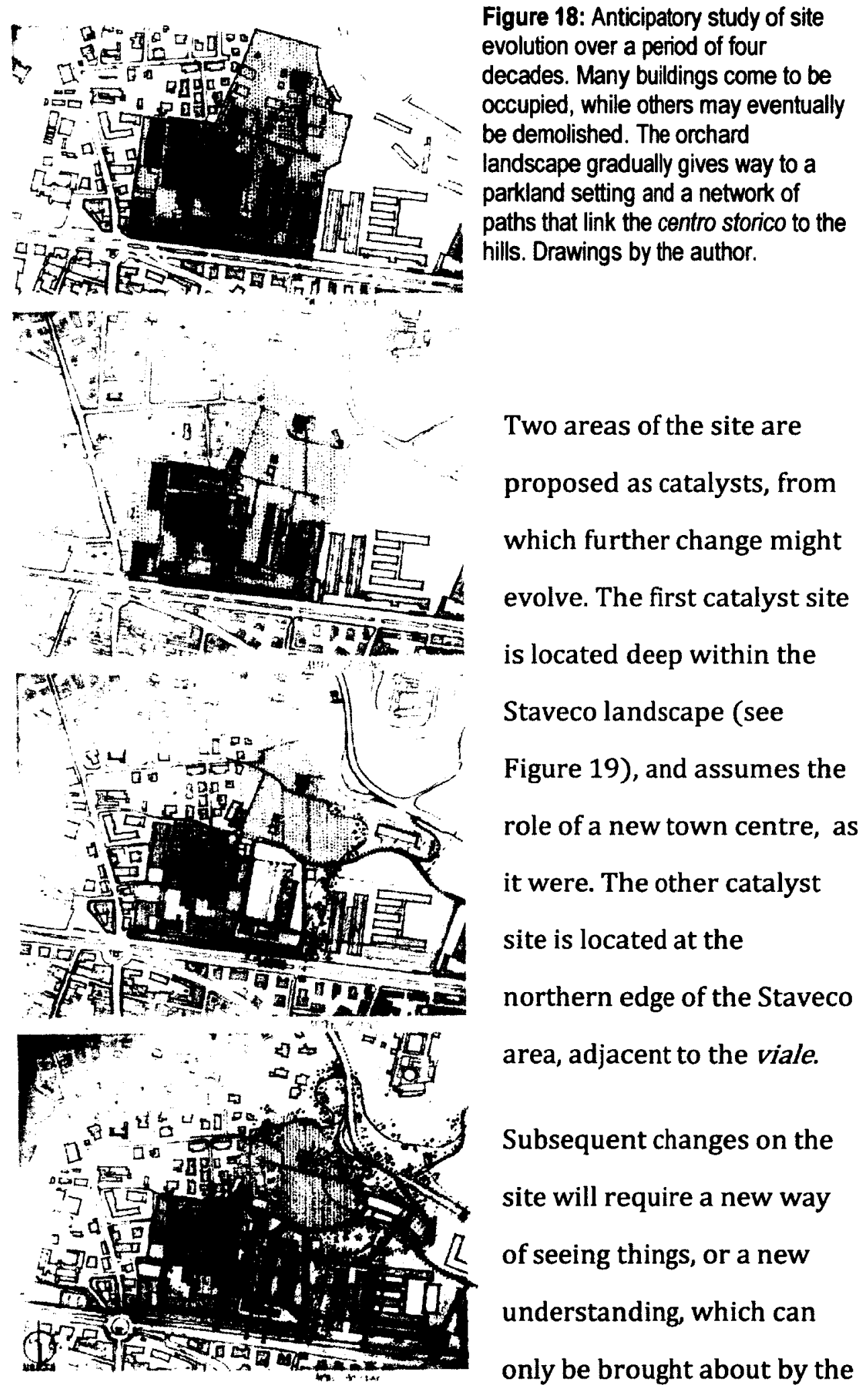


Regenerating the Uban Landscape An Architectural Joumey through Fallow Time

Chapter 04_Harvest

gentleness of the initial interventions, and the gradual occupation and appropriation of the spaces by the community. Adaptive reuse lies along a continuum, not as an end condition.

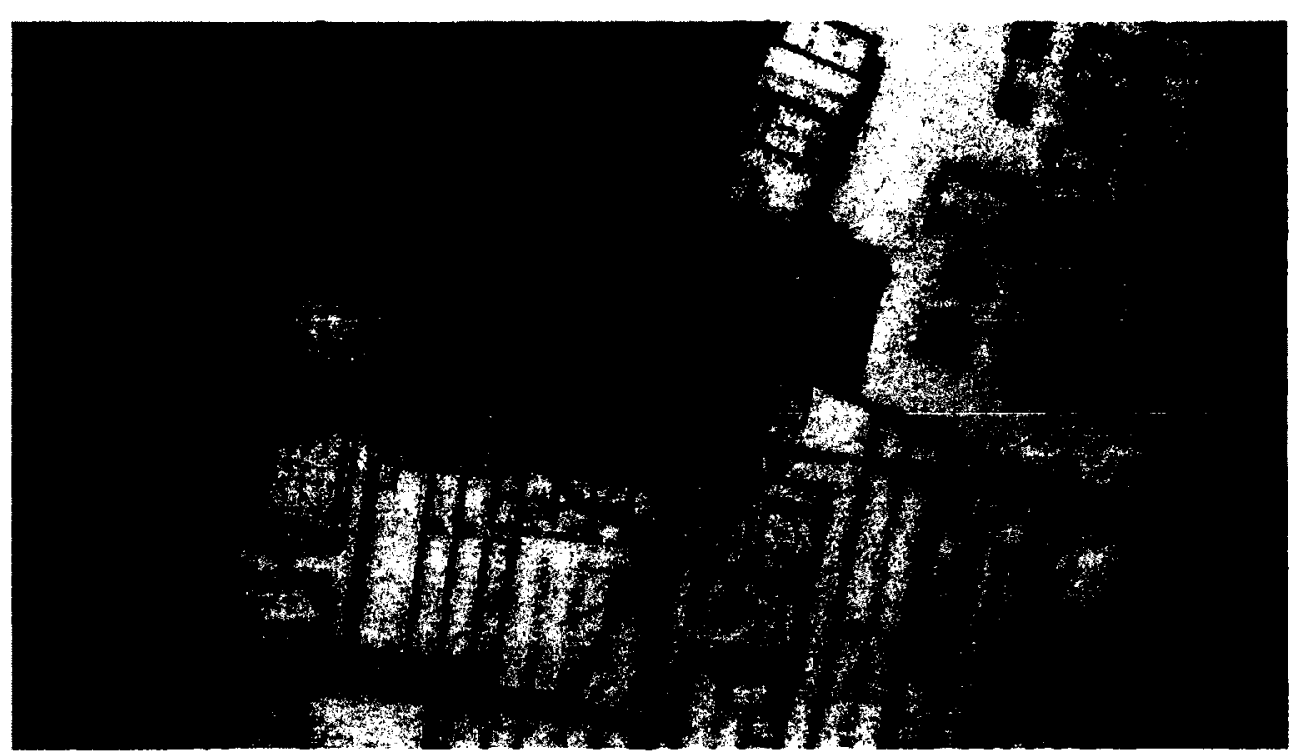

Figure 19: Study showing axes and selection of catalyst site. (North down) Drawing by the author. 


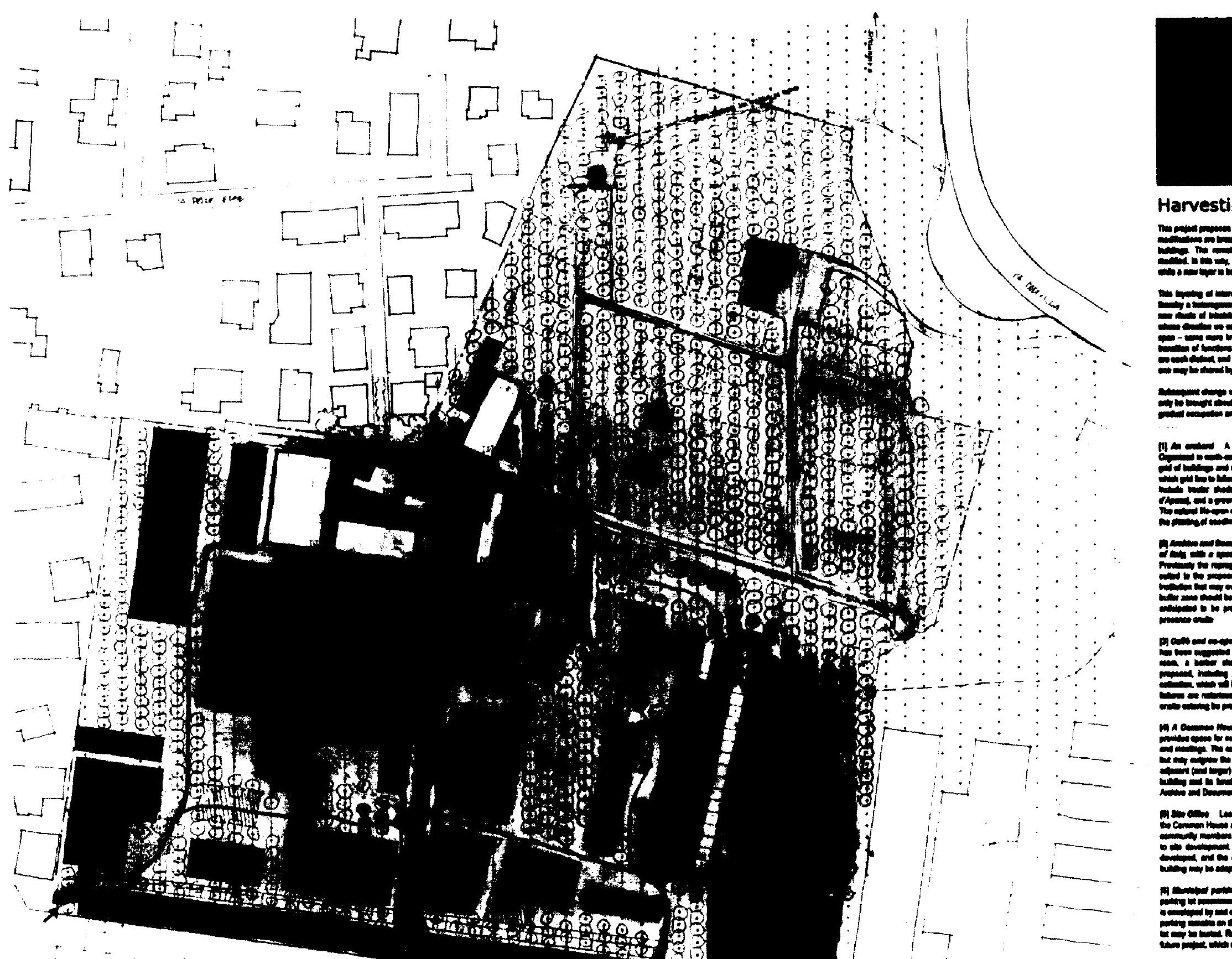




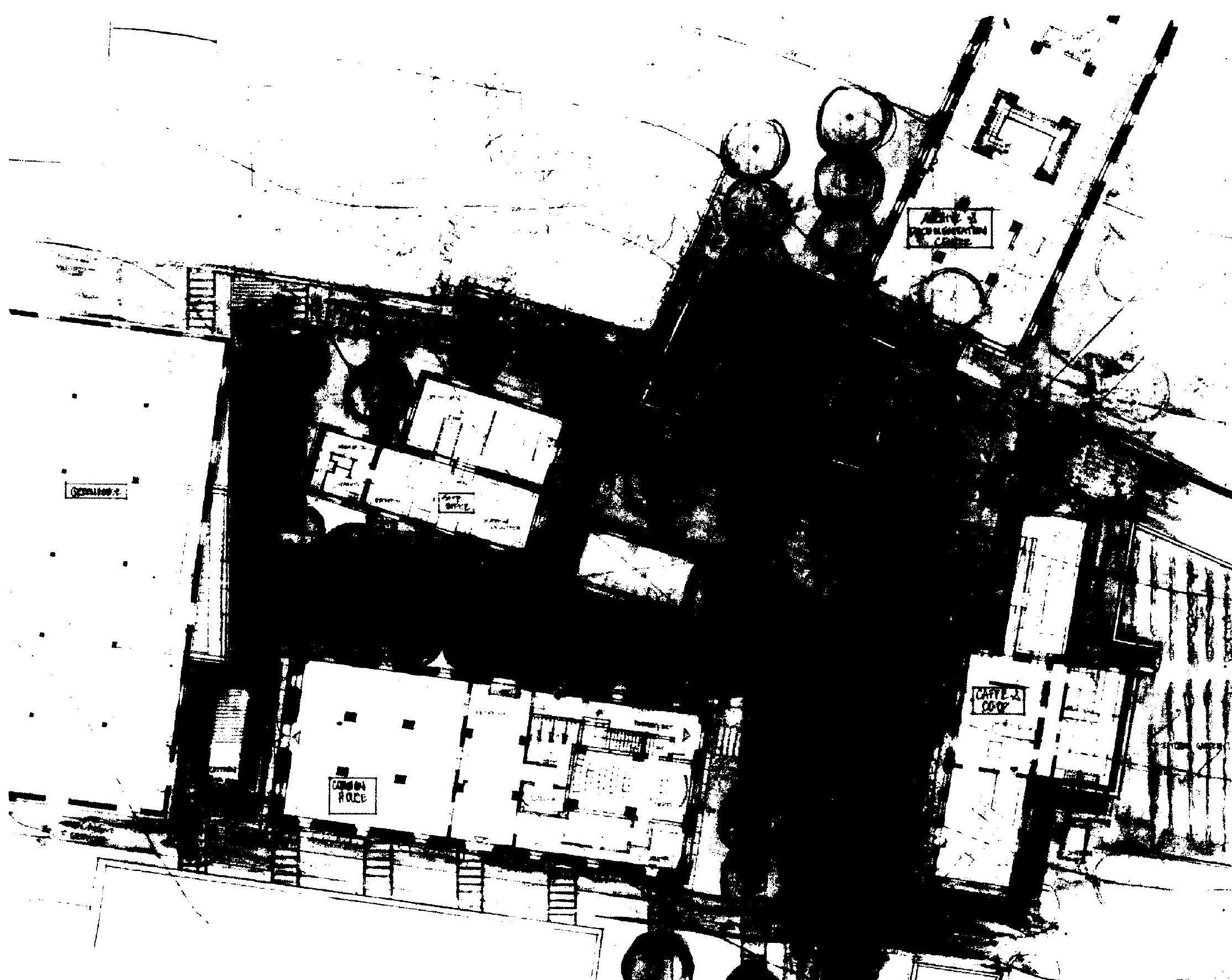




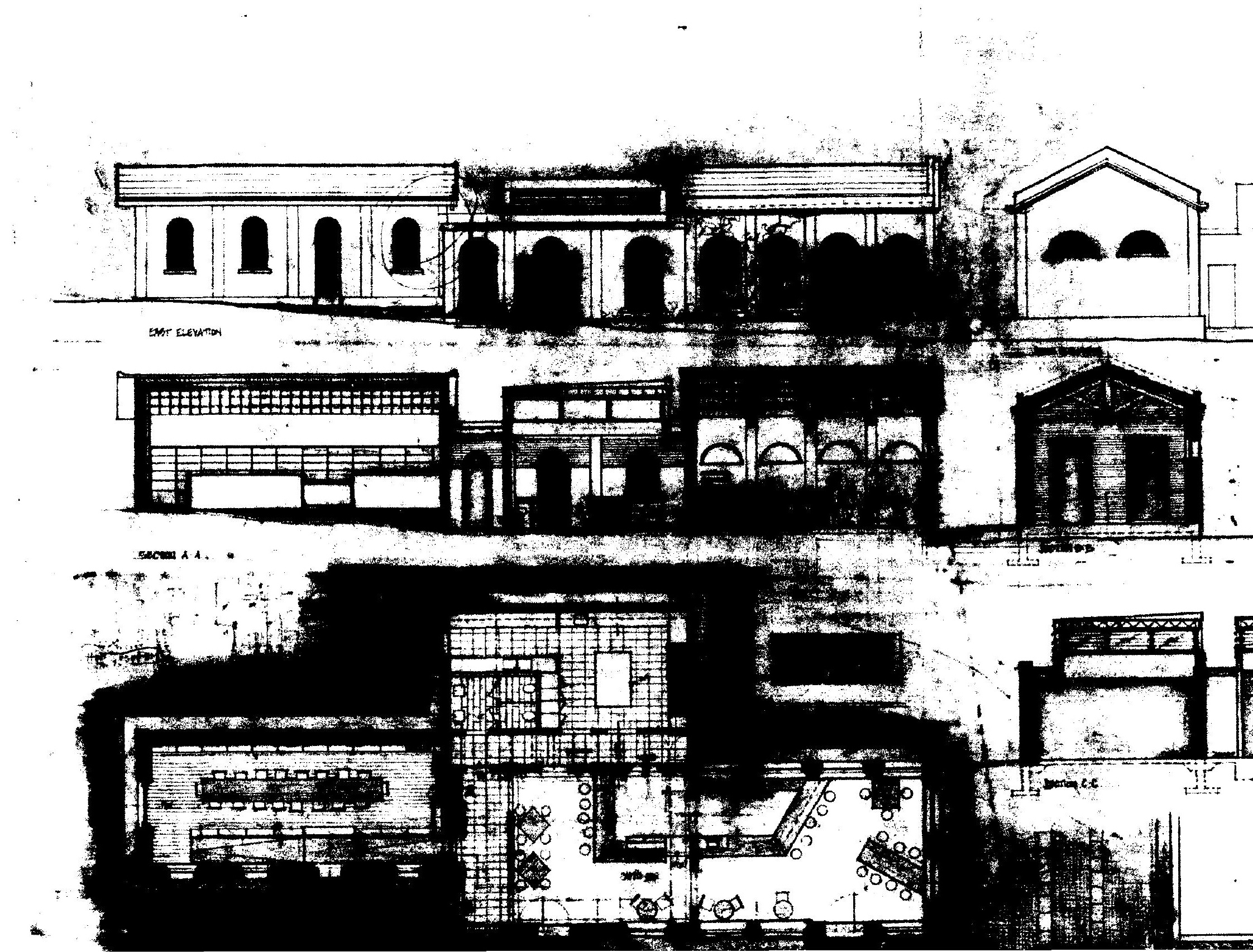




\section{Proposed Programming}

Interventions are proposed to the landscape, as well as a select number of buildings. The landscape interventions are perhaps the most visible and important to reorienting (shifting) an awareness and adoption of the site:

\section{An orchard}

A pear orchard is laid like a blanket across the entirety of the site. Organized in north-south orientation, rows are $7.5 \mathrm{~m}$ apart; trees within the rows are $5 \mathrm{~m}$ apart. The orchard grid intersects the grid of buildings and roads, and creates moments of pause, perhaps even uncertainty, to contemplate which grid line to follow, but never seeks to destabilize.
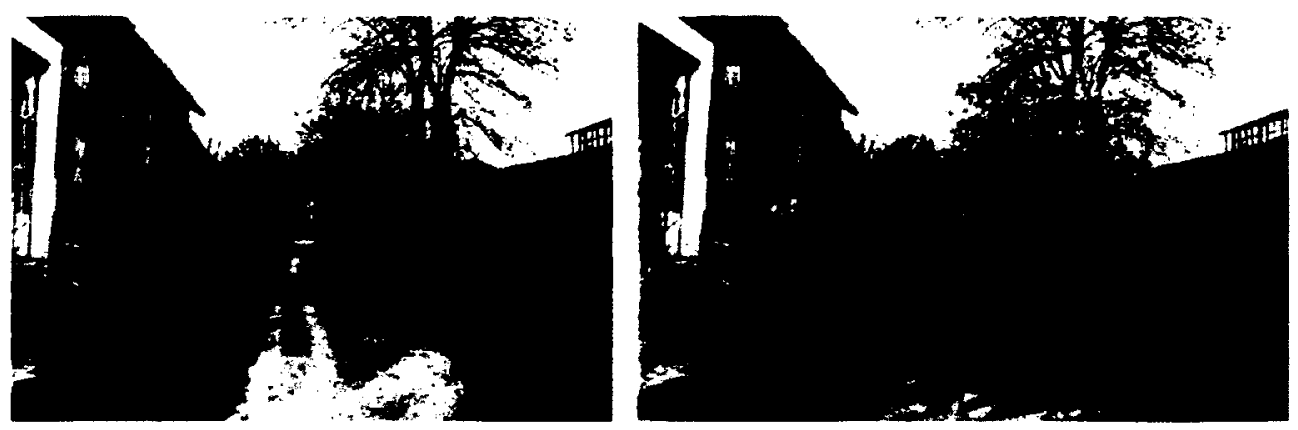

Figure 23: Shift from military road to orchard path. Looking north along Via Principale, showing intersection of the site's principal axis and the new orchard landscape. Montages by the author. 
Regenerating the Urban Landscape An Architectural Journey through Fallow Time

Associated functions will require tractor sheds, a water tower (to be fed through onsite water collection and diversion of the Torrente d'Aposa), and a greenhouse - open to the public — for fostering specimens, testing tree varieties and growing vegetables for the Caffe.

The natural life-span of a production orchard is approximately 35 years from the planting of seedlings to the end of productive capacity.

Archive and Documentation Centre for the Former Communist Party of Italy, with a special collection on the Political History of Bologna

Previously the reprographics shop, the proposed Archive building features an open plan that is well-suited to the proposed function. It is anticipated that the Archive will begin small, and eventually grow into the existing building. However, an area should be reserved at the perimeter of the building to permit future expansion, if required.

This institution is anticipated to be present for many years, and may join the already well-established network of municipally-run museums and documentation centres. Users will include academics, students, municipal researchers, and other researchers interested in political history. 


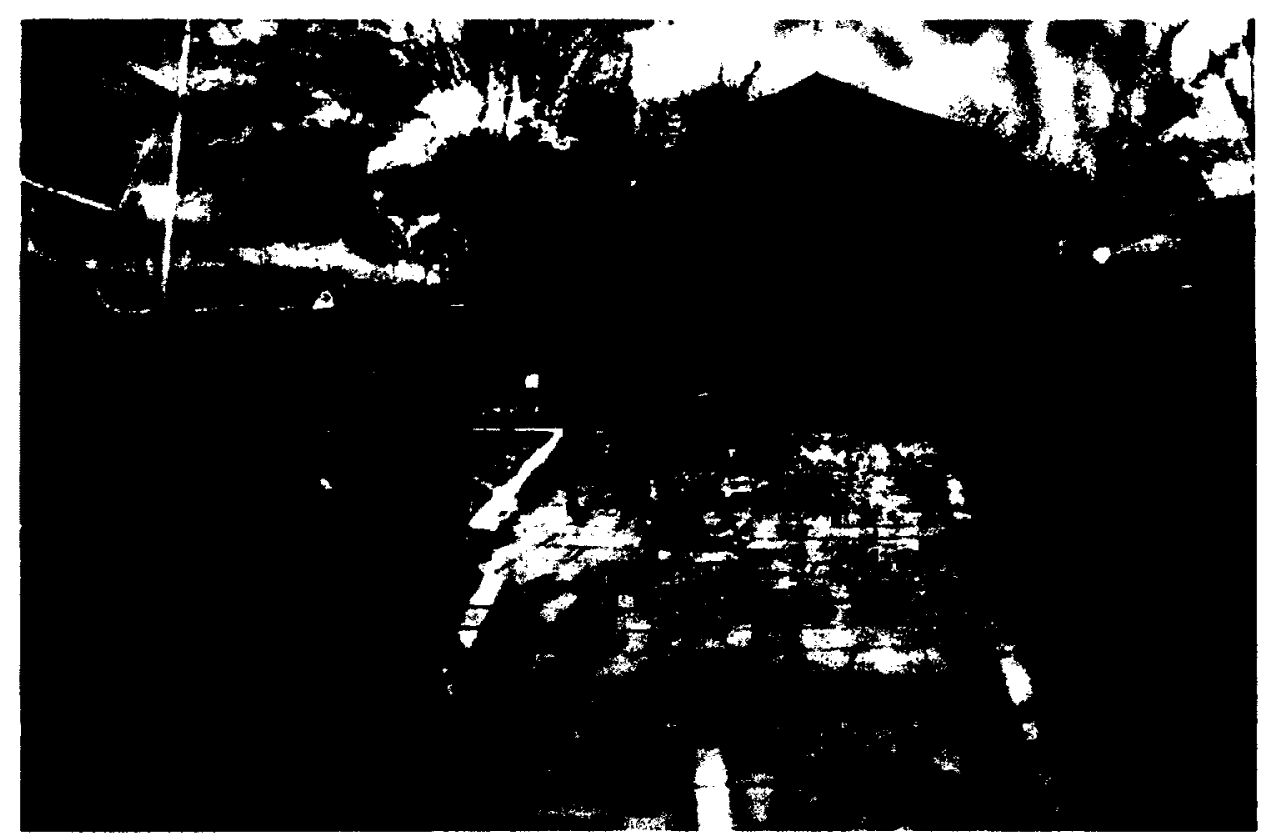

Figure 24: View looking south along Via Principale, with Archive Building on axis, Upper Piazza at left, Coop Building at right foreground. Montage by the author.

\section{Caffe and co-operative store}

Situated within one of the more derelict buildings, which has been suggested for possible demolition, the Caffè and Co-operative store are the seeds for future commercial development of Staveco. The building previously hosted a plans room, a barber shop and storage room. Significant renovations are proposed to house the new programme, as well as a redesigned roof structure to allow for rain water collection. 


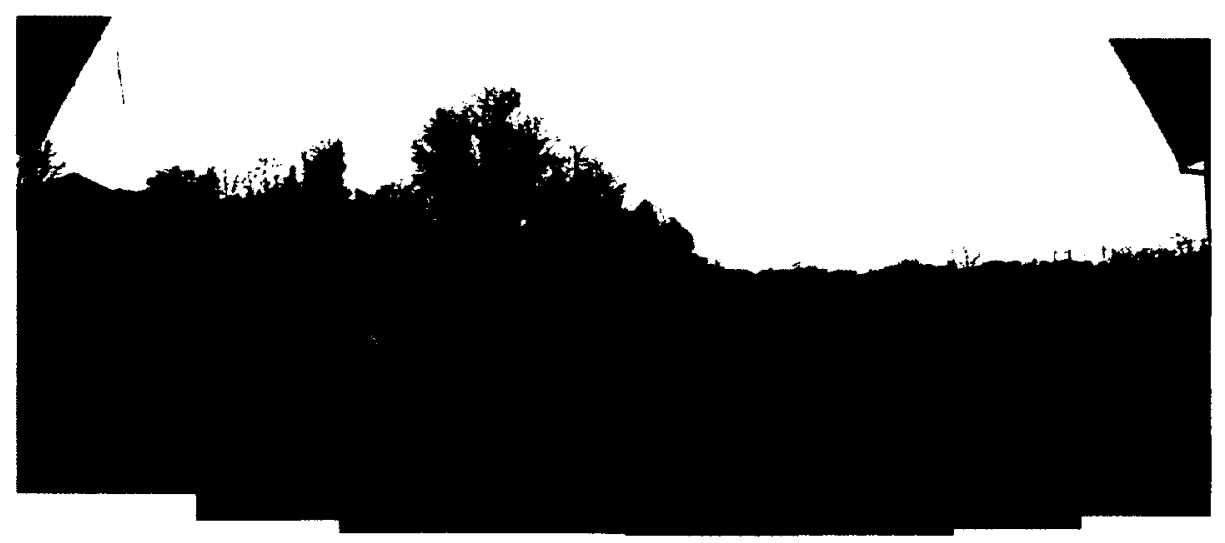

Figure 25: Site investigation: View of future Caffè / Co-op building from second storey of Common House. The Archive building is at far left. Via Principale is in the foreground, extending left and right. Photos courtesy of Benoît Lagacé.

Restaurant failures are notorious. To assist in its sustainability, it is proposed that all onsite catering be provided by the Caffè. The intervention is conceived to be flexible enough to allow for multiple future uses.

\section{A Common House}

The Common House provides space for community gatherings, social events, small conferences and meetings. It is hosted in the former Police offices. Alterations are minimal, and mostly contained to the interior of the building, save the removal of a façade addition. The communal function will likely reside in the medium term; but may outgrow the facilities in a longer term, at which point relocation into adjacent (and larger) building(s) becomes an option. 
Regenerating the Urban Landscape An Architectural Joumey through Fallow Time

The Common House building and its functions might then be offered for use by the (one would hope) expanding Archive and Documentation Centre.

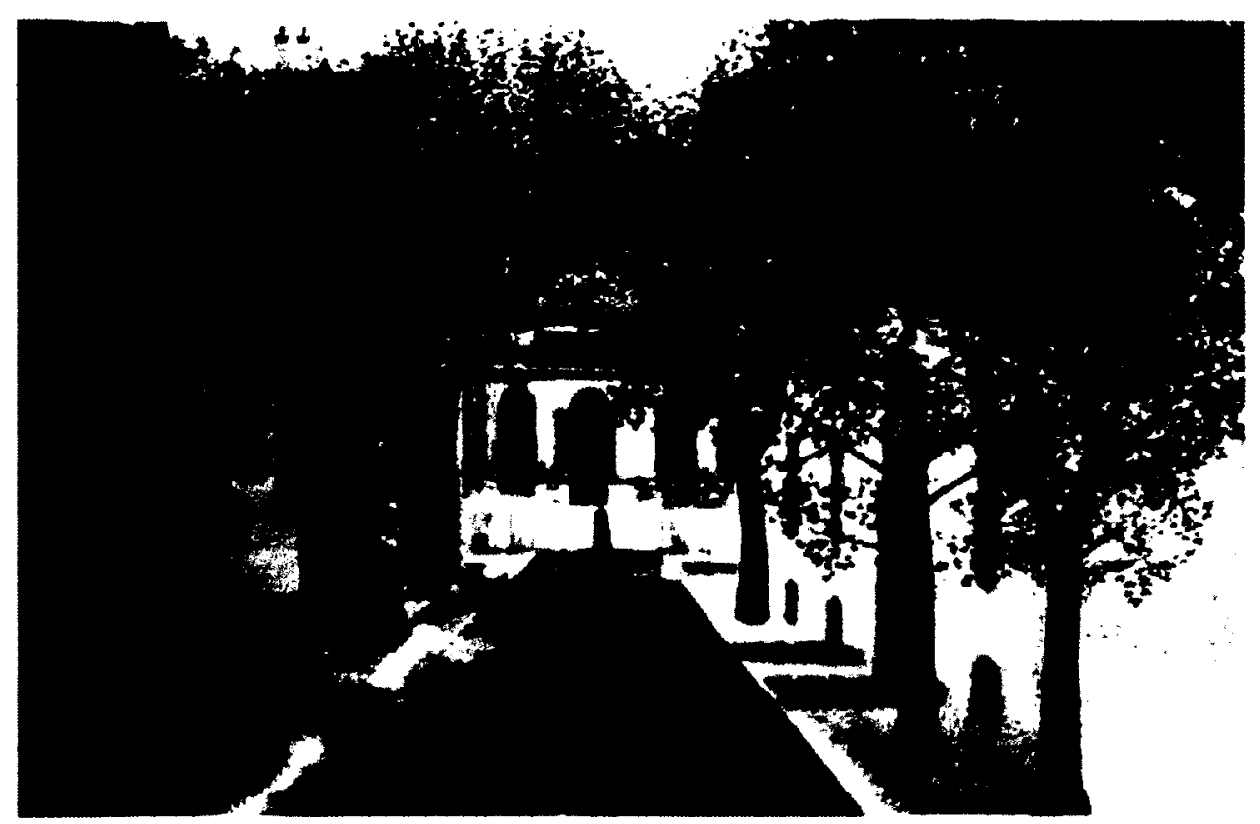

Figure 26: Montage of Lower Piazza, with Common House at right, Site Office at left, Coop in background. Rain water is channelled to a saw tooth gully on the surface of the piazza. Montage by the author.

\section{Site Office}

The Site Office is located in the former electrical plant and faces the Common House across the intimate lower piazza. It hosts a plans room where community members can consult the plans and historic documents related to site development. The office accommodates a site coordinator (or coordinators) and support staff. The office will exist for as long as the site is being developed, and the mandate of the 
Regenerating the Urban Landscape An Architectural Joumey through Fallow Time

office remains useful. After that, the building may be adapted to other uses.

\section{A hospital residence with adjacent camper-van park}

The Rizzoli Hospital is an orthopaedic centre. Patients and their families travel from all across Italy to attend surgery, and recovery, in this specialized centre. The hospital does not offer accommodations for the families. Instead, many of the latter arrive in camper-vans and park on the road below the hospital, sometimes for weeks at a time, while other families rent 'vacation properties', which can be quite expensive.

The Staveco site offers a temporary dwelling for these concerned families in the form of studios, which are to be located adjacent to the parking lot. Also included is a private camper-van park. The project has the interest of adding a temporary, heterogeneous but evidently resilient population to the site. This function may last for a long time.

\section{Municipal parking lot}

Accessed from the Viale Panzacchi, the parking lot accommodates commuters arriving from the suburbs to their jobs in the city centre. The lot is enveloped by and organized around the orchard grid. In the first instance, parking remains on the surface. At a later time, when resources permit, the lot may be buried. It may take several years, or even up to a decade, to achieve financing for this project. 


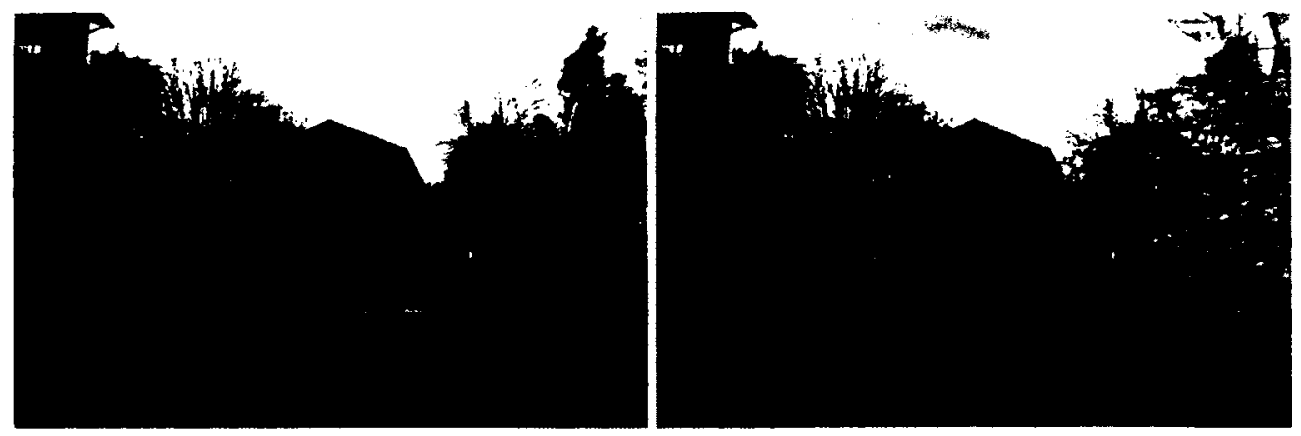

Figure 27: View towards Upper Piazza, with Archive and Documentation Centre on axis. Study of the Upper Piazza as Parking Lot (left), with shift towards piazza/orchard landscape (right). The decision was made to situate the parking lot closer to the Viale Panzacchi (north end of the site), in order to reserve this site for community use. Montages by the author.

\section{Implementation}

The project is proposed for implementation in two phases: the first is an opening-up of the entire project site to the urban fabric and the hills; the second is the refurbishment of select buildings for the proposed new programmes.

In the first phase, it is proposed that a number of actions be initiated:

i. Stabilize those buildings not proposed for immediate redevelopment; fence off areas of proposed construction;

ii. Upgrade natural and agricultural land uses by removing unwanted growth; re-grading to improve rainwater retention; stabilizing access roads and pathways; and beginning experimentation with new plantings, pear varieties in 
Regenerating the Urban Landscape An Architectural Joumey through Fallow Time

particular. This latter initiative might be done in collaboration with students from the University of Bologna.

iii. Plant the orchard, and provide for its associated agricultural functions.

iv. Construct the new parking lot.

v. Begin removal of the fencing at the perimeter of the property, so as to allow public (pedestrian) access to and through the site.

In the second phase, after stabilization, new interventions can begin:

i. Refurbish the Site office;

ii. Renovate the Patina building for temporary hospital housing, and install the camper-van park;

iii. Refurbish the Common House, and install the new Piazza,

iv. Renovate the Caffè and Coop store;

v. Install the Archive and Documentation Centre; expand the Piazza to incorporate this building. 


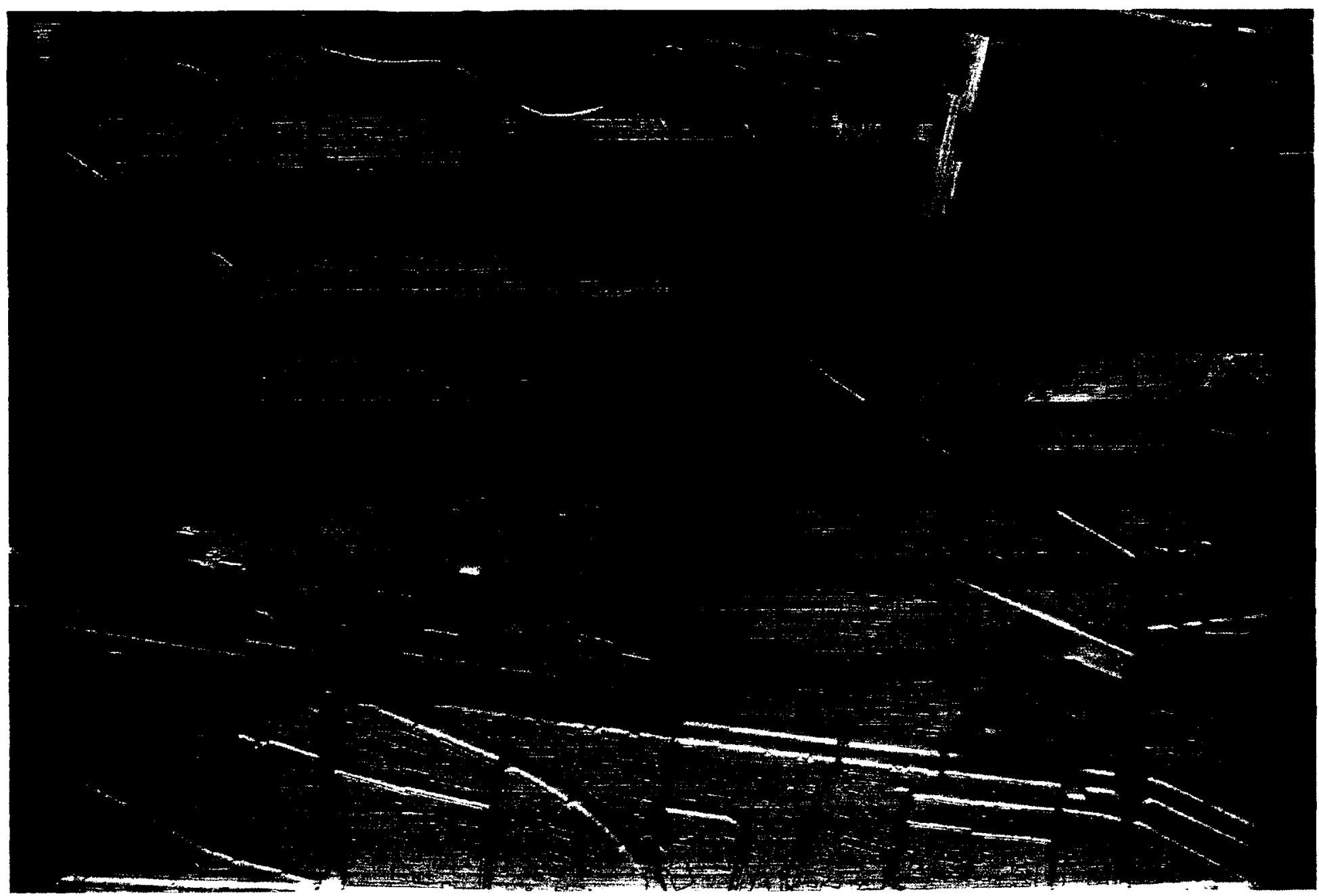

Figure 28: Left: Site model, oriented south, showing catalyst sites in dark wood and orchard grid. Three churches border the site to the east, west and south industrial buildings set amidst the orchard grid, and the San Michele in Bosco church is in the background. Model and images by the author. 


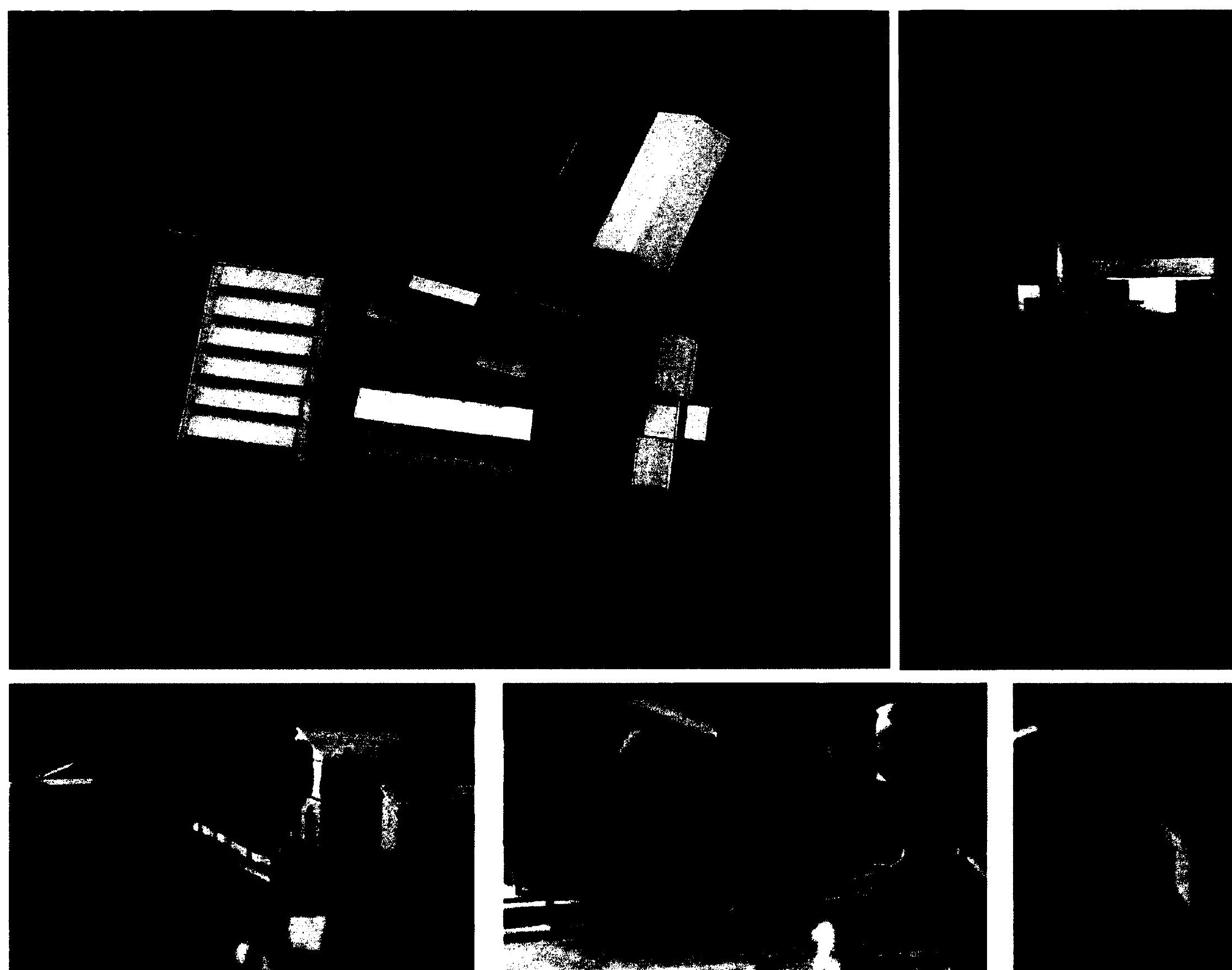


Regenerating the Urban Landscape An Architectural Joumey through Fallow Time

\section{Discussion}

The design of this project acknowledges that it is part of a wider regeneration strategy and as such plays a pivotal role in drawing a link between the city centre and the hills.

Thinking specifically about the public and civic role that the proposed interventions might play, this project seeks to extend built elements towards existing urban elements, while at the same time dissolving a managed orchard into the natural landscape beyond.

An itinerary of paths and pauses is proposed, which form the foundation of a conservation policy for the Staveco site, the aim being to allow access to all parts of the site from where occupants and users can begin to monitor and observe transformations, witness the permitted decay of select unused and condemned buildings, and begin to participate in gradually changing the site.

\section{The landscape}

The landscape is an influential element of the fabric of the larger site, and is therefore considered one of the main themes of the project. Historically, the Staveco site expanded as a series of axial projections, radiating in a strong north-south orientation, with only one predominant east-west axis at the northern edge of the site. A 
Regenerating the Urban Landscape An Architectural Joumey through Fallow Time

secondary east-west axis once linked the central part of the site, but it has been allowed to grow over and fade.

The project takes its cue from this original pattern of development, and reintroduces the subservient east-west axis (see Figure 20). This gesture serves two functions: to begin a process of integrating the site in a transverse pattern, and to create an interruption or a pause so as to allow for reflection on the future development of the site. Opening this axis might also initiate a more direct relationship with the immediate residential neighbourhoods - into which the axis might extend at a future date.

A central and strong north-south axis, Via Principale, is anchored by the Operations Building at one end and the proposed Archive at the top end. Here, it encounters the revived east-west axis and a newly designed pair of Piazzas.

Historically, this area formed the core of the military site, and marked a threshold between the more public functions of administration, command and manufacturing (to the north); and the more private functions of barracks and mess halls (to the south). This area once contained showers, a barber shop, a print shop, and offices, among other functions. What was once the town centre of a military compound is proposed to be revisited and revitalized as a new social space that may begin to take a life of its own, in time. 
The selection of a space deep within the Staveco landscape provides what Esther Choi calls a "location of roughness," a place where architecture might find "catalysts for creativity," 81 and wherein to begin the process of regeneration.

Figure 30: Site model. View from south across the catalyst site (in darker wood, at centre), showing the centro storico beyond, the delle Rose residential neighbourhood in foreground, and the orchard grid extending across the whole site. Model and image by the author.

Opening Staveco from the centre allows for a moment of pause along the proposed itinerary that links the city to its hillside. The contrast of a well-kept landscape and vacant buildings is resolved when visitors

${ }^{81}$ Choi, 133. 
reach this site of reuse, which shows the potential future enjoyment of the entire Staveco area.

This pivotal location brings together a pair of piazzas and several adjoining programmes which introduce a diversity of occupants to the site. This reconfigured town centre is imagined as an exterior communal space where interior functions are invited to spill into and across the piazzas, thus adding value to these existing structures.

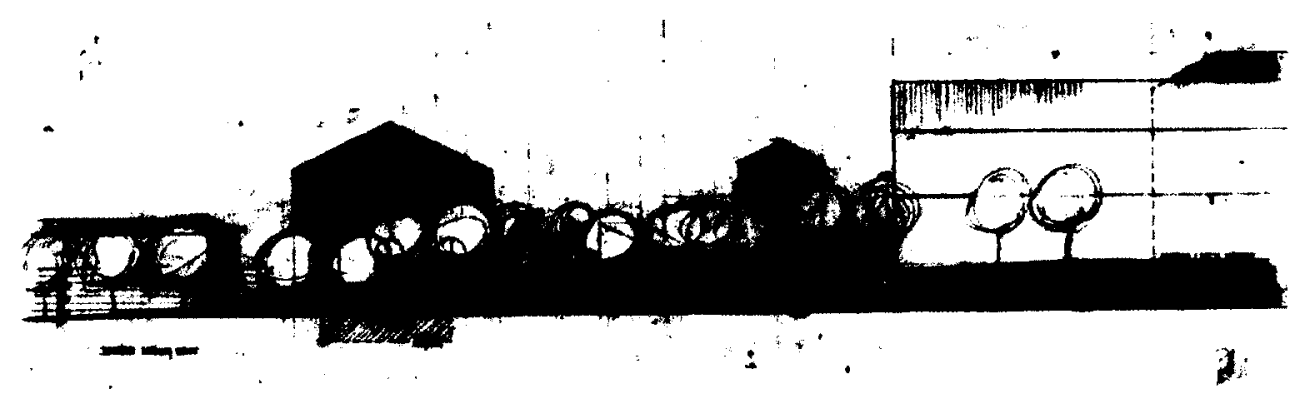

Figure 31: North-south section (looking east). Lower Piazza at left with Common House in elevation, Upper Piazza at centre-right showing semi-enclosed gather space, with Archive Building in silhouette (at right). Drawing by the author.

The lower piazza is an existing space that functions as a natural courtyard for the Common House, Site Office, and greenhouse. It is both a space internal to these buildings, and a throughway that links the caffe/coop and orchard functions to the greenhouse. It will be refurbished and designed to perform an additional infrastructural role by directing collected rainwater towards new cisterns.

A previous addition to the façade to the Common House is eliminated in order to bring into focus its original encounter with via Principale, 
which had been lost. The main entrance is proposed to be relocated to the side of the building, where it faces the lower piazza.

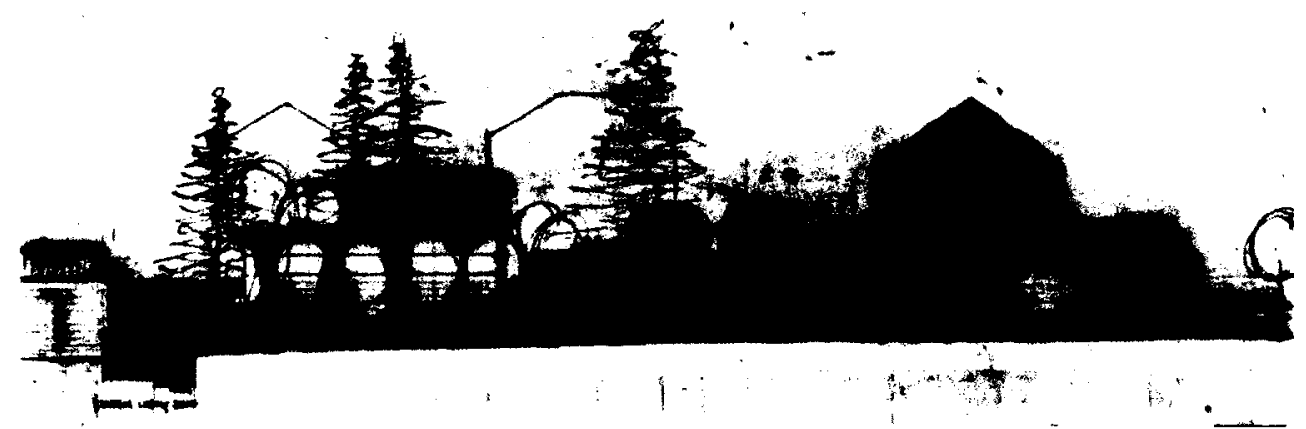

Figure 32: East-west section across Lower Piazza (looking south). Site Office is in elevation, greenhouse at left. Upper Piazza (above right) shows semi-enclosed gather space, Archive Building in elevation (at right), and Coop in right foreground (in sithouette). Drawing by the author.

The proposed Archive Building occupies an important position at the termination of the via Principale axis, and as such is highly visible. This building is given its own piazza - the upper piazza, which serves several additional functions. In addition to providing termination of via Principale, this piazza collects the flow of traffic from the caffè/coop, provides a pause in the itinerary leading to the orchard, and provides a secondary access (a back door, as it were) to the Site Office and greenhouse. It also provides a discrete entrance to the delle Rose neighbourhood, all the while preserving the privacy of these residents by buffering the threshold with heavy plantings and a semienclosed gathering space that is anchored by a raised water feature. 


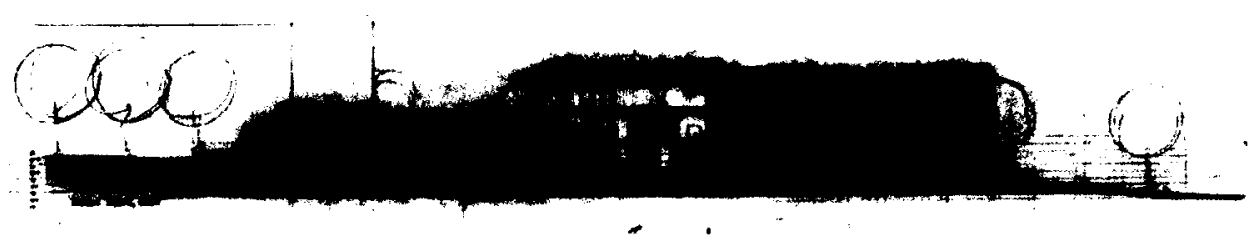

Figure 33: North-south section through the Via Principale (looking west), with Coop building in centre foreground, Archive building in silhouette (at left), and the Upper Piazza water feature in left-foreground. Drawing by the author.

The orchard landscape becomes more evident at this juncture and begins to recall the religious inheritance of the site - a meeting ground of churches, convents and monasteries, and their respective gardens that once occupied this very place.

From the piazzas, the itinerary branches-out and dissolves into footpaths that terminate at the base of the San Michele in Bosco hill. At strategic points, the itinerary is designed to allow visitors to appreciate both the environmental and natural quality of the site alleés of trees, buildings gradually dissolving into an orchard landscape, and views inside and outside the site. 


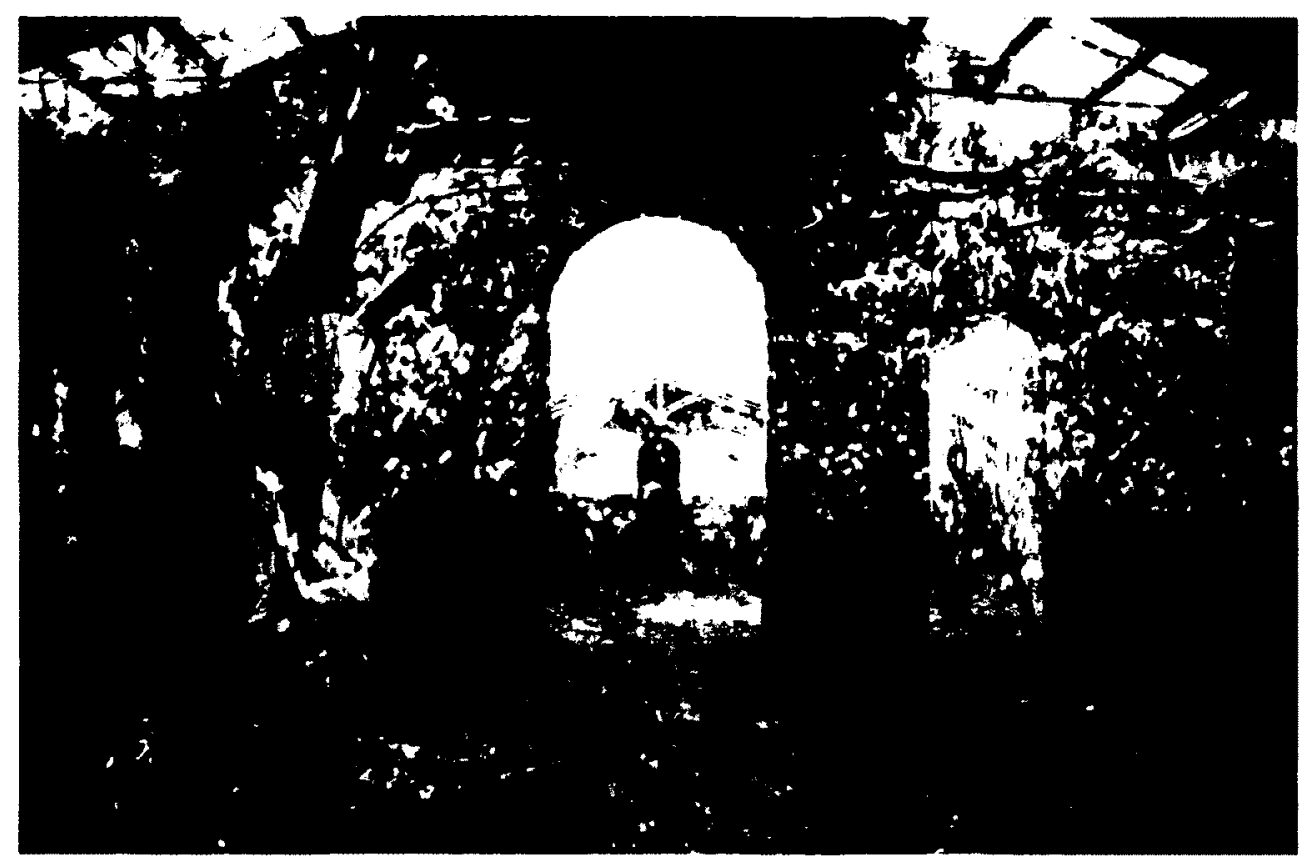

Figure 34: Orchard occupying a collapsing building. Montage by the author.

In the first years, the orchard may perform as a physical hierarchy dispersed across the site -- a highly organized space that seeks to order time. But, with time, it might become a meshwork. As trees lose their production capacity, they may be removed or replaced. The space in between may be planted with other varieties, or none. The planting pattern may evolve from a grid to a grove - a space that is free of social or behavioural controls and where time is lost. Or buildings may be inserted. The orchard will be expended by time, as plans for the landscape's future become appropriated by its occupants.

The orchard is proposed to be irrigated by water that is harvested from the Torrente d'Aposa. In the spring, this stream runs very high. 
Water might be diverted to a water tower, where it would be stored for use during the growing season. The water that courses through this stream is not used or harvested in any other way. It simply flows underground through the city and back out again.

\section{The Buildings}

This proposal is in essence a conservation project in that, while the built fabric is largely preserved, the project alters and builds a new architecture within the industrial landscape. Few but significant initiatives allow usage of the spaces within existing building footprints.

By and large, interventions are designed to be reversible. The buildings are equipped for present and future functions, but these insertions may be removed if a future generation desires complete restoration. Exterior façades are left intact, including original windows and doors, which serve memory, less than function. New roofs are designed to collect rainwater, but also respect their original pitch and relationship to the building façades.

Interventions are also designed to minimize the environmental footprint of the site as it is being regenerated: cisterns collect rainwater from the Piazzas and roofs of adjoining buildings, which is used to feed toilets and garden irrigation; natural light and ventilation 
are favoured over artificial; radiant floor heat is proposed; solar panels and solar collectors might be contemplated at a future date.

New interior walls are proposed to provide proper thermal insulation. New windows and doors are installed on interior façades. The original doors and windows are largely beyond repair. However, they provide an historic legibility, as well as an expression of the passing of the Staveco site from one state (historic) to another (future). As such, it is proposed that this hardware be allowed to continue its decay until it must be removed for safety.

The Co-op and Caffè receive the most substantial interventions. As mentioned, this building was identified for potential removal, and finds itself in a derelict state. New roofs are proposed which seek to maximize natural light by inserting clerestory windows to allow deep penetration of light in winter and good ventilation in the warmer months, and window shades to control heat gain in the warm summer months. A kitchen addition is proposed at the rear (west side).

The proposed interventions are designed with one intention in mind, but before they are even executed, they might already begin to change, as energy (in the form of people) flows into and through the site, and the possibilities for different and unpredictable outcomes begin to emerge. 
We won't understand a thing about human life if we persist in avoiding the most obvious fact: that a reality no longer is what it was when it was; it cannot be reconstructed.

From Ignorance, a novel by Milan Kundera (2000)

\section{5_Yield}

Understanding fallow time as an opportunity in the urban landscape allows a city to be developed, not for economic expediency, but, for sustainability that is achieved by the gradual accumulation and layering of cultural and natural values over time.

Fallowing the urban landscape differs from conventional heritage conservation practices, and conventional urban planning and development practices, in three meaningful ways:

i. It gradually takes a site from fallow to generative by considering social processes, not just physical resources; 
Regenerating the Urban Landscape An Architectural Joumey through Fallow Time

ii. It introduces the notion of an ecosystem that arrives at equilibrium through a process of catalysis;

iii. It considers a fallow landscape within its broader environment, that these may mutually feed on (but not devour) each other.

Fallowing is the middle ground between the developer-driven prescription of users and uses, which for all its utopian aspirations also tends towards an anarchic 'taking down the barricades' and letting happen whatever will happen; and the conservation-driven prescription of form, into which unanticipated uses must fit.

This is not to say that these conventional means of managing urban development cannot be flexible nor achieve a version of success, only that they grope at stability rather than facilitating it.

A managed regeneration strategy combines elements of both hierarchy and meshwork with the aim of satisfying multiple claims to a fallow landscape by giving each claim a fair chance to influence the regeneration process.

The strategy of fallowing an urban landscape seeks to instigate and manage change, while fostering stability within diversity, but without prescribing outcomes. In offering lasting, flexible and adaptable interventions, the strategy seeks to build internal resilience and equilibrium over time, while protecting the once fallow landscape 
Regenerating the Urban Landscape An Architectural Joumey through Fallow Time

Chapter 05_Yield

from becoming a mere instrument of the broader environment to which it belongs.

To that end, the proposed interventions at Bologna's fallow Staveco site, seek to offer a communal gathering space in which the management process can be devised and evolve. These interventions are both the idea and the representation of the idea.

By selecting a catalyst site located deep within the Staveco landscape, the proposal offers the opportunity for the Staveco to begin its regeneration process far enough away from the centro storico not to be absorbed by the latter's identity and challenges, while also lending the opportunity for self-organization. These small gestures occupy and animate the site, but they are also impermanent, or rather flexible enough to adapt to change, whenever change dictates its need to evolve. And so, this proposal aspires to leave more than a metaphor. Rather, it hopes to have left something flexible and lasting.

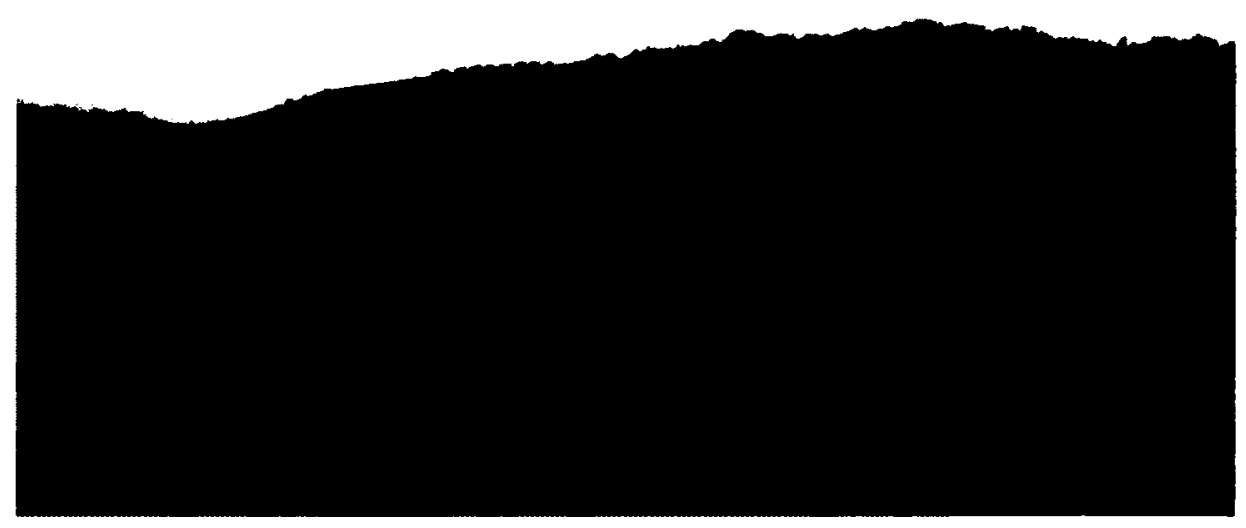

Figure 35: Fallow time lain across the Staveco site. Montage by the author. 


\section{Postscript}

The strategy devised and tested through this thesis was specific to Bologna and the Staveco site. However, there are notions that could be applied towards different types of fallow time, which may not appear readily comparable to Bologna's situation, such as the instances of tragedy, disaster or war that were alluded to in the preamble. In these situations, a dramatic shift leaves in its wake a fallow landscape, or possibly a fallow space, that would require a deeper reading of cultural conditions, memory and loss and therefore a more specialized consideration of cultural recovery and healing than the present approach has attempted.

While the empty buildings and landscape may be understood as being in the fallow time conceived in this thesis, the required cultural healing would be far more complex than that arrived at from managing the simple ebb and flow of urban development. Perhaps, in these instances, the concept of pause lends itself to a different understanding of disequilibrium - not one to be reconciled by reviving rituals within artefacts, but by reconciling rituals in spite of artefacts. 
Another possibility is to conceive of fallowing an urban landscape as a counter-strategy to rapid urban development. In this case, fallow time may be introduced as a deliberate pause that seeks to interrupt the rapid pace of change and therefore offer opportunity for reflection before further development proceeds.

Finally, the fallow time approach might be incorporated into a broader urban planning framework, whereby fallowing may be considered as a policy-making tool for urban development. In complex urban redevelopment projects, the notion of fallowing may lend itself as a neutral ground for bringing together a diversity of stakeholders - who may have diverging interests, mandates and jurisdictions - for negotiating and envisioning a collective future for a site / urban area. 


\section{Bibliography}

\section{[1] books}

Barzini, Luigi. The Italians. London: Hamish Hamilton Ltd, 1964.

Calvino, Italo. If on a Winter's Night a Traveller. Translated from the Italian by William Weaver. Toronto: L\&OD, 1981.

De Landa, Manuel. $A$ Thousand Years of Nonlinear History. Brooklyn, New York: Zone Books, 1997. Paperback edition: The MIT Press, Swerve Editions, 2011.

Eco, Umberto. The Mysterious Flame of Queen Loana, Translated from the Italian by Geoffrey Brock. Orlando: Harcourt, 2005.

Scott, Duncan Campbell, ed. The Poems of Archibald Lampman. Toronto: The Musson Book Company Ltd., 1900. Pp. 228-229. Online: http://archive.org/stream/poemsofarchibald00lampuoft\#page/n5/m ode/2up.

Evans, Robert H. Coexistence: Communism and its Practice in Bologna, 19451965. Notre Dame, Indiana: University of Notre Dame Press, 1967.

Frascari, Marco. Eleven Exercises in the Art of Architectural Drawing; Slow Food for the Architect's Imagination. New York: Routledge, 2011.

Gresleri, Glauco, M. Beatrice Bettazzi and Giuliano Gresleri. Chiesa e Quartiere; storia di una rivista e di un movimento per l'architettura a Bologna. Bologna: Editrice Compositori, 2004.

Kostof, Spiro. The City Assembled: The Elements of Urban Form Through History. London: Thames and Hudson Ltd., 1992.

Kundera, Milan. Ignorance. Translated from the French by Linda Asher. New York: Harper Collins, 2000.

Mostafavi, Mohsen and David Leatherbarrow. On Weathering: The Life of Buildings in Time. Cambridge, Mass.: The MIT Press, 1993.

Pollan, Michael. A Place of My Own, the Architecture of Daydreams. Toronto: Penguin Books, 1997. 
Regenerating the Urban Landscape An Architectural Joumey through Fallow Time Bibliography

Saramago, José. The Cave. Translated from the Portuguese by Margaret Jull Costa. London: Vintage Books, 2008.

Till, Jeremy. Architecture Depends. Cambridge, Mass.: The MIT Press, 2009.

\section{[2] articles}

Bravo, Luisa. Genius Loci and Genius Seaculi: A sustainable way to understand contemporary urban dynamics. $14^{\text {th }}$ International Planning History Society (IPHS) Conference, Istanbul, Turkey, July 2010. Online. http://web.itu.edu.tr/ csuygar/iphs2010/abs/1D446.pdf.

Bravo, Luisa. 'Area Conservation as Socialist Standard-Bearer: A Plan for the Historical Centre of Bologna in 1969' in Mirror of Modernity: The Postwar Revolution in Urban Conservation, DoCoMoMo E-Conference Proceedings, Edinburgh, Scotland, May 2009. Online. http://www.docomomo.com/eproceedings 2 dec09/mirror of modernity bravo.htm.

Cameron, Christina. Heritage Conservation, Rehabilitation and Urban Revitalization: An International Perspective. World Planners Forum, June 2006. Online: www.patrimoinebati.umontreal.ca/pdf/vancouver\%20text.short.pdf.

De Pieri, Filippo and Paolo Scrivano. 'Representing the "Historical Centre" of Bologna: Preservation Policies and Reinvention of an Urban Identity' in Urban History Review, 23:1, Fall 2004. Pp. 34-45.

Heidegger, Martin. 'Building, Dwelling, Thinking' in Poetry, Language, Thought. New York: Harper Row, 1971. Pp 160-91. Online.

Lowenthal, David. 'Fabricating Heritage' in History \& Memory, 10:1, Spring 1998. Pp. 5-24.

Ricoeur, Paul. 'The Metaphorical Process as Cognition, Imagination, and Feeling' in Critical Inquiry, 5:1, Special Issue on Metaphor, Autumn 1978, pp 143-159.

Smith, Julian. 'Marrying the Old with the New in Historic Urban Landscapes' in World Heritage Papers, 27, UNESCO 2010. Pp. 45-51.

----. 'Sharing Knowledge in a Postmodern Age' in Momentum, 6:2, ICOMOS Canada 1997. Online: www.icomos.org/icomosca/bulletin/vol6_no2_smith_e.html.

\section{[3] legislative documents}

Agenzia del Demanio. Information Memorandum: Area Ex Staveco + Caserma D'Azeglio (aliquota), Comune di Bologna. Bologna, 2010. 
Regenerating the Urban Landscape An Architectural Joumey through Fallow Time

Bibliography

Agenzia del Demanio. Programma Unitario di Valorizzazione di Immobili Pubblici siti nel Comune di Bologna. Fascicolo Descrittivo - Area ex Staveco-Caserma D'Azeglio. Bologna, 2008.

Comune di Bologna. Bologna - Changing City. Bologna: Urban Center, Central Exhibition, n.d.

Comune di Bologna. Bologna si fa in Sette, Città della Collina. Bologna, n.d.

Comune di Bologna. Piano Strutturale Comunale. Bologna, 2007

Quartiere Santo Stefano. Quaderno Staveco N. 1, La Città Proibita. Mostra di fotografie dell'area ex Staveco, 2008.

Quartiere Santo Stefano. http://www.comune.bologna.it/quartieresantostefano/staveco/

UNESCO. 2005. Adoption of a Declaration on the Conservation of Historic Urban Landscapes. WHC-05/15.GA/7.

http://whc.unesco.org/uploads/activities/documents/activity-473.pdf.

-.-.-.- 2007. Olinda Report of the Regional Conference "Historic Urban Landscapes in the Americas". World Heritage Centre, Olinda, Brazil, November 2007.

http://whc.unesco.org/uploads/activities/documents/activity-479.pdf.

-------. 2010. Managing Historic Cities. World Heritage Papers 27. http://whc.unesco.org/documents/publi wh papers 27 en.pdf.

--------. 2011. Proposals Concerning the Desirability of a Standard-Setting Instrument on Historic Urban Landscapes. UNESCO General Conference, 36 $6^{\text {th }}$ Session, Paris, 2011. http://unesdoc.unesco.org/images/0021/002110/211094e.pdf.

[4] reference and other

Centro Studi per l'architettura sacra e la città. Fondazione Cardinale Giacomo Lercaro. http://www.centrostudi.fondazionelercaro.it/

Fondazione Cardinale Giacomo Lercaro. http://www.fondazionelercaro.it/.

Rohter, Larry. 'In Europe, Where Art Is Life, Ax Falls on Public Financing' in The New York Times. New York, 24 March 2012. Online version: http://www.nytimes.com/2012/03/25/world/europe/the-eurocrisis-is-hurting-culturalgroups.html? $r=1$ \&nl=todaysheadlines\&emc=edit th 20120325.

Styger, Erika and Erick C. M. Fernandes. 'Contributions of Managed Fallows to Soil Fertility Recovery.' In World Bank Technical Paper. Washington, DC: N.d. pp 425-437. Online. 
Regenerating the Urban Landscape An Architectural Joumey through Fallow Time

Bibliography

http://betuco.be/compost/Fallow\%20Book $\% 20$ for $\% 20$ Soil\%20Fertil itv\%20Recovery.pdf

Zironi, Stefano and Fulvia Branchetta. Architetti Bolognesi: Luigi Vignali. Collana Monografica, No.1. Bologna: Arnaldo Forni Editore, n.d. 


\section{Appendix_01}

The following essay was recommended for 2010-2011 Azrieli Scholarship. The award allowed me to travel to Bologna, Italy, where the fallow time idea was further explored.

\section{Occupying the Gap}

An Architectural Journey through Fallow Time

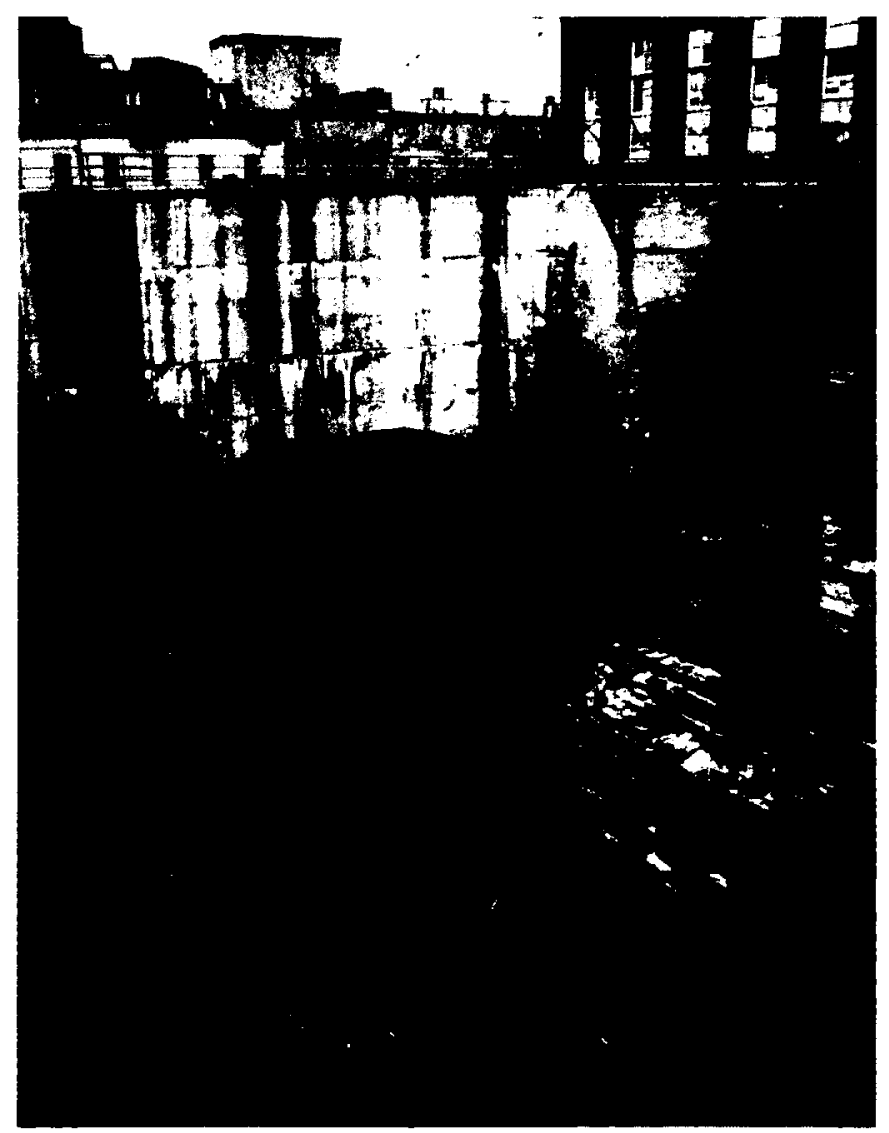




\section{Occupying the Gap}

\section{An Architectural Journey through Fallow Time}

I am going to tell you a story. I don't know where it will take you. Perhaps we can talk about it when you get there.

When you are midway 'cross the river, clear your way through the brush, and you will amive at Witaskewin, ${ }^{82}$ the shared city of ideas, favourably exposed to the elements, arranged in continually evolving time-layers, each one revealing its own logic through complex negotiation with the other.

To reach the deep and distant time-layers, the inhabitants of Witaskewin must follow the paths of the ideas: a network of gorges and basins, bridges and landings and tunnels - or are they hanging streets? In time, each idea path becomes a place - an idea-place - a shared space where the time-layers coexist, but neither outdoes the other. Each is encouraged, to express its own very particular relationship to place through time and practice.

Immensely thick and tight, some idea-places are deeply embedded in the ground, as if anchored against the fierce eastward flowing water that wraps its body around Witaskewin; while others, unfixed, allow themselves to be shaped and reshaped by the eroding elements. Countless more ideas float by on the ether, like a leaf floating down a stream, some to be plucked and scooped, some deflecting their way through the channels of collective consciousness. A joumey through this network is not only about arrival; it is about a negotiation at every point, at every view, at every layer.

${ }^{82}$ Witaskewin: Cree word meaning a continually renegotiated peaceful coexistence; to live in peace and harmony with one another; living together on the Land. 
Regenerating the Urban Landscape An Architectural Joumey through Fallow Time

Appendix_01

This is how Witaskewin started out. The Ancients - that is what they called the previous inhabitants - started with this singular idea: that peacefut coexistence in this place requires continual renegotiation.

This idea was lost for a long while; and the time-layers began to erode. The Ancients forgot what this place was about, and why they had come here. And then the Ancients were forgotten about, too. Instead of a shared city of ideas, Witaskewin became a mislaid remnant, grown over, emptied of significance.

You are there now, and you can see that the brush has cleared, allowing the latest inhabitants to participate in a renewed and evolving use of this place. $A$ beautiful tension exists, created by the gap in the time-layers. This tension grows more and more useful each day, as the space grows tighter, filling with new layers, reviving the idea of coexistence. Soon there will be a new idea-place, and it will be nipe for renegotiation. fallow year between agricultural crops. On occasion, it is necessary to leave a field uncultivated for a time so that it may regenerate itself and thereby provide better growing medium in the future. In architectural terms, fallow time refers to a previously occupied place that is currently in a state of inactivity but possesses the potential to be reactivated and inhabited in the future. On occasion, fallow time is also necessary in architecture in order to provide the required distance between a place we have known and the place we must renegotiate. 
Regenerating the Urban Landscape An Architectural Joumey through Fallow Time

Appendix_01

When a place has lain fallow, and before (re)occupation can occur, it requires a renegotiation among the time-layers, or the edges of the gap. With this, a place can be reactivated, (re)shaped and (re)inhabited in a way that is meaningful and of value to its inhabitants. Renegotiation may be guided by an architectural intervention, but this task may be a difficult one, depending on the situation that brought about the state of fallowness.

Fallow time may arise because a building or landscape no longer meets the needs of its users and is abandoned, such as occurs with some frequency in the industrial areas of many Canadian cities. It may be the result of neglect by an absentee landlord, such as occurs when a speculator buys a building for the land value only. A place may have succumbed to fire or other damage, and only a sturdy shell remains. It may be the resuit of hurtful situations, where people choose to forget (at least temporarily) what happened 'in that place', such as Canadian Residential Schools where Aboriginal children were separated from their families, denied their culture, and abused; or camps where Japanese-Canadians were unjustly interred during the second World War. Or, inhabitants may have been forced to leave a place, such as occurred at LeBreton Flats in Ottawa or Africkville in Halifax, where lands were expropriated and flattened. Fallow time may also simply be the result of indecision or an inability to agree on a future use, and so a place remains uninhabited, such as the innumerable surface parking lots that dot the downtowns of many cities.

Some places find a new vocation. Some remain fallow. In all cases, there is a time-gap, whether big or small, between the place that people have known and the place they must renegotiate before they can inhabit it once again.

There is something very compelling about exploring these [sad] places. Not because of a voyeuristic desire to witness the reoccupation of a painful place, but rather as an opportunity to explore how the fallow time can be occupied. Moreover, it is the possibility that a sad or painful place might be healed not only through time and tempered memory, 
Regenerating the Urban Landscape An Architectural Joumey through Fallow Time

Appendix_01

but through an appropriate intervention of our choosing, such that the gap can become a wonderful, beautiful place.

The intervention, therefore, would not entail adding a new layer on top of the existing so as to cover what has passed (although, in practical terms, this might be what happens). Rather, the attempt should be to metaphorically occupy that place in between the layers, that fallow time that separates then from now. From this an appropriate architectural intervention can be devised that would surely be quite different from the one that simply adds to the accretion of layers.

Joumey through Fallow Time

The first challenge is to clarify the need to occupy the gap. With the knowledge of these sad places and the [sometimes painful] memories they embody, why not simply demolish them? Why keep the memory alive? If, as I have suggested, the gap is a potential healing space as it is, why renegotiate it?

During the fallow time, a place may grow over, and become literally covered in debris and scrub, or figuratively covered in brush and controversy. The challenge is that the memories and values associated with these places are not always tangible ones. Evidence is not literally set in the stones of a building, but rather exists in the minds and on the bodies of people. A successful renegotiation requires an awareness of the nature of these memories, and the nature of the overgrowth, as it were. Through a process of sharing these memories, i.e. awareness-making, a collective path can be defined.

In the end, the collective may choose to demolish a physical place, but the memory will persist, and eventually that physical place will want to be occupied in some form or another. Why not make that re-occupation as rich as possible?

"If you are Canadian and travel at all, then you leam very quickly that the place you come from is just that - Nowhere - that Canada is not on the map."

- Noah Richler, This is My Country, What's Yours? 
Regenerating the Urban Landscape An Architectural Joumey through Fallow Time

Appendix_01

Once it is decided that the fallow time will be renegotiated, comes the task of thoroughly understanding the gap. If we believe Noah Richler's statement, the gap is nowhere. It is between here and there, between this place and that space, and between ideas. It cannot be found on a map, or a drawing, or in a book. It is an inherited space that can only be understood as a set of ideas, lacking any attachment to a physical artefact.

How does one go about understanding nowhere? Architects have long relied on the European-inherited approach of using physical artefacts as a means of identifying, documenting and remembering. The first inclination would therefore want to produce yet another artefact - a drawing - as a means of understanding the gap. To be sure, physical artefacts are valuable, but what if the fallow time is about people's activities, rituals and practices? These non-artefacts are difficult to understand and certainly lack the tangibility that architects seek. Perhaps a different artefact could be used, one that is less tangible, such as a story. Aboriginal cultures have long relied on the practice of storytelling to guide a moral decision or the path through rugged terrain, and in this instance could also be used to guide memory and understanding.

Once a place is understood, and it is agreed that the time is ripe to renegotiate the gap, how do we go about occupying it? This would surely involve an iterative process of imagining, negotiating, stepping back, testing, and re-imagining.

What did you imagine when you read the story of Witaskewin? Was it the same place I imagined when I wrote it? The coming together of our imaginations has the potential to produce an even more beautiful place than either of us had imagined on our own. This landscape of shared imagination could prove useful in devising the space in between realities - a space in between the fixity of artefacts, and the elusiveness of ideas. An intervention in this gap might be guided by the story, but not confined to it. 
Regenerating the Urban Landscape An Architectural Joumey through Fallow Time

Appendix_01

Occupying the gap

One might turn to contemporary heritage conservation

theory and practice as a guide for intervening in the gap. However, the artefact-based methods associated with these practices leave few openings for accommodating the intangible qualities associated with fallow time. Current heritage legislation ${ }^{83}$ largely seeks to protect only buildings and built places from inappropriate intervention. These tools do not protect the uses and intangible memories associated with built places. While cultural landscapes offer a potential avenue, they too are only acknowledged if physical (i.e. tangible) evidence exists of the idea that generated the landscape.

That said, contemporary conservation practice wants to see that when new layers are added to historic place, they 'be of their own time'. While the legislation intends that "our time" is an architectural style that does not imitate the past, could this be the opening for reading "fallow time" instead of "our time"? Such that the new layer reaches back, not in nostalgia, but in the gesture of an open hand slipping into the wedge created by the timegap, and negotiates the past forward.

Respectfully submitted,

${ }^{83}$ Including, but not limited to, the Ontario Heritage Act and Parks Canada's Standards and Guidelines for the Conservation of Historic Places in Canada. 


\section{Appendix_02}

Operational Guidelines for the Implementation of the World Heritage Convention

UNITED NATIONS EDUCATIONAL, SCIENTIFIC AND CULTURAL ORGANISATION

WHC. 08/01

January 2008

[Excerpt, p 86]

\section{Definition and Categories}

10. Cultural landscapes fall into three main categories, namely:

(i) The most easily identifiable is the clearly defined landscape designed and created intentionally by man. This embraces garden and parkland landscapes constructed for aesthetic reasons which are often (but not always) associated with religious or other monumental buildings and ensembles.

(ii) The second category is the organically evolved landscape. This results from an initial social, economic, administrative, and/or religious imperative and has developed its present form by association with and in response to its natural environment. Such landscapes reflect that process of evolution in their form and component features. They fall into two sub-categories:

- a relict (or fossil) landscape is one in which an evolutionary process came to an end at some time in the past, either abruptly or over a period. Its significant distinguishing features are, however, still visible in material form.

- a continuing landscape is one which retains an active social role in contemporary society closely associated with the 
traditional way of life, and in which the evolutionary process is still in progress. At the same time it exhibits significant material evidence of its evolution over time.

(iii) The final category is the associative cultural landscape. The inscription of such landscapes on the World Heritage List is justifiable by virtue of the powerful religious, artistic or cultural associations of the natural element rather than material cultural evidence, which may be insignificant or even absent. 


\section{Appendix_03}

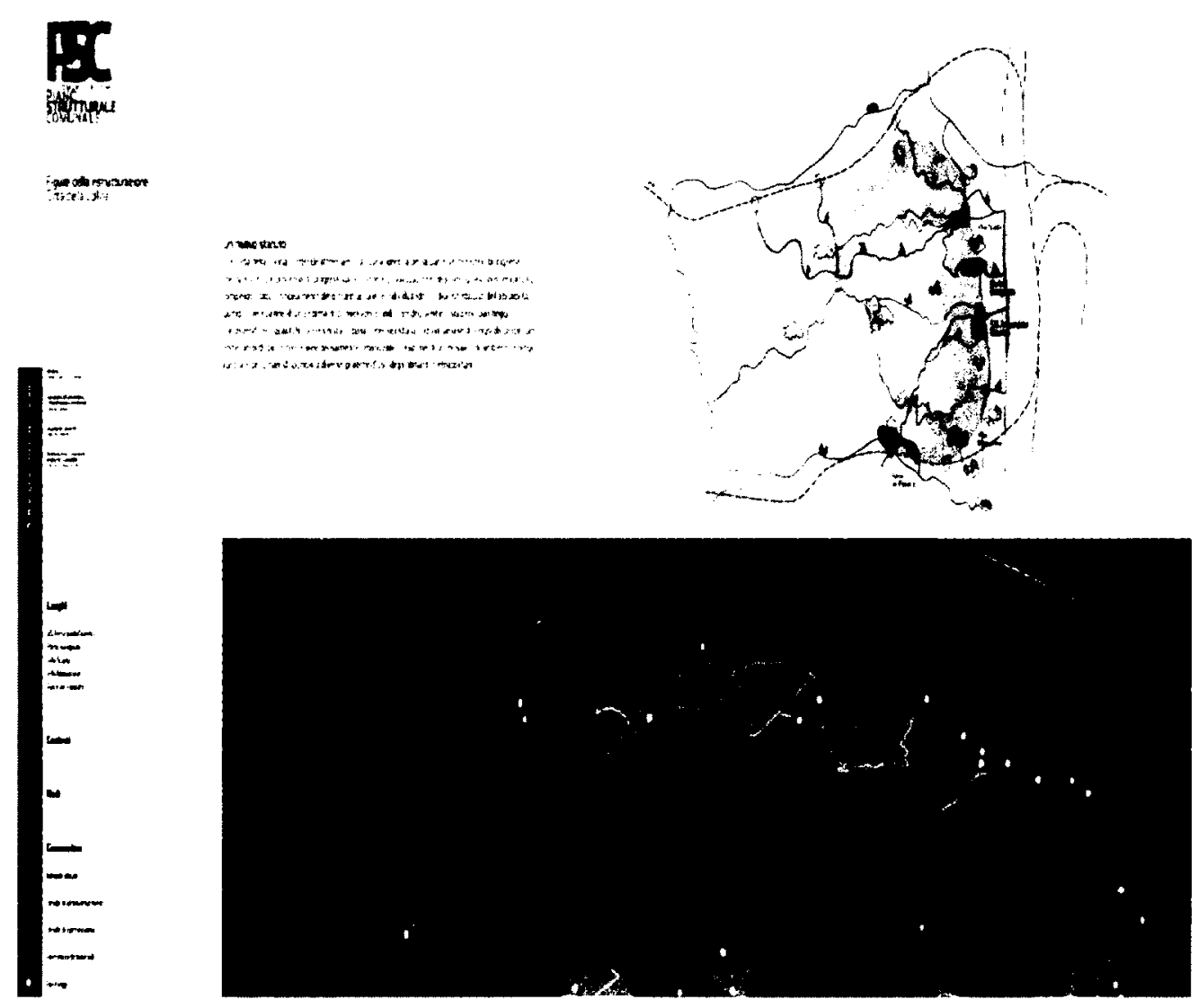


Piano Strutturale Comunale

2007 COMMUNE DI BOLOGNA

Anteprima

18 January 2007

[Excerpt]

City of the hills - $A$ new statute

City of the Hills seeks to give a new identity to a part of the city area that has been subjected to a process of progressive reduction and privatisation in its uses (almost entirely residential), by breaking taboos (hill areas to remain as they are now) and establishing a new "habitability statute".

Therefore: reconstruction of a system of connections and focal points (corridors, footpaths, stations, car parks) that diversify and qualify urban and metropolitan accessibility; the identification of places to be developed as park links with areas that are heavily urbanised; creation of a mosaic of ecological, agricultural and semi-urban environments that are available for various uses by metropolitan inhabitants. 